LBNL-56144

\title{
Sectoral Trends in Global Energy Use and Greenhouse Gas Emissions
}

\author{
Lynn Price, Stephane de la Rue du Can, Jonathan Sinton, Ernst Worrell, \\ Zhou Nan, Jayant Sathaye and Mark Levine
}

\author{
Energy Analysis Department \\ Environmental Energy Technologies Division \\ Lawrence Berkeley National Laboratory
}

July 2006

This work was supported by Laboratory Directed Research and Development funds under the U.S. Department of Energy Contract No. DE-AC02-05CH11231. 


\section{Sectoral Trends in Global Energy Use and Greenhouse Gas Emissions}

Lynn Price, Stephane de la Rue du Can, Jonathan Sinton, Ernst Worrell, Zhou Nan, Jayant Sathaye and Mark Levine

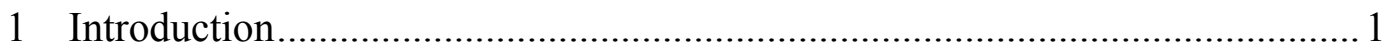

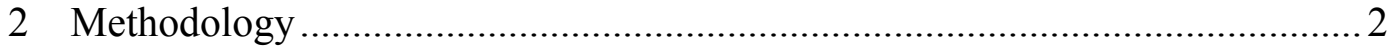

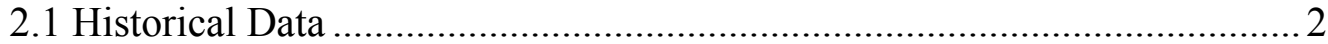

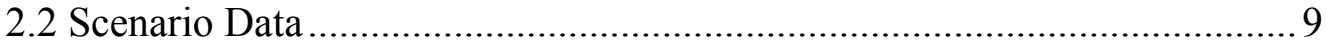

3 Historical and Projected Primary Energy Consumption ........................................ 11

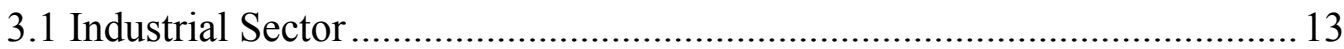

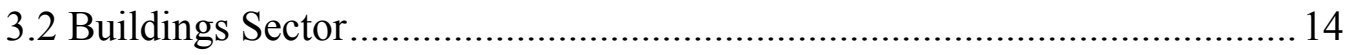

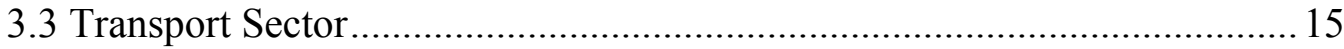

4 Historical and Projected Energy-Related Carbon Dioxide Emissions................. 16

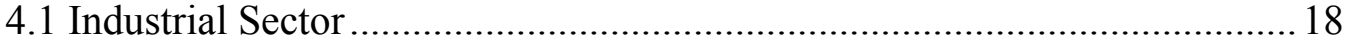

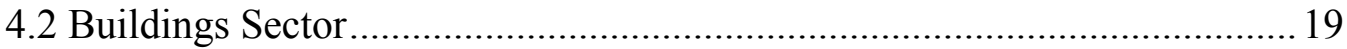

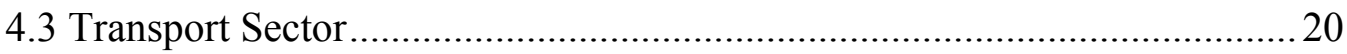

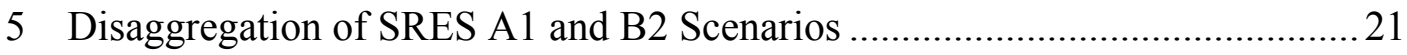

5.1 Macro Level Drivers ........................................................................... 21

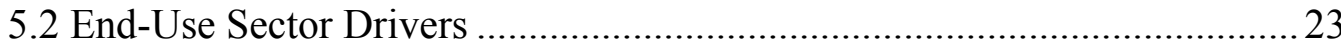

5.3 Disaggregation Example: Residential Sector in China .................................2 27

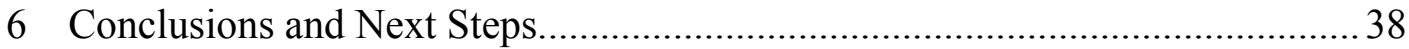

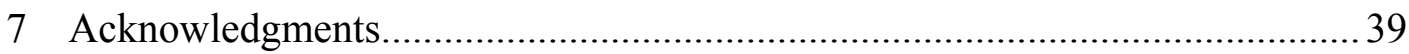

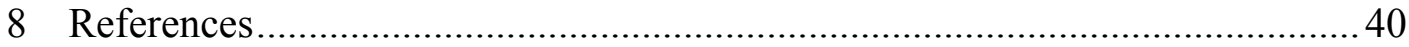

Appendices

1. World Regions

2. Primary Energy Accounting Methodologies

3. Comparison of Disaggregated SRES Scenarios and the IEA WEO Reference Scenario

4. Regression Analyses of Commercial Sector Share and Revenue

5. Commercial Share of Electricity in Building Sector Electricity Consumption 


\title{
Sectoral Trends in Global Energy Use and Greenhouse Gas Emissions
}

\author{
Lynn Price, Stephane de la Rue du Can, Jonathan Sinton, Ernst Worrell, \\ Zhou Nan, Jayant Sathaye and Mark Levine
}

\section{Introduction}

In 2000, the Intergovernmental Panel on Climate Change (IPCC) published a new set of baseline greenhouse gas (GHG) emissions scenarios in the Special Report on Emissions Scenarios (SRES) (Nakićenović et al., 2000). The SRES team defined four narrative storylines (A1, A2, B1 and B2) describing the relationships between the forces driving GHG and aerosol emissions and their evolution during the 21 st century. The SRES reports emissions for each of these storylines by type of GHG and by fuel type to 2100 globally and for four world regions (OECD countries as of 1990, countries undergoing economic reform, developing countries in Asia, rest of world). Specific assumptions about the quantification of scenario drivers, such as population and economic growth, technological change, resource availability, land-use changes, and local and regional environmental policies, are also provided.

End-use sector-level results for buildings, industry, or transportation or information regarding adoption of particular technologies and policies are not provided in the SRES. The goal of this report is to provide more detailed information on the SRES scenarios at the end use level including historical time series data and a decomposition of energy consumption to understand the forecast implications in terms of end use efficiency to 2030. This report focuses on the A1 (A1B) and B2 marker scenarios since they represent distinctly contrasting futures.

The A1 storyline describes a future of very rapid economic growth, low population growth, and the rapid introduction of new and more efficient technologies. Major underlying themes are convergence among regions, capacity building, and increased cultural and social interactions, with a substantial reduction in regional differences in per capita income. The B2 storyline describes a world with an emphasis on economic, social, and environmental sustainability, especially at the local and regional levels. It is a world with moderate population growth, intermediate levels of economic development, and less rapid and more diverse technological change (Nakićenović et al., 2000).

Data were obtained from the SRES modeling teams that provide more detail than that reported in the SRES. For the A1 marker scenario, the modeling team provided final energy demand and carbon dioxide $\left(\mathrm{CO}_{2}\right)$ emissions by fuel for industry, buildings, and transportation for nine world regions. Final energy use and $\mathrm{CO}_{2}$ emissions for three sectors (industry, transport, buildings) for the four SRES world regions were provided for the B2 marker scenario.

This report describes the results of a disaggregation of the SRES projected energy use and energy-related $\mathrm{CO}_{2}$ emissions for the industrial, transport, and buildings sectors for 10 world regions (see Appendix 1) to 2030. An example of further disaggregation of the two SRES scenarios for the residential buildings sector in China is provided, illustrating how such aggregate scenarios can be interpreted at the end use level. 


\section{Methodology}

\subsection{Historical Data}

Historical energy consumption and energy-related $\mathrm{CO}_{2}$ emissions data back to 1971 were assembled in order to better interpret energy consumption trends over time. The main source of data is the International Energy Agency (IEA, 2004a; IEA, 2004b). Several modifications to the original time series were conducted to calculate primary energy consumption at the end use sector level as well as to complete and correct some data anomalies. This section describes the data and the methodology used to calculate historical primary energy and $\mathrm{CO}_{2}$ emissions factors.

Modifications to the original data were performed for biomass energy consumption, for the former Soviet Union (FSU) region, and for the breakdown of non-specified energy use sector. For the regions of South Asia, East Asia and Africa, the IEA provides detailed information regarding biomass energy consumption only after 1994. Before 1994, no breakdown of consumption is shown and all domestic supply appears as a statistical difference. To include biomass consumption before 1994 for these regions, we extrapolated the breakdown of 1994 consumption back to 1971. For the FSU region before 1993, the IEA statistics for the buildings sector have a number of anomalous values. We compared these values to BP energy consumption statistics, and then adjusted the values in order to produce a smoother time trend (BP, 2004).

The IEA energy statistics report final energy and electricity use for the end-use sectors of industry (TOTIND), transport (TOTTRANS), and other (TOTOTHER). The other category is further divided into agriculture (AGRICULT), commercial and public services (COMMPUB), residential (RESIDENT), and non-specified other (ONONSPEC). This last category includes energy use in the agriculture, commercial and public services, and residential sectors that has not been allocated to these end-use sectors by the submitting countries. In most cases, there is no entry for the non-specific other category, indicating that all end-use energy consumption has been allocated to the other end-use sectors. However, for some countries the energy reported in the non-specified other category needed to be reallocated to the end-use sectors. This is especially important for those years in which a particular country reports all of the other energy use as non-specified. To perform this reallocation, the non-specified other category was allocated to the other end-use sectors (agriculture, commercial and public services, residential) based on the share of allocated energy in each of these sub-sectors for each region (Price et al., 1998).

\subsubsection{Primary Energy Factors}

Historical statistics on energy consumption in an economy are generally available in the form of an energy balance and are disaggregated into six main sectors: transformation, energy, industry, services, residential and transport. However, only the last four end-use sectors actually drive energy consumption; some of the fuels consumed by these end users need to undergo refinement or complete transformation before they deliver energy to meet the demand of the end-use sectors. This transformation itself requires energy. About $30 \%$ of the total energy supply worldwide is lost into upstream processes that 
transform primary energy into secondary forms of energy ${ }^{1}$ such as electricity, heat, petroleum and coal products. LBNL previously developed a method to reallocate energy use in electricity and heat processes (Schipper et al., 1997); we have now added the reallocation of energy use in the processing of petroleum and coal products. It is often difficult to correctly account for all inputs and outputs in energy transformation industries for all countries. As a result, global trends need to be interpreted carefully.

\section{Electricity and Heat Primary Factors}

The production of electricity and heat are the most important forms of secondary energy produced worldwide; the energy lost in their transformation represents approximately $70 \%$ of the total energy lost in secondary energy production.

Primary factors were derived as the ratio of fuel inputs at power plants to electricity or heat delivered and reflects the process energy efficiency. Fuel inputs for electricity production were separated from inputs to heat production in combined heat and power plants (CHP) according to the shares of electricity and heat produced in these plants (IEA, 2005). Primary energy associated with secondary energy consumption was then calculated by multiplying the amount of electricity and heat consumed in the end-use sectors by these primary electricity and heat factors.

In order to calculate the primary energy associated with electricity production from nonfossil-fuel energy such as renewable and nuclear energy, the "direct equivalent" accounting method was used. This method accounts for the primary energy of the nonfossil-fuel energy at the level of secondary energy with an efficiency of a $100 \%$ (Nakićenović et al., 2000). For example, the primary energy equivalence of electricity generated from solar photovoltaic or nuclear power plants is set equal to their respective gross electricity output not to the heat equivalent of radiation energy from fissile reaction, the solar radiance that falls onto a photovoltaic panel, or the heat that would have been necessary by burning fossil fuels to produce the same amount of electricity as generated in a photovoltaic cell or a nuclear reactor as used in the so-called "substitution" accounting method. Appendix 2 provides a description of the primary energy accounting methodologies.

Figure 1 shows the electricity factors calculated using the direct equivalent methodology. A region with a high value factor is a region using relatively more energy to generate electricity or using relatively more fossil fuel in the fuel mix. Factors for fossil fuel are around three depending on the technology used and factors for renewables and nuclear energy are equal to one according to the direct equivalent methodology. Regions like Latin America that rely on significant levels of hydroelectric power have a lower primary electricity factor. Also, countries such as those of the former Soviet Union that produce considerable heat as a byproduct of cogeneration also have a lower factor, as the energy used for electricity generation is reduced by the quantity needed to produce the associated

\footnotetext{
${ }^{1}$ Primary energy is the energy embodied in natural resources (e.g., coal, crude oil, sunlight, uranium) that has not undergone any anthropogenic conversion or transformation (IPCC, 2001). Secondary energy is the energy contained in products or carriers that result from the transformation or conversion of primary energy. They mainly consist of electricity, petroleum products and different coal products.
} 
heat. Finally, the quality of data available worldwide is reflected in these factors and can explain some anomalies.

\section{Figure 1. Primary Electricity Factors}

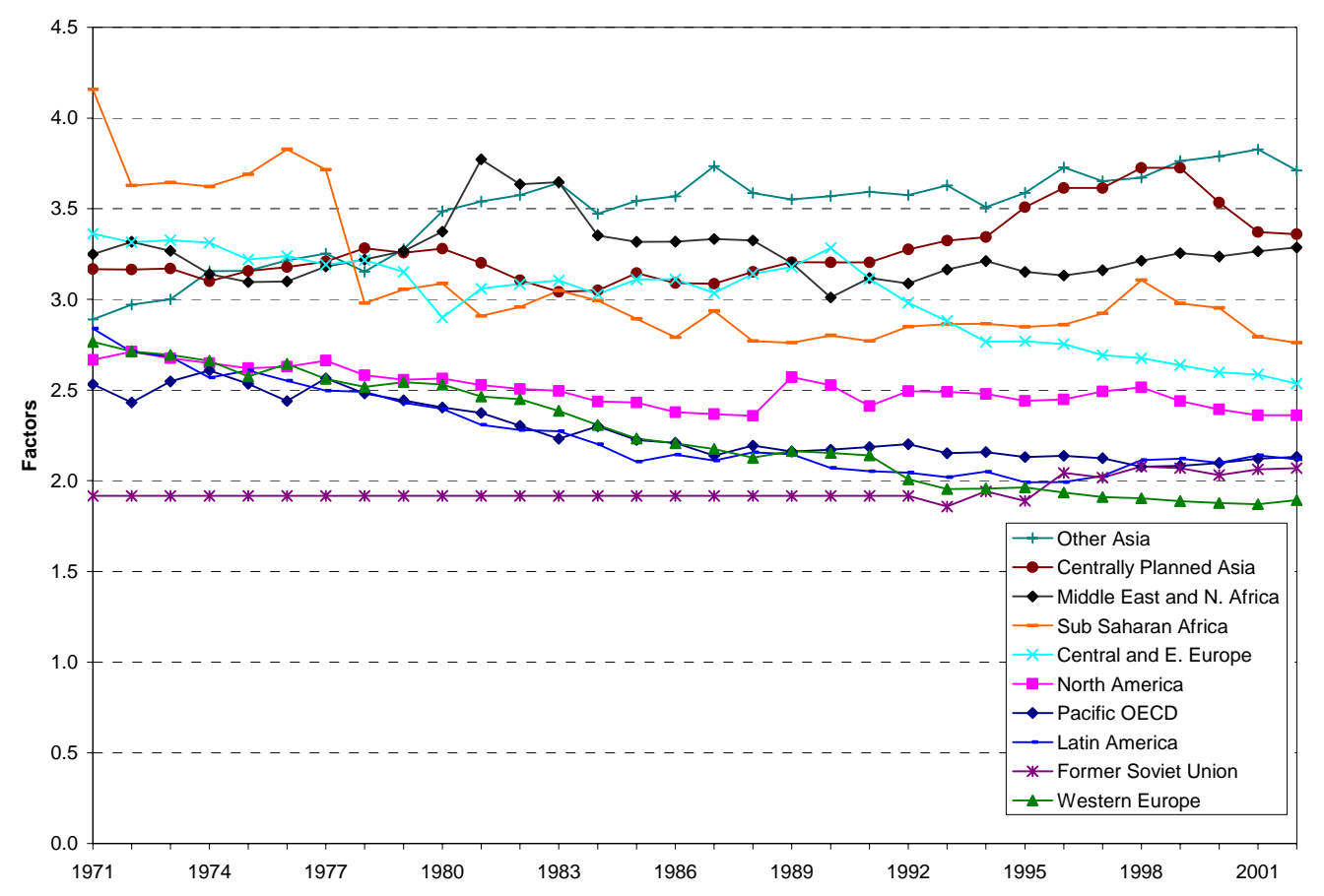

\section{Coal and Petroleum Products Primary Factors}

Approximately $30 \%$ of total energy consumption is residual energy use in the transformation and energy sector. About $90 \%$ of this residual energy loss is due to the transformation of coal into more refined products and the conversion of crude oil into petroleum products. In order to redistribute this energy consumption in proportion to its final use, we calculated primary factors for coal products and petroleum products.

Primary factors for production of coal products -- patent fuel, coke oven coke, coke oven gas, blast furnace gas and briquettes (BKB) -- were derived as the ratio of fuel inputs at coke ovens, patent fuel plants, blast furnaces and briquettes plants to total coal products produced. Primary energy associated with coal products was then calculated by multiplying the amount of coal products consumed by the coal products primary factor.

Some coal undergoes transformation into cleaner products with higher energy content before being consumed. For instance, coke ovens produce coke oven coke that is then consumed in blast furnaces to produce molten iron for the production of steel. Coke oven gas is produced as byproduct and blast furnace gas is produced as a byproduct from blast furnaces. Patent fuels and briquettes are secondary products of coal consumed in the residential sector. Figure 2 shows that coal product primary factors for the 10 regions generally ranged between 1.5 to 2.5 , meaning that it requires 1.5 to 2.5 times more energy to produce one unit of coal products than is contained in the products themselves. 
Figure 2. Primary Coal Product Factors

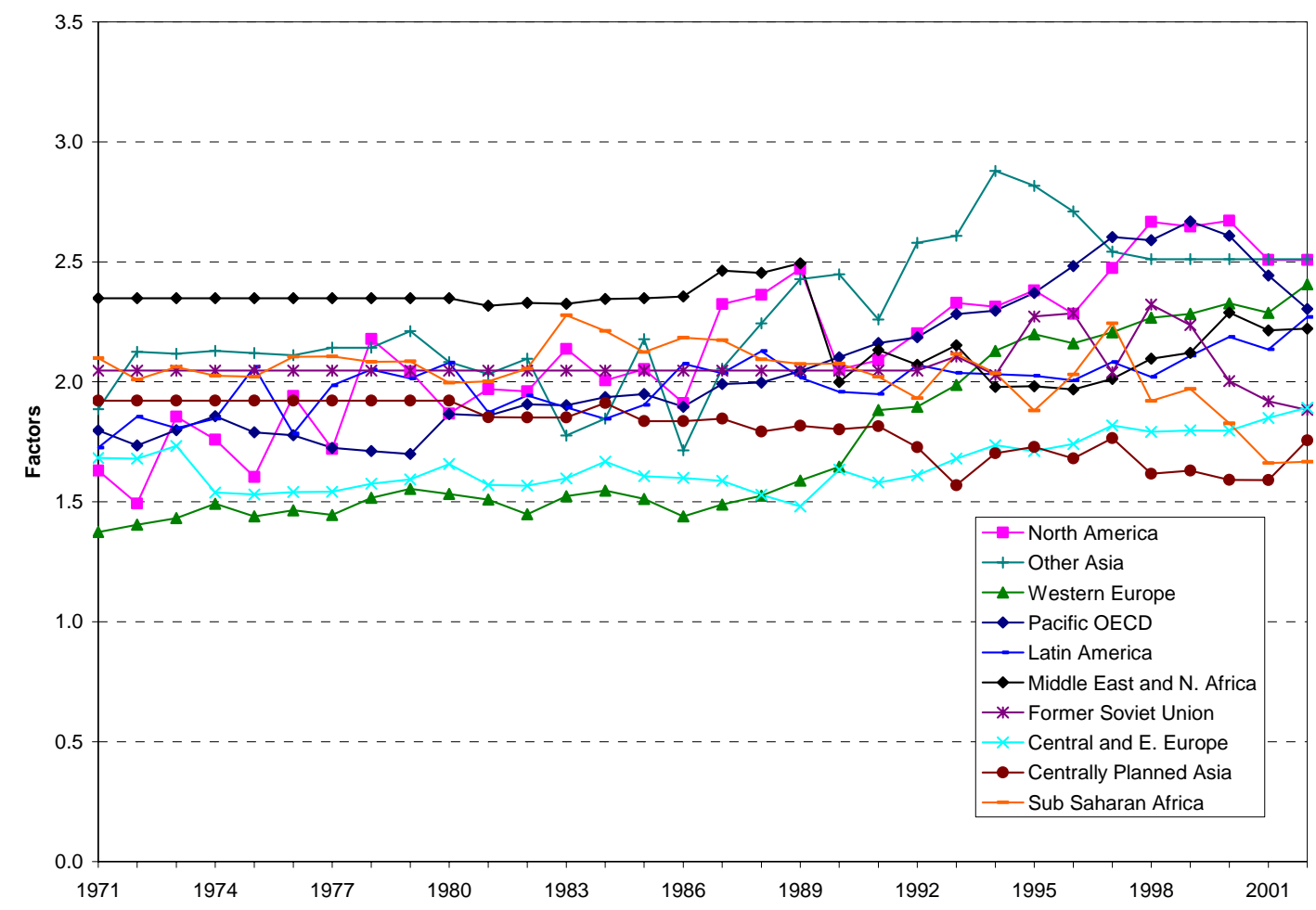

Most of the oil consumed in the world first undergoes transformation which produces different types of light to heavier fuels needed in the economy. This oil transformation requires energy as represented by the coefficients shown in Figure 3.

Primary factors for the production of petroleum products were derived as the ratio of fuel inputs at refineries and own use to petroleum products produced. Primary energy associated with petroleum products was calculated by multiplying the amount of petroleum products consumed by each end-use sector by the petroleum products primary factors.

The primary energy factor of oil products ranges between 1.05 to 1.2 , meaning that it requires up to $20 \%$ more energy to transform crude oil and feedstocks in petroleum products than is in the products themselves. This factor is low compared to the production of electricity or coal products. However, it is applied to a much larger range as all crude oil undergoes transformation. The exploitation of less accessible oil and unconventional oil will raise the petroleum product coefficient as these reserves of oil require more energy to be exploited. 
Figure 3. Primary Petroleum Factors

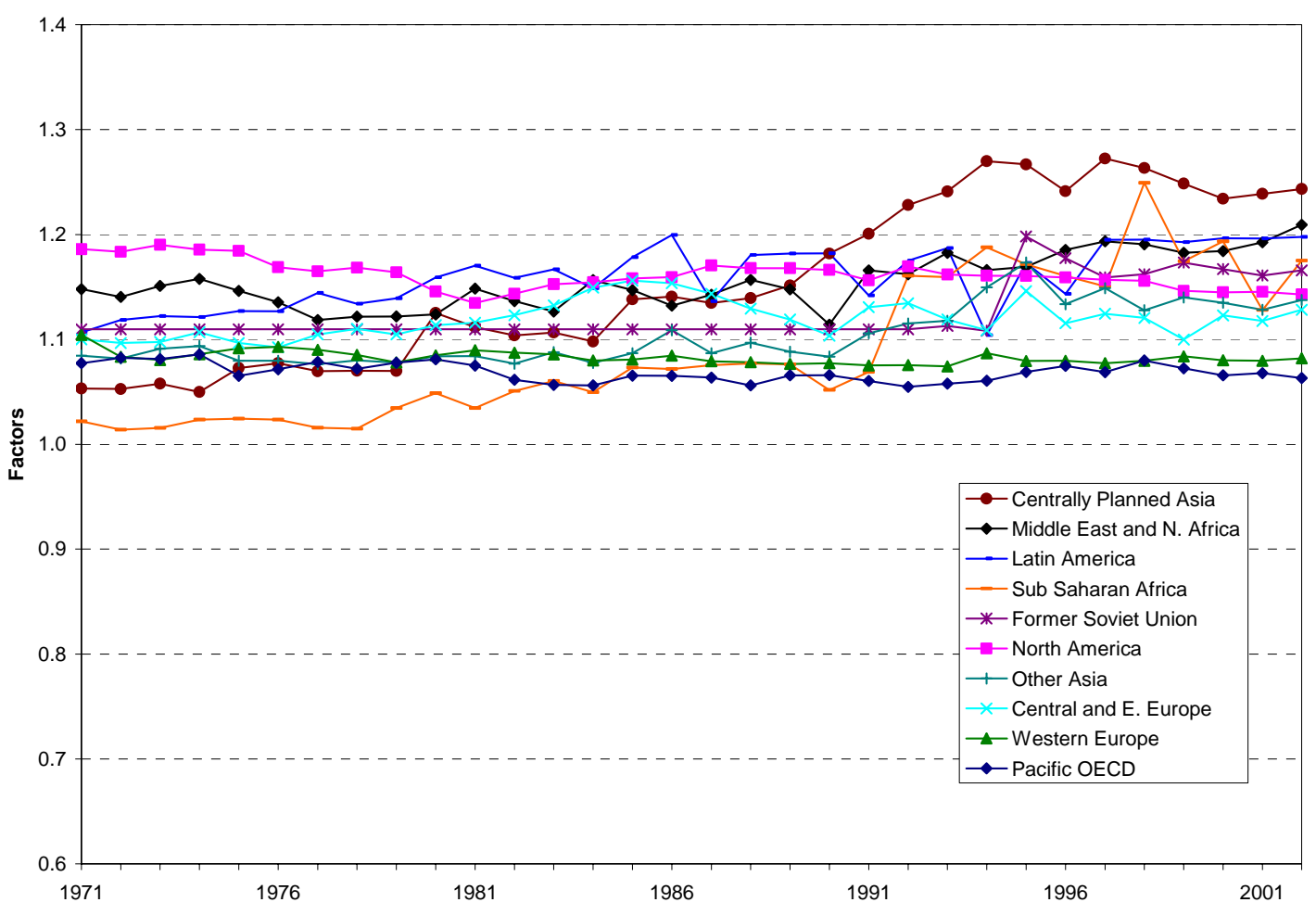

\subsection{2 $\mathrm{CO}_{2}$ Emissions Factors}

The energy consumed during the processing of primary energy into secondary energy resulted in $46 \%$ of the world total $\mathrm{CO}_{2}$ emissions in 2002. In the IEA statistics, these emissions are shown under the following sectors: Public Electricity and Heat Production, Unallocated Auto-producers, Other Energy Industries and Differences due to Losses and/or Transformation. $\mathrm{CO}_{2}$ emissions factors were calculated to allow a proportional redistribution of these emissions to the end use sectors where ultimately the secondary energy products are consumed. Four sets of factors were estimated: for the production of electricity, heat, petroleum products and coal products.

\section{Electricity and Heat $\mathrm{CO}_{2}$ Emissions Factors}

$\mathrm{CO}_{2}$ emissions factors for electricity and heat were derived as the ratio of carbon emissions resulting from fuel inputs at power plants to electricity or heat delivered. The same method as described above for the primary factors was used to account for the fuel inputs in power, heat and CHP plants. The fuel inputs were then multiplied by the respective carbon emission factors for each type of fuel given by the IPCC (IPCC, 1996). A $\mathrm{CO}_{2}$ emissions factor was calculated for each of the ten regions. Carbon embodied in electricity and heat consumption was then calculated by multiplying the amount of electricity and heat used by the electricity and heat carbon factors. 
Figure 4. Electricity Carbon Factors (ktC/PJ)

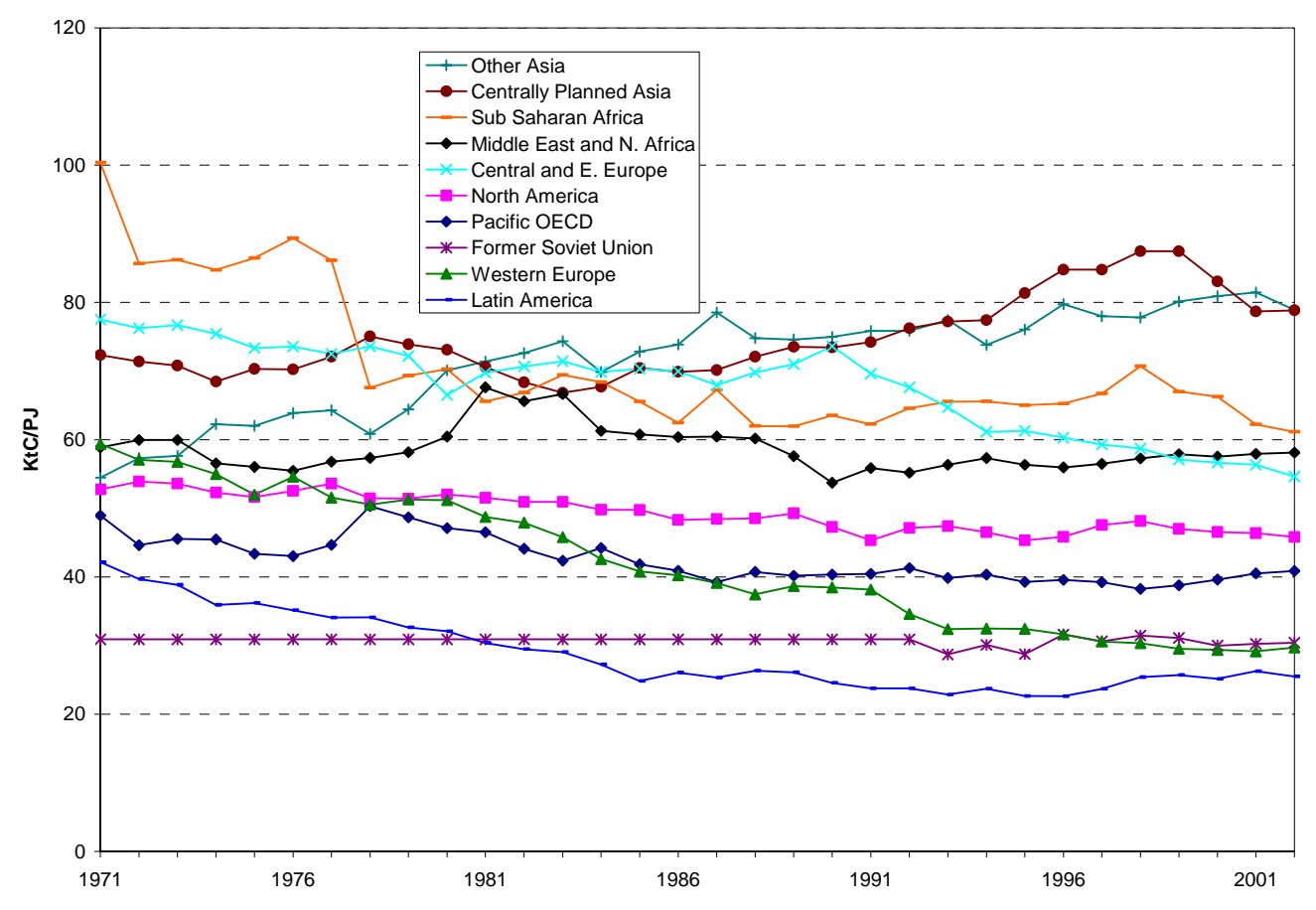

Figure 4 shows the electricity $\mathrm{CO}_{2}$ factors which indicate the level of $\mathrm{CO}_{2}$ emissions that are emitted per unit of electricity produced. These factors reflect the fuel mix in the power sector and the efficiency of power generation. A region with a high share of nonfossil-fuel use in their power generation has a low coefficient. Latin America which has a high share of hydroelectric power has the lowest $\mathrm{CO}_{2}$ emission factor for electricity production.

\section{Coal and Petroleum Products $\mathrm{CO}_{2}$ Emissions Factors}

In order to redistribute the emissions due to other energy transformation processes, carbon emissions factors associated with the production of coal products and petroleum products were calculated. Hence, for coal products, the carbon emissions due to fuel combustion in coke ovens, patent fuel plants, blast furnaces and briquette (BKB) plants were accounted for, then a ratio of these emissions to total coal products produced was calculated. Carbon embodied in the coal products was then distributed by multiplying the amount of coal products consumed in each sectors by this ratio.

$\mathrm{CO}_{2}$ emissions associated with petroleum products production were calculated by multiplying the amount of petroleum products consumed in each end-use sector by a $\mathrm{CO}_{2}$ emissions factor using a similar method. $\mathrm{CO}_{2}$ emissions factors were derived as the ratio of $\mathrm{CO}_{2}$ emissions due to fuel combustion in refineries to total petroleum product produced. This factor was used to redistribute the $\mathrm{CO}_{2}$ emissions due to the production of petroleum products among end-use sectors.

The carbon emissions associated with the production of coal products and petroleum products derived through the $\mathrm{CO}_{2}$ factors varied widely across regions (see Figures 5 and 6) due to the quality of data available across the world concerning these specific 
transformation processes. In practice, it often proves difficult to correctly account for all inputs and outputs in energy transformation industries, and to separate energy that is transformed from energy that is combusted. This distinction is however necessary when accounting for $\mathrm{CO}_{2}$ since the transformation of primary fuels into secondary fuels by physical or chemical processes does not involve combustion of input fuel, hence does not result in $\mathrm{CO}_{2}$ emissions.

Figure 5. Coal Product $\mathrm{CO}_{2}$ Emissions Factors

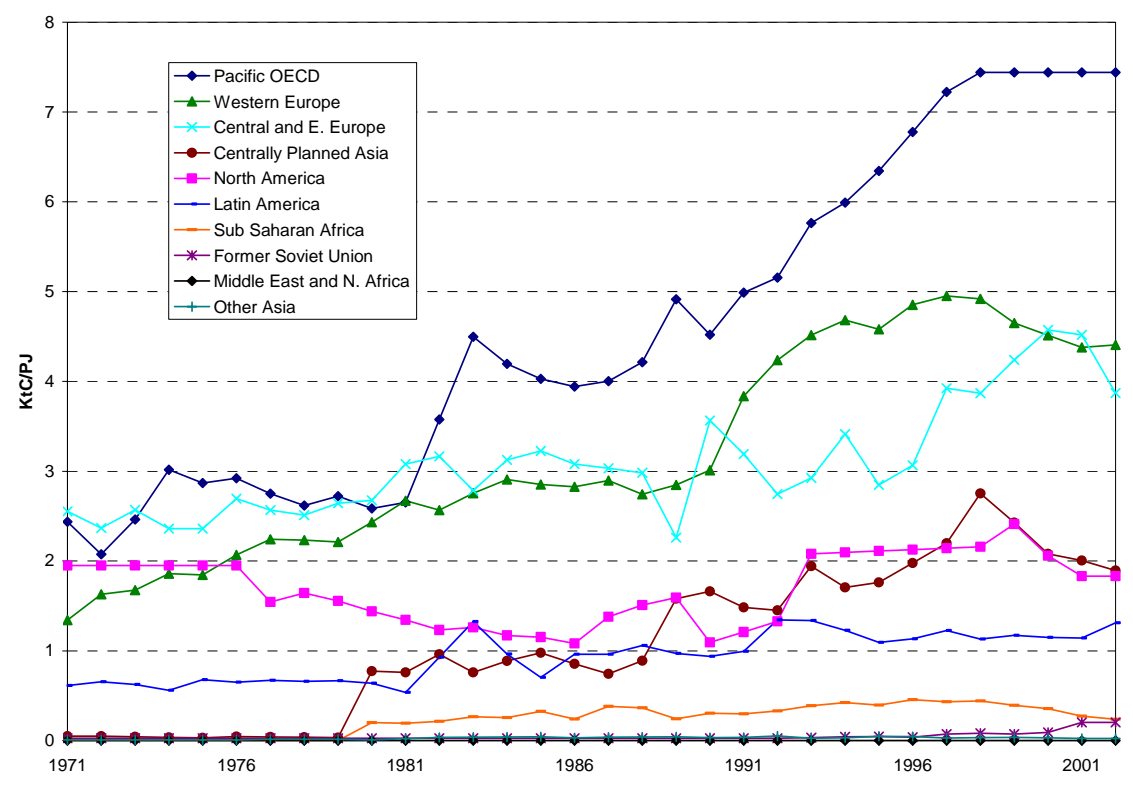

Figure 6. Petroleum Products $\mathrm{CO}_{2}$ Emissions Factors

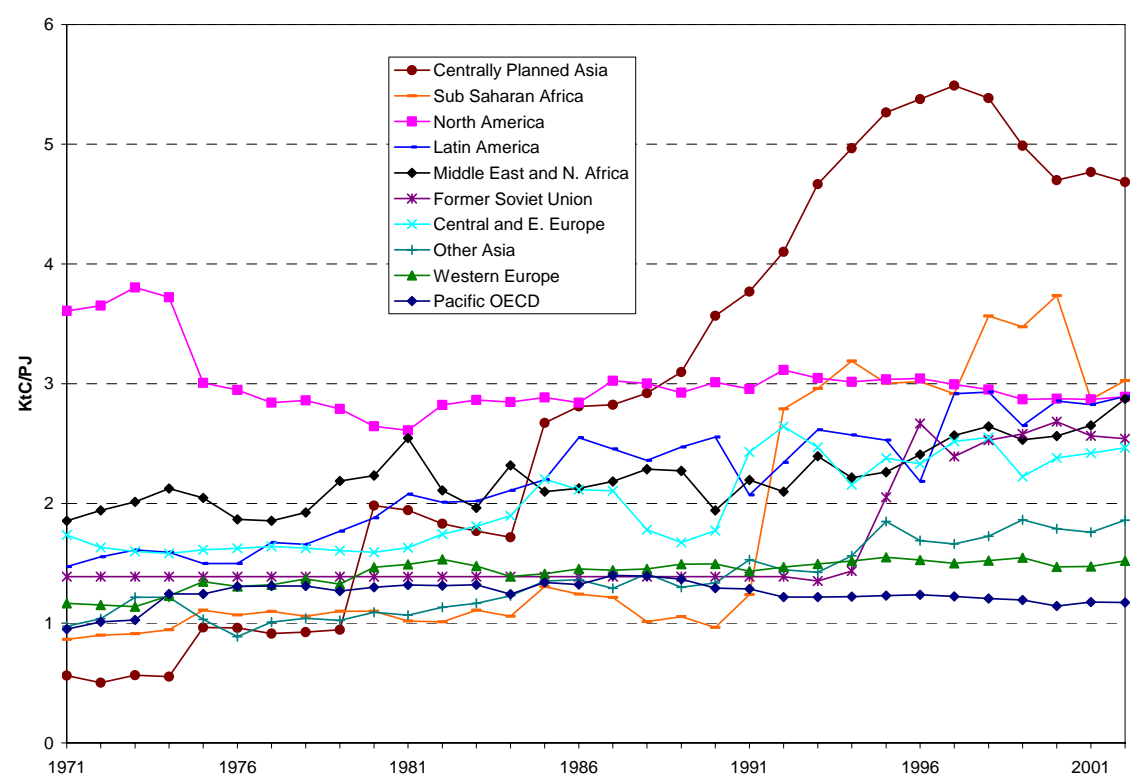




\subsubsection{Comparison with IEA Statistics}

Subsequent to the reallocation calculation, a comparison with the IEA data for primary energy was performed. An average statistical difference of 3\% was found between the total primary energy calculated by Lawrence Berkeley National Laboratory (LBNL) using the methodology described above and the IEA Total Primary Energy Supply (TPES). An average of statistical difference of $2 \%$ was found between the total $\mathrm{CO}_{2}$ emissions calculated by LBNL and the IEA data. There are three main reasons for these differences.

First there are statistical differences between supply and demand. The IEA TPES is a topdown approach and the data calculated by LBNL are based on a bottom-up approach. Hence the statistical differences accounted in the IEA data are reflected in this comparison. Second, imports and exports are not differentiated. The calculation of the primary energy factors and $\mathrm{CO}_{2}$ emissions factors is applied to the final consumption without distinction between domestic produced and imports. Third, not all energy industries are taken into account. Energy used in LNG plants, charcoal plants, and other non specified process is not taken into account in our reallocation scheme.

\subsection{Scenario Data}

\subsubsection{A1 Marker Scenario}

Data for the A1 marker scenario were provided to LBNL by the National Institute for Environmental Studies in Japan. The data provided were for final energy demand and carbon dioxide emissions for nine world regions (USA, OECD-E, OECD-P, EEFSU, CPASIA, SEASIA, M-EAST, AFRICA, LA) by fuel for the industry, buildings, and transportation sectors.

LBNL converted the final energy data into primary energy by multiplying the electricity consumed by each end-use sector by a final-to-primary conversion factor that accounts for conversion, transmission and distribution losses. This factor varied by year and by the regional groups and was determined by comparing the final to primary energy values reported in the SRES results for the A1 marker scenario. As only data on electricity were available, we assumed that most of the energy consumed in the transformation sector is due to electricity production.

LBNL re-aggregated the nine world regions into the LBNL-10 world regions using historical data trends. For example, in order to remove Canada from the A1 scenario's OECD-E grouping so that it could be grouped with the U.S. to form the North America region, LBNL used historic data on Canadian and OECD-E energy consumption by fuel type to determine the share of Canadian energy consumption and $\mathrm{CO}_{2}$ emissions that would be represented in the OECD-E region. This value was then subtracted from the OECD-E region and added to the U.S. to determine the North America region values. Similar calculations using historical data were made to split the Former Soviet Union and Eastern Europe as well as to divide Africa into North Africa and Sub-Saharan Africa.

The A1 model includes the agriculture sector within the industrial sector. LBNL divided these two sectors by using the historic ratio of agriculture to industry energy use for each 
region in 2000 for the 2000 scenario value and the historical ratio for 2002 for the 20052030 scenario values. A flat ratio over time was assumed.

\subsubsection{B2 Marker Scenario}

Data for the B2 marker scenario were provided to LBNL by the International Institute for Applied Systems Analysis (IIASA). ${ }^{2}$ The data provided were for primary energy use and $\mathrm{CO}_{2}$ emissions for 11 world regions (NAM, WEU, PAO, EEU, NIS, CPA, SAS, PAS, MEA, LAM, AFR) ${ }^{3}$ by fuel for industry, transport, and residential/commercial sectors.

LBNL converted the final energy to primary energy by multiplying the secondary products (electricity, heat and synfuels) consumed by each end-use sector by a final-toprimary conversion factor that accounts for conversion, transmission and distribution losses. This factor varied by year and for the 10 regions and was determined by comparing the final to primary energy values reported in the SRES results for the B2 marker scenario.

As with the A1 marker scenario, LBNL re-aggregated the 11 world regions into the LBNL-10 world regions using historical data trends. For example, in order to remove Korea from the PAS grouping so that it could be grouped with Japan, New Zealand and Australia to form Pacific OECD region, LBNL used historic data on Korea and PAS energy consumption to determine the share of Korea energy consumption and carbon dioxide emissions that would be represented in the PAS region. This value was then subtracted from the PAS region and added to Japan, New Zealand and Australia to determine the Pacific OECD region values. Similar calculations using historical data were made to subtract Chinese Taipei from PAS to form the Centrally Planned Asia and Other Asia regions.

The B2 scenario includes the agriculture sector, which is very small, within the buildings sector. LBNL divided these two sectors by using the historic ratio of agriculture to buildings energy use or carbon emission for each region in 2000 for the 2000 scenario value and the historical ratio for 2002 for the 2005-2030 scenario values and for each fuel. A flat ratio over time was assumed.

\footnotetext{
${ }^{2}$ Note that the data deviates slightly from the original SRES scenario, since it is based on the latest version of the MESSAGE model (version V).

${ }^{3}$ http://www.iiasa.ac.at/Research/ECS/docs/11worldregions.html for more details.
} 


\section{Historical and Projected Primary Energy Consumption}

Using the methodologies described above, LBNL calculated historical primary energy (1971-2000) for the ten world regions by end-use sector. Using the scenario data provided by the SRES modelers, LBNL compiled the projected primary energy (20002030) for the A1 and B2 scenarios for the industrial, buildings and transport sectors for the ten world regions. ${ }^{4,5}$ Table 1 provides a summary of these data for the end-use sectors, while Figures 7 and 8 illustrate the sectoral trends for both the historical data from 1971 to 2000 and the SRES A1 and B2 scenario data, respectively.

Table 1. World Primary Energy Consumption, A1 and B2 Projection (EJ)

\begin{tabular}{|c|c|c|c|c|c|c|c|c|c|c|c|}
\hline & \multicolumn{2}{|c|}{ Historical } & \multicolumn{3}{|c|}{ A1 } & \multicolumn{3}{|c|}{ B2 } & \multicolumn{3}{|c|}{$\begin{array}{c}\text { Average Annual } \\
\text { Growth Rate }\end{array}$} \\
\hline & 1971 & 2000 & 2010 & 2020 & 2030 & 2010 & 2020 & 2030 & $\begin{array}{l}1971- \\
2000\end{array}$ & $\begin{array}{c}\text { A1 } \\
2000- \\
2030 \\
\end{array}$ & $\begin{array}{c}\text { B2 } \\
2000- \\
2030\end{array}$ \\
\hline Total & 222 & 384 & 557 & 709 & 892 & 457 & 546 & 648 & $1.9 \%$ & $2.9 \%$ & $1.8 \%$ \\
\hline Industrial & 89 & 140 & 234 & 287 & 346 & 172 & 202 & 237 & $1.6 \%$ & $3.1 \%$ & $1.8 \%$ \\
\hline Buildings & 86 & 147 & 194 & 243 & 312 & 173 & 206 & 236 & $1.9 \%$ & $2.5 \%$ & $1.6 \%$ \\
\hline Transport & 42 & 86 & 111 & 158 & 209 & 102 & 126 & 161 & $2.5 \%$ & $3.0 \%$ & $2.1 \%$ \\
\hline Agriculture & 6 & 11 & 11 & 22 & 25 & 11 & 10 & 12 & $2.2 \%$ & $2.9 \%$ & $0.8 \%$ \\
\hline
\end{tabular}

Total primary energy consumption in the A1 scenario is expected to grow at an annual rate of $2.9 \%$ while the $\mathrm{B} 2$ scenario predicts an annual growth rate of $1.8 \%$-- virtually the same as the historical rate over the 1971 to 2000 period. The A1 scenario forecasts the highest energy consumption growth of $3.1 \%$ in the industrial sector, compared to $3.0 \%$ in the transport sector, $2.9 \%$ in the agriculture sector, and $2.5 \%$ in the buildings sector. In the B2 scenario, the fastest growing sector is expected to be the transport sector with an average annual growth of $2.1 \%$, slightly lower than historical trend of $2.5 \%$. For the buildings sector, the $\mathrm{B} 2$ scenario forecasts a growth of $1.6 \%$, lower than the historical value of $1.9 \%$, while the A1 scenario foresees much higher growth of $2.5 \%$ per year.

\footnotetext{
${ }^{4}$ LBNL compared the projections described in this section to those of the International Energy Agency's World Energy Outlook 2004 Reference Scenario. Appendix 3 provides details regarding this comparison.

${ }^{5}$ The time series reported here use historical data from 1971 to 2000 and scenario data from 2000 to 2030 . Since the actual 2000 value and the 2000 values in the scenarios differed, the actual value was used for 2000 and the values between 2000 and the scenario value for 2010 were extrapolated. Thus, the values for 2000 to 2010 do not exactly match the reported scenario values, but do match the scenario growth rates during this period. The 2010 to 2030 values exactly match the scenario values.
} 
Figure 7. Global Primary Energy by End-Use Sector, Historical to 2000 and Projected by the SRES A1 Scenario to 2030.

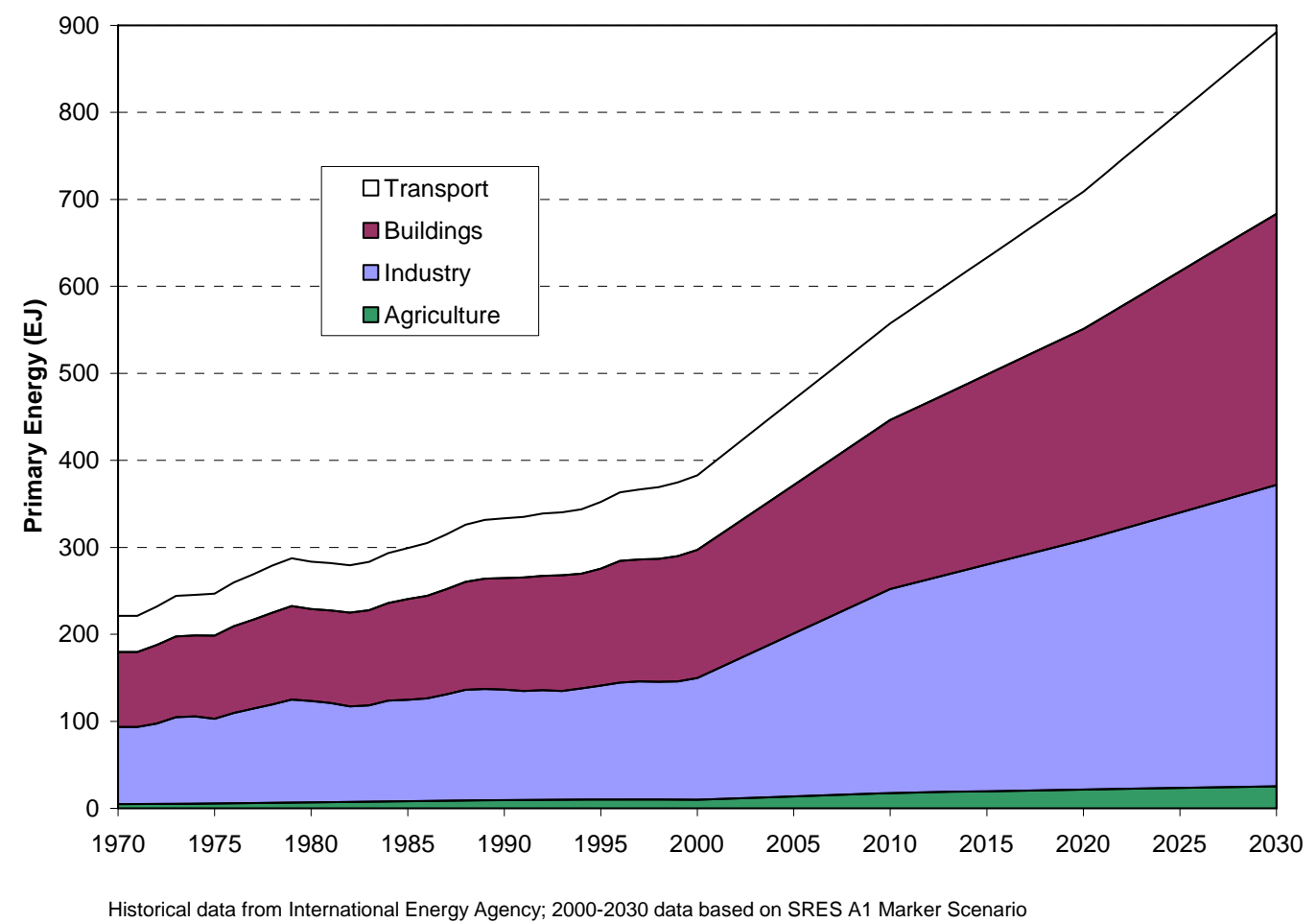

Figure 8. Global Primary Energy by End-Use Sector, Historical to 2000 and Projected by the SRES B2 Scenario to 2030.

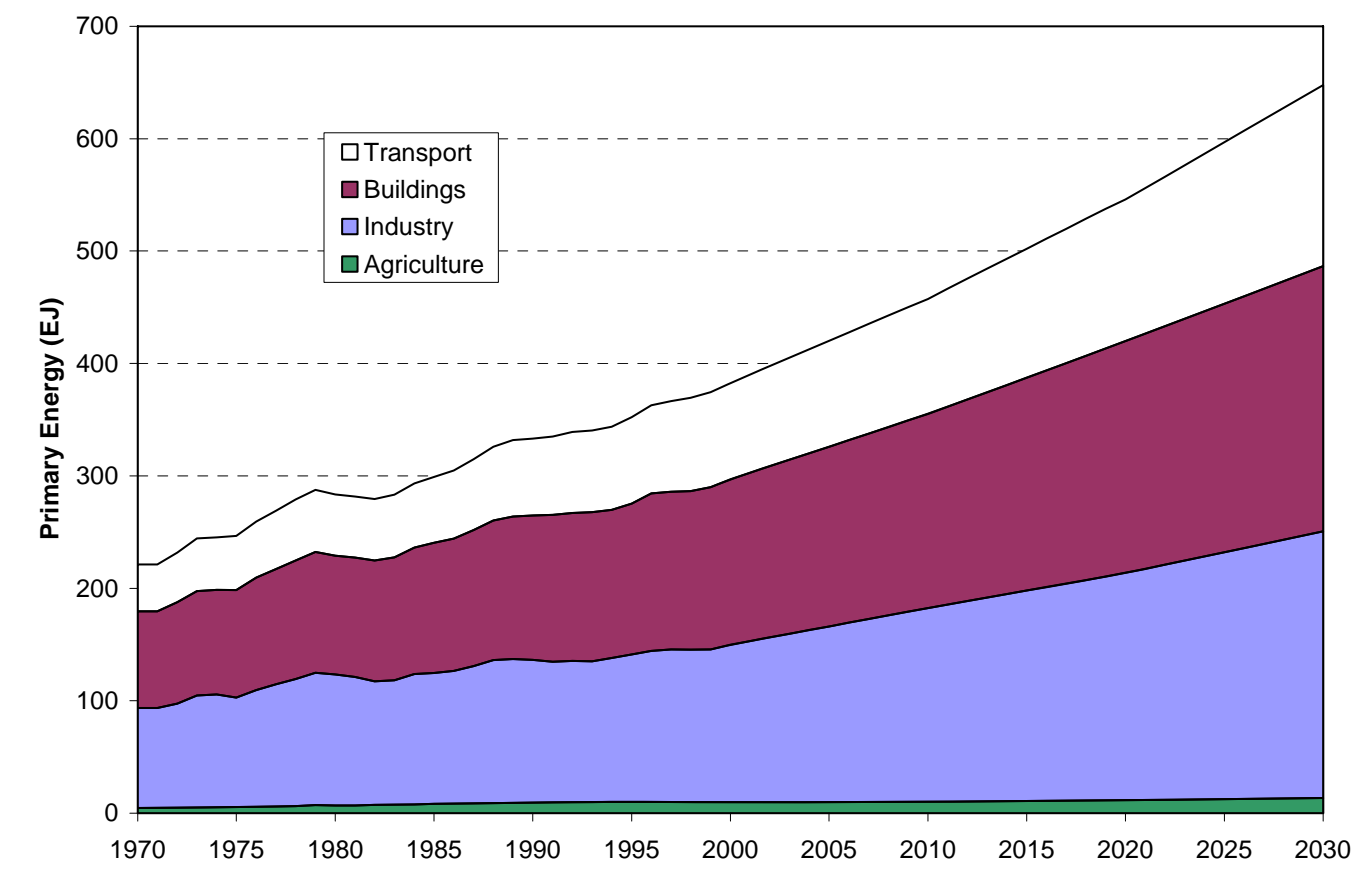

Historical data from International Energy Agency; 2000-2030 data based on SRES B2 Marker Scenario 


\subsection{Industrial Sector}

Primary energy consumption in the industrial sector represented $37 \%$ of total energy consumption globally in 2000. Table 2 and Figure 9 provide historical and forecast energy consumption in the industrial sector for the ten world regions for the A1 and B2 scenarios. Both scenarios forecast most growth to occur in the developing countries due to the energy required to fuel their growing economies. In general, the A1 scenario envisages more intensive growth in the developing countries than the B2 scenario. Both scenarios predict that energy use in the industrial sector of the Centrally Planned Asia region will surpass that of the North America region before 2010. The Centrally Planned Asia region is the region that is expected to have the highest growth by far, reaching an energy consumption level of $68 \mathrm{EJ}$ in the A1 scenario and $55 \mathrm{EJ}$ in the $\mathrm{B} 2$ scenario in 2030.

Table 2. Historical and Projected Industrial Sector Primary Energy, 1971-2030 (EJ)

\begin{tabular}{|c|c|c|c|c|c|c|c|c|c|c|c|}
\hline & \multicolumn{2}{|c|}{ Historical } & \multicolumn{3}{|c|}{ A1 } & \multicolumn{3}{|c|}{ B2 } & \multicolumn{3}{|c|}{$\begin{array}{c}\text { Average Annual } \\
\text { Growth Rate }\end{array}$} \\
\hline & 1971 & 2000 & 2010 & 2020 & 2030 & 2010 & 2020 & 2030 & $\begin{array}{l}1971- \\
2000 \\
\end{array}$ & $\begin{array}{c}\text { A1 } \\
2000- \\
2030 \\
\end{array}$ & $\begin{array}{c}\text { B2 } \\
2000 \\
2030 \\
\end{array}$ \\
\hline Pacific OECD & 8.4 & 13.7 & 14.2 & 14.2 & 14.5 & 14.3 & 14.2 & 12.8 & $1.7 \%$ & $0.2 \%$ & $-0.2 \%$ \\
\hline North America & 25.9 & 31.4 & 32.3 & 32.8 & 32.9 & 28.6 & 29.3 & 29.2 & $0.7 \%$ & $0.2 \%$ & $-0.2 \%$ \\
\hline Western Europe & 19.7 & 21.0 & 24.8 & 25.4 & 25.5 & 19.7 & 18.6 & 17.7 & $0.2 \%$ & $0.6 \%$ & $-0.6 \%$ \\
\hline Central/E. Europe & 5.3 & 3.8 & 9.4 & 10.3 & 11.0 & 4.4 & 5.3 & 6.1 & $-1.1 \%$ & $3.6 \%$ & $1.5 \%$ \\
\hline Former Soviet Union & 13.9 & 13.0 & 28.8 & 32.2 & 35.4 & 16.1 & 19.1 & 22.3 & $-0.2 \%$ & $3.4 \%$ & $1.8 \%$ \\
\hline $\begin{array}{l}\text { Centrally Planned } \\
\text { Asia }\end{array}$ & 6.6 & 24.6 & 41.8 & 55.4 & 68.2 & 36.3 & 46.0 & 55.3 & $4.6 \%$ & $3.5 \%$ & $2.7 \%$ \\
\hline Other Asia & 2.7 & 12.7 & 20.2 & 29.3 & 41.1 & 19.0 & 26.4 & 35.2 & $5.4 \%$ & $4.0 \%$ & $3.4 \%$ \\
\hline Latin America & 3.4 & 9.7 & 29.1 & 38.7 & 51.1 & 15.8 & 20.1 & 24.8 & $3.7 \%$ & $5.7 \%$ & $3.2 \%$ \\
\hline Sub Saharan Africa & 1.9 & 3.3 & 13.3 & 19.0 & 27.4 & 4.3 & 7.5 & 14.5 & $2.0 \%$ & $7.3 \%$ & $5.1 \%$ \\
\hline Middle East/N. Africa & 1.0 & 6.8 & 20.3 & 29.2 & 39.3 & 13.9 & 15.5 & 19.2 & $6.7 \%$ & $6.0 \%$ & $3.5 \%$ \\
\hline World & 89 & 140 & 234 & 287 & 346 & 172 & 202 & 237 & $1.6 \%$ & $3.1 \%$ & $1.8 \%$ \\
\hline
\end{tabular}

Figure 9. Historical and Projected Industrial Sector Primary Energy, 1971-2030 (EJ)
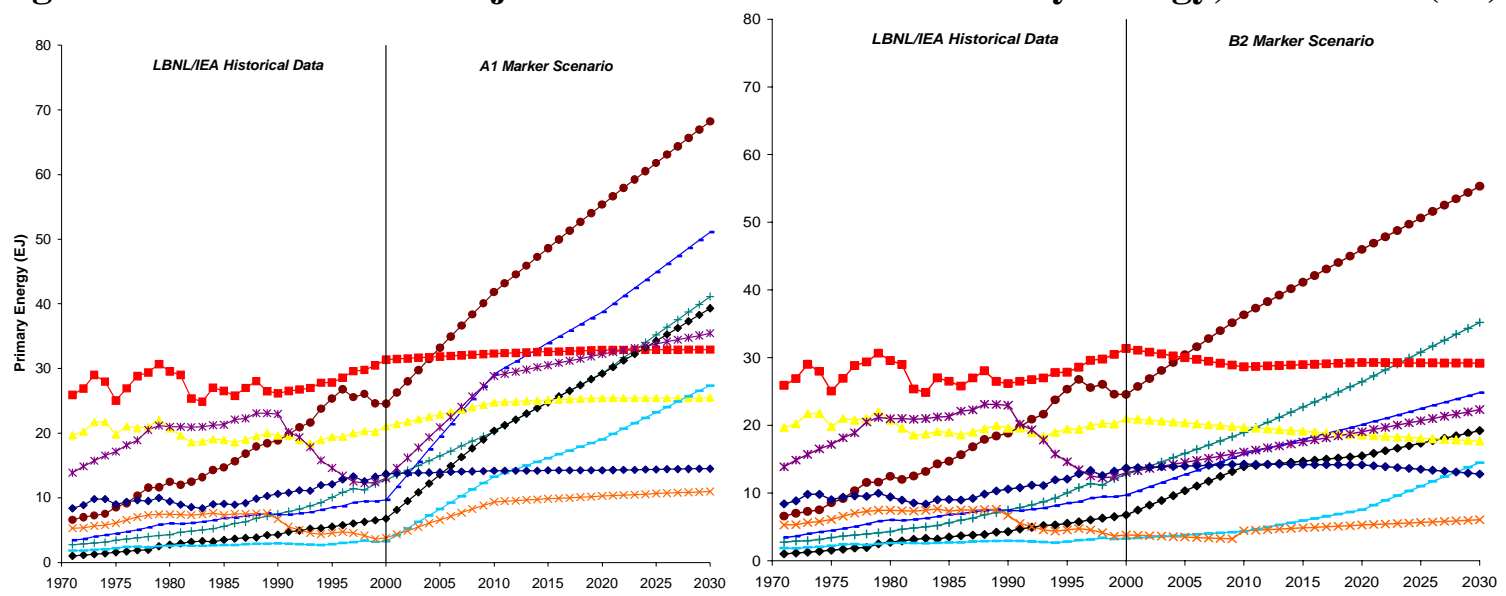


$\begin{array}{llll}\rightarrow-\text { Centrally Planned Asia } & - \text { Other Asia } & - \text { Latin America } & \rightarrow \text { North America } \\ \rightarrow \text { Middle East and N. Africa } & - \text { Western Europe } & * \text { Former Soviet Union } & - \text { Sub Saharan Africa } \\ \rightarrow \text { Pacific OECD } & \rightarrow \text { Central and E. Europe }\end{array}$

\subsection{Buildings Sector}

The buildings sector represented $38 \%$ of the total primary energy use in 2000 . The breakdown by region shows a growing demand for energy in this sector for all regions (see Table 3 and Figure 10). The main difference between the two scenarios is that the B2 scenario foresees more intense growth in the North American region than the A1 scenario. Across regions, the A1 scenario foresees more intense growth in developed countries for this sector.

Table 3. Historical and Projected Buildings Sector Primary Energy, 1971-2030 (EJ)

\begin{tabular}{|c|c|c|c|c|c|c|c|c|c|c|c|}
\hline & \multicolumn{2}{|c|}{ Historical } & \multicolumn{3}{|c|}{ A1 } & \multicolumn{3}{|c|}{ B2 } & \multicolumn{3}{|c|}{$\begin{array}{c}\text { Average Annual } \\
\text { Growth Rate }\end{array}$} \\
\hline & 1971 & 2000 & 2010 & 2020 & 2030 & 2010 & 2020 & 2030 & $\begin{array}{l}1971- \\
2000\end{array}$ & $\begin{array}{c}\text { A1 } \\
2000- \\
2030\end{array}$ & $\begin{array}{c}\text { B2 } \\
2000- \\
2030\end{array}$ \\
\hline Pacific OECD & 3.2 & 9.8 & 11.1 & 12.5 & 14.7 & 10.7 & 11.4 & 12.7 & $4.0 \%$ & $1.4 \%$ & $0.9 \%$ \\
\hline North America & 25.2 & 35.2 & 39.7 & 42.2 & 45.1 & 49.3 & 58.2 & 61.4 & $1.2 \%$ & $0.8 \%$ & $1.9 \%$ \\
\hline Western Europe & 16.4 & 21.3 & 28.7 & 31.8 & 33.9 & 25.1 & 27.7 & 30.8 & $0.9 \%$ & $1.6 \%$ & $1.2 \%$ \\
\hline Central/E. Europe & 3.3 & 4.2 & 2.6 & 3.0 & 3.6 & 3.9 & 4.3 & 5.4 & $0.9 \%$ & $-0.5 \%$ & $0.9 \%$ \\
\hline Former Soviet Union & 11.2 & 14.2 & 6.2 & 7.9 & 9.9 & 16.8 & 19.4 & 20.7 & $0.8 \%$ & $-1.2 \%$ & $1.3 \%$ \\
\hline Centrally Planned Asia & 9.9 & 20.0 & 29.6 & 41.0 & 53.2 & 20.9 & 29.3 & 40.2 & $2.5 \%$ & $3.3 \%$ & $2.4 \%$ \\
\hline Other Asia & 8.1 & 18.8 & 24.0 & 33.2 & 41.0 & 19.7 & 25.6 & 30.2 & $2.9 \%$ & $2.6 \%$ & $1.6 \%$ \\
\hline Latin America & 3.1 & 6.1 & 20.3 & 27.4 & 38.7 & 9.1 & 10.2 & 12.0 & $2.4 \%$ & $6.4 \%$ & $2.3 \%$ \\
\hline Sub Saharan Africa & 4.9 & 9.2 & 15.5 & 20.3 & 33.5 & 9.0 & 10.3 & 10.8 & $2.2 \%$ & $4.4 \%$ & $0.5 \%$ \\
\hline Middle East/N. Africa & 0.9 & 8.5 & 16.6 & 23.3 & 37.9 & 8.2 & 9.9 & 11.7 & $7.9 \%$ & $5.1 \%$ & $1.1 \%$ \\
\hline World & 86 & 147 & 194 & 243 & 312 & 173 & 206 & 236 & $1.9 \%$ & $2.5 \%$ & $1.6 \%$ \\
\hline
\end{tabular}

Figure 10. Historical and Projected Buildings Sector Primary Energy, 1971-2030 (EJ)

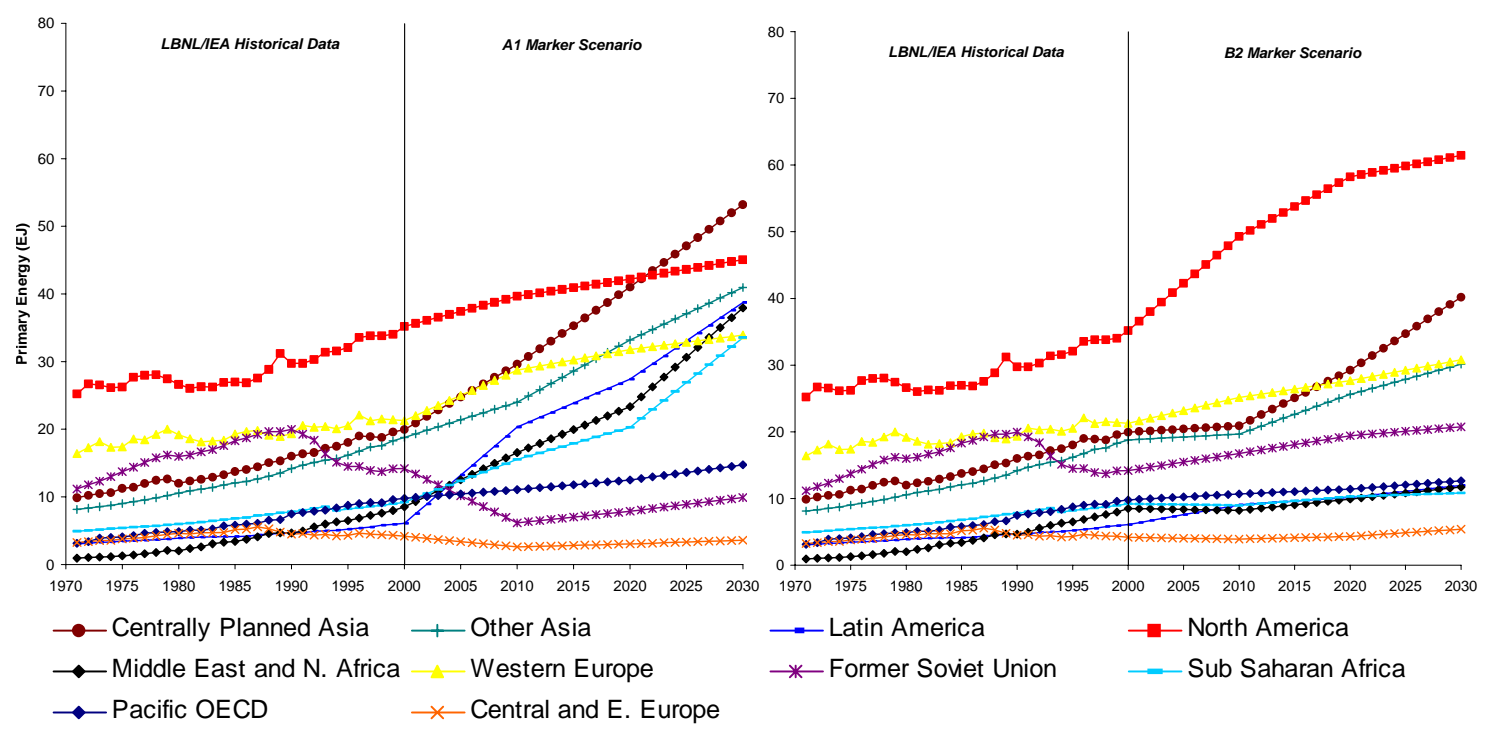




\subsection{Transport Sector}

Primary energy consumption in the transport sector represented $22 \%$ of total primary energy consumption in the world in 2000, an annual increase of $2.5 \%$ since 1971 . This sector is expected to grow in all regions but most intensively in developing countries (see Table 4 and Figure 11). The A1 and B2 scenarios project an annual growth rate of 3\% and $2.1 \%$, respectively, for the period 2000 to 2030 .

Table 4. Historical and Projected Transport Sector Primary Energy, 1971-2030 (EJ)

\begin{tabular}{|c|c|c|c|c|c|c|c|c|c|c|c|}
\hline & \multicolumn{2}{|c|}{ Historical } & \multicolumn{3}{|c|}{ A1 } & \multicolumn{3}{|c|}{ B2 } & \multicolumn{3}{|c|}{$\begin{array}{c}\text { Average Annual } \\
\text { Growth Rate }\end{array}$} \\
\hline & 1971 & 2000 & 2010 & 2020 & 2030 & 2010 & 2020 & 2030 & $\begin{array}{c}1971- \\
2000\end{array}$ & $\begin{array}{c}\text { A1 } \\
2000- \\
2030\end{array}$ & $\begin{array}{c}\text { B2 } \\
2000- \\
2030 \\
\end{array}$ \\
\hline Pacific OECD & 2.47 & 7.19 & 8.09 & 11.19 & 14.82 & 8.34 & 9.52 & 10.05 & $3.8 \%$ & $2.4 \%$ & $1.1 \%$ \\
\hline North America & 20.34 & 31.92 & 30.01 & 34.94 & 38.87 & 33.80 & 38.86 & 45.30 & $1.6 \%$ & $0.7 \%$ & $1.2 \%$ \\
\hline Western Europe & 7.44 & 15.84 & 22.94 & 26.54 & 29.16 & 17.77 & 19.42 & 21.28 & $2.6 \%$ & $2.1 \%$ & $1.0 \%$ \\
\hline Central/E. Europe & 1.14 & 1.54 & 1.42 & 1.54 & 1.61 & 1.41 & 1.69 & 2.26 & $1.0 \%$ & $0.2 \%$ & $1.3 \%$ \\
\hline Former Soviet Union & 4.27 & 5.01 & 3.64 & 4.48 & 5.84 & 5.66 & 7.24 & 9.77 & $0.6 \%$ & $0.5 \%$ & $2.3 \%$ \\
\hline Centrally Planned Asia & 0.86 & 5.15 & 9.95 & 18.49 & 27.72 & 7.84 & 11.81 & 16.46 & $6.4 \%$ & $5.8 \%$ & $3.9 \%$ \\
\hline Other Asia & 1.23 & 5.49 & 9.45 & 17.72 & 28.59 & 9.25 & 14.16 & 22.61 & $5.3 \%$ & $5.7 \%$ & $4.8 \%$ \\
\hline Latin America & 2.39 & 7.34 & 10.90 & 18.13 & 24.56 & 9.00 & 11.06 & 14.61 & $4.0 \%$ & $4.1 \%$ & $2.3 \%$ \\
\hline Sub Saharan Africa & 0.68 & 1.70 & 4.26 & 7.61 & 12.44 & 1.77 & 3.26 & 6.36 & $3.2 \%$ & $6.9 \%$ & $4.5 \%$ \\
\hline Middle East/N. Africa & 0.78 & 4.53 & 10.35 & 17.43 & 25.18 & 7.37 & 9.08 & 12.48 & $6.2 \%$ & $5.9 \%$ & $3.4 \%$ \\
\hline World & 42 & 86 & 111 & 158 & 209 & 102 & 126 & 161 & $2.5 \%$ & $3.0 \%$ & $2.1 \%$ \\
\hline
\end{tabular}

Figure 11. Historical and Projected Transport Sector Primary Energy, 1971-2030 (EJ)

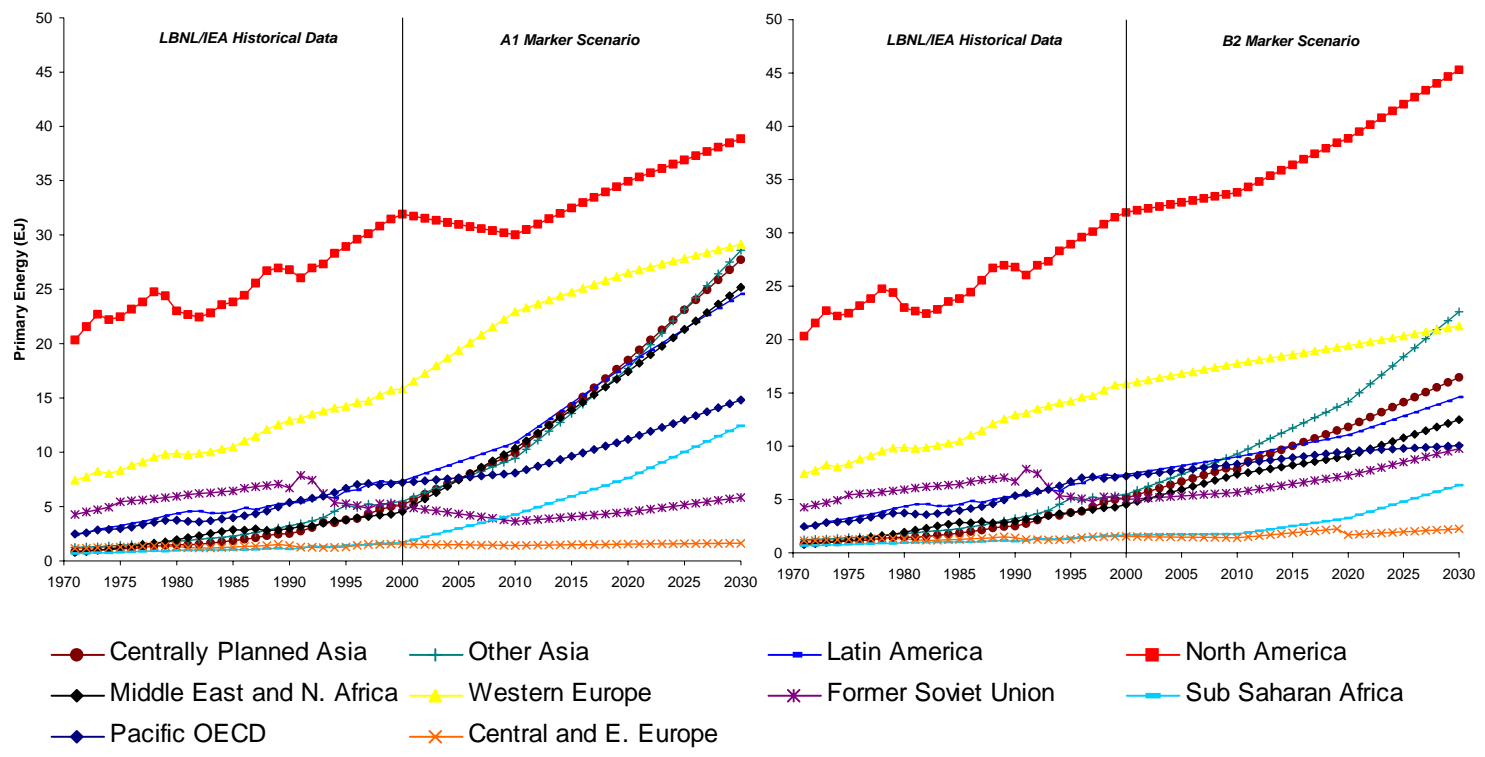




\section{Historical and Projected Energy-Related Carbon Dioxide Emissions}

Using the methodologies described above, LBNL calculated historical $\mathrm{CO}_{2}$ emis sions (1971-2000) for the ten world regions by end-use sector. Using the scenario data provided by the SRES modelers, LBNL compiled the projected energy-related $\mathrm{CO}_{2}$ emissions (2000-2030) for the A1 and B2 scenarios for the industrial, buildings and transport sectors for the ten world regions. ${ }^{6}$ Table 5 provides a summary of these data for the end-use sectors, while Figures 12 and 13 illustrate the sectoral trends for both the historical data from 1971 to 2000 and the SRES A1 and B2 scenario data, respectively

The A1 scenario projects total energy-related $\mathrm{CO}_{2}$ emissions to grow at an average annual rate of $2.9 \%$, a much faster pace than either the historical growth rate over the past 30 years $(1.7 \%)$ or the B2 scenario projection $(1.8 \%)$. The transport sector has historically had the highest average annual growth rate and is projected to remain the highest growing end-use sector in both scenarios. The industrial sector is projected to grow faster than historical trends, while for buildings the A1 scenario projects faster than historical growth rates and the $\mathrm{B} 2$ scenario foresees slower than historical growth rates to 2030 .

Table 5. World Carbon Emissions, A1 and B2 Scenarios (MtC)

\begin{tabular}{|c|c|c|c|c|c|c|c|c|c|c|c|}
\hline & \multicolumn{2}{|c|}{ Historical } & \multicolumn{3}{|c|}{ A1 } & \multicolumn{3}{|c|}{ B2 } & \multicolumn{3}{|c|}{$\begin{array}{l}\text { Average Annual } \\
\text { Growth Rate }\end{array}$} \\
\hline & 1971 & 2000 & 2010 & 2020 & 2030 & 2010 & 2020 & 2030 & $\begin{array}{l}1971- \\
2000\end{array}$ & $\begin{array}{c}\text { A1 } \\
2000- \\
2030\end{array}$ & $\begin{array}{c}\text { B2 } \\
2000- \\
2030\end{array}$ \\
\hline Total & 3,690 & 6,068 & 9,495 & 12,089 & 14,358 & 7,936 & 9,042 & 10,215 & $1.7 \%$ & $2.9 \%$ & $1.8 \%$ \\
\hline Industrial & 1,605 & 2,282 & 4,156 & 4,959 & 5,447 & 3,192 & 3,479 & 3,789 & $1.2 \%$ & $2.9 \%$ & $1.7 \%$ \\
\hline Buildings & 1,233 & 2,060 & 2,719 & 3,482 & 4,261 & 2,260 & 2,719 & 3,114 & $1.8 \%$ & $2.5 \%$ & $1.4 \%$ \\
\hline Transport & 741 & 1,517 & 2,216 & 3,157 & 4,092 & 2,260 & 2,555 & 2,947 & $2.5 \%$ & $3.4 \%$ & $2.2 \%$ \\
\hline Agriculture & 109 & 209 & 403 & 491 & 557 & 224 & 289 & 367 & $2.3 \%$ & $3.3 \%$ & $1.9 \%$ \\
\hline
\end{tabular}

\footnotetext{
${ }^{6}$ The time series reported here use historical data from 1971 to 2000 and scenario data from 2000 to 2030 . Since the actual 2000 value and the 2000 values in the scenarios differed, the actual value was used for 2000 and the values between 2000 and the scenario value for 2010 were extrapolated. Thus, the values for 2000 to 2010 do not exactly match the reported scenario values, but do match the scenario growth rates during this period. The 2010 to 2030 values exactly match the scenario values.
} 
Figure 12. Global Energy-Related CO2 Emissions by End-Use Sector, Historical to 2000 and Projected by the SRES A1 Scenario to 2030.

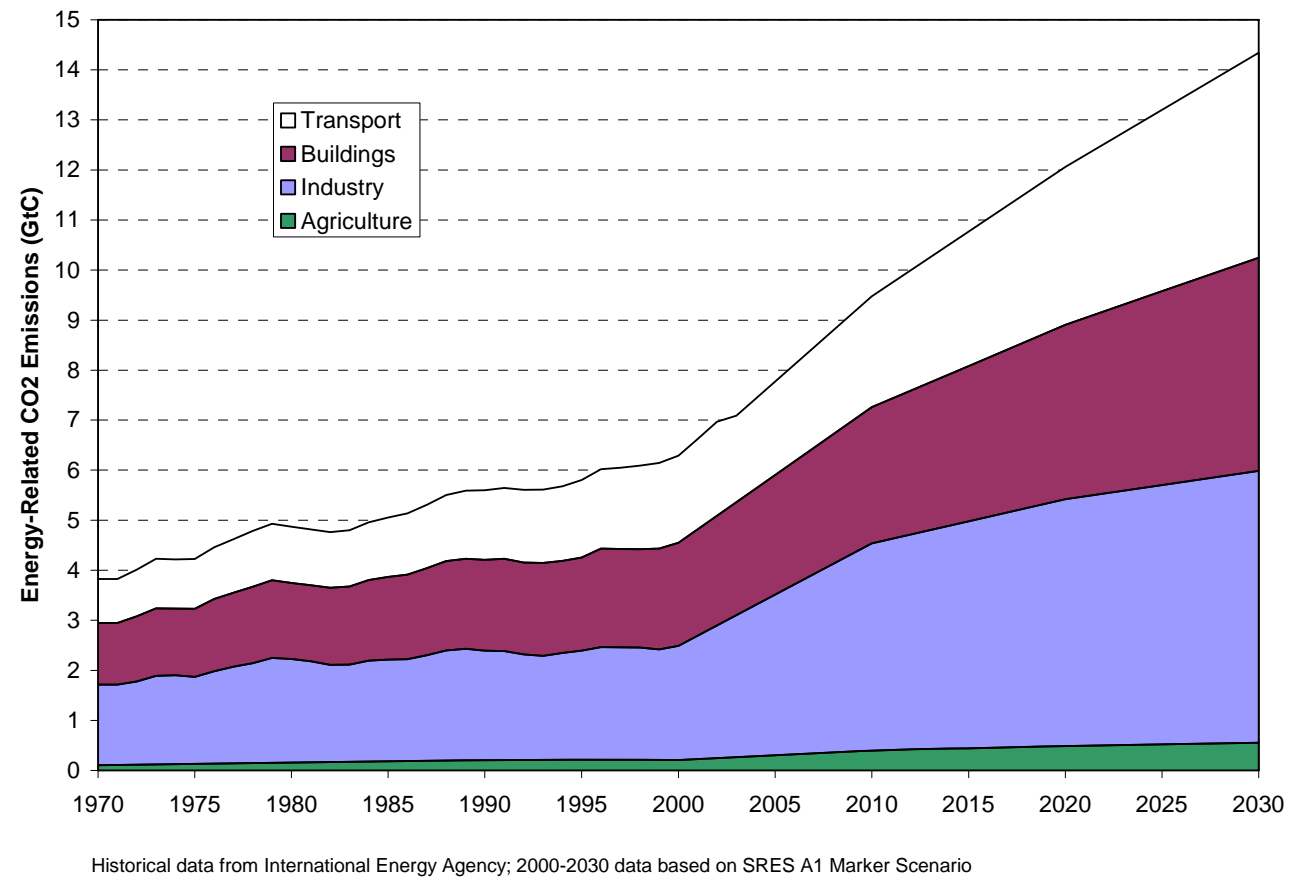

Figure 13. Global Energy-Related CO2 Emissions by End-Use Sector, Historical (1971-2000) and Projected by the SRES B2 Scenario (2000-2030).

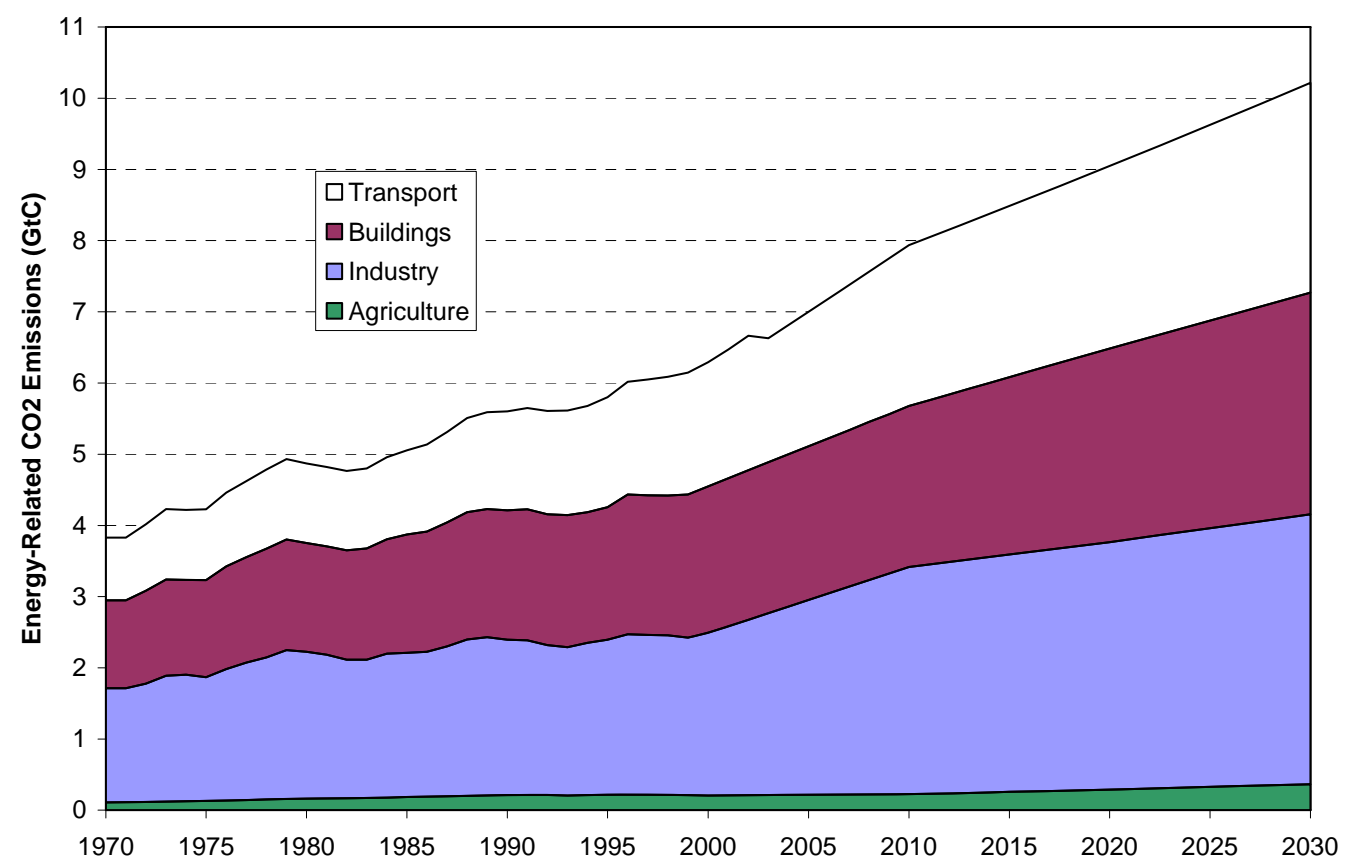

Historical data from International Energy Agency; 2000-2030 data based on SRES B2 Marker Scenario 


\subsection{Industrial Sector}

In $\mathrm{A} 1$ and $\mathrm{B} 2$ scenarios, $\mathrm{CO}_{2}$ emissions in the industrial sector are projected to continue increasing for all regions until 2010 when $\mathrm{CO}_{2}$ emissions from the developed countries of the North America, Western Europe and Pacific OECD regions will peak and start declining (see Table 6 and Figure 14). In both scenarios, emissions from developing countries and economies in transition are forecast to continue their growth after 2010, albeit at a much slower pace. In absolute terms, developing countries are expected to be by far the largest contributor to the growth in annual emissions due to increased industrial activity. The A1 scenario forecasts that most developing countries today will exceed the $\mathrm{CO}_{2}$ emissions from developed regions in the industrial sector. In the B2 scenario, only the two Asian regions will surpass the emissions of the North America region.

Table 6. Historical and Projected Industrial Sector $\mathrm{CO}_{2}$ Emissions, 1971-2030 (MtC)

\begin{tabular}{|c|c|c|c|c|c|c|c|c|c|c|c|}
\hline & \multicolumn{2}{|c|}{ Historical } & \multicolumn{3}{|c|}{ A1 } & \multicolumn{3}{|c|}{ B2 } & \multicolumn{3}{|c|}{$\begin{array}{l}\text { Average Annual } \\
\text { Growth Rate }\end{array}$} \\
\hline & 1971 & 2000 & 2010 & 2020 & 2030 & 2010 & 2020 & 2030 & $\begin{array}{c}1971- \\
2000\end{array}$ & $\begin{array}{c}\text { A1 } \\
2000- \\
2030\end{array}$ & $\begin{array}{c}\text { B2 } \\
2000 \\
2030\end{array}$ \\
\hline Pacific OECD & 144 & 211 & 319 & 319 & 310 & 267 & 228 & 188 & $1.3 \%$ & $1.3 \%$ & $-0.4 \%$ \\
\hline North America & 418 & 453 & 512 & 486 & 450 & 523 & 518 & 470 & $0.3 \%$ & $0.0 \%$ & $0.1 \%$ \\
\hline Western Europe & 383 & 302 & 348 & 335 & 316 & 346 & 315 & 290 & $-0.8 \%$ & $0.2 \%$ & $-0.1 \%$ \\
\hline Central/E. Europe & 108 & 70 & 162 & 167 & 164 & 89 & 104 & 116 & $-1.5 \%$ & $2.9 \%$ & $1.7 \%$ \\
\hline Former Soviet Union & 263 & 218 & 482 & 505 & 506 & 298 & 313 & 330 & $-0.6 \%$ & $2.8 \%$ & $1.4 \%$ \\
\hline Centrally Planned Asia & 156 & 549 & 906 & 1,130 & 1,223 & 764 & 889 & 990 & $4.4 \%$ & $2.7 \%$ & $2.0 \%$ \\
\hline Other Asia & 38 & 209 & 411 & 569 & 779 & 358 & 463 & 587 & $6.1 \%$ & $4.5 \%$ & $3.5 \%$ \\
\hline Latin America & 46 & 117 & 418 & 572 & 662 & 259 & 313 & 342 & $3.2 \%$ & $5.9 \%$ & $3.6 \%$ \\
\hline Sub Saharan Africa & 32 & 53 & 234 & 361 & 430 & 71 & 94 & 181 & $1.7 \%$ & $7.2 \%$ & $4.2 \%$ \\
\hline Middle East/N. Africa & 17 & 99 & 366 & 515 & 607 & 216 & 242 & 295 & $6.3 \%$ & $6.2 \%$ & $3.7 \%$ \\
\hline World & 1,605 & 2,282 & 4,156 & 4,959 & 5,447 & 3,192 & 3,479 & 3,789 & $1.2 \%$ & $2.9 \%$ & $1.7 \%$ \\
\hline
\end{tabular}

Figure 14. Historical and Projected Industrial Sector $\mathrm{CO}_{2}$ Emissions, 1971-2030 (MtC)

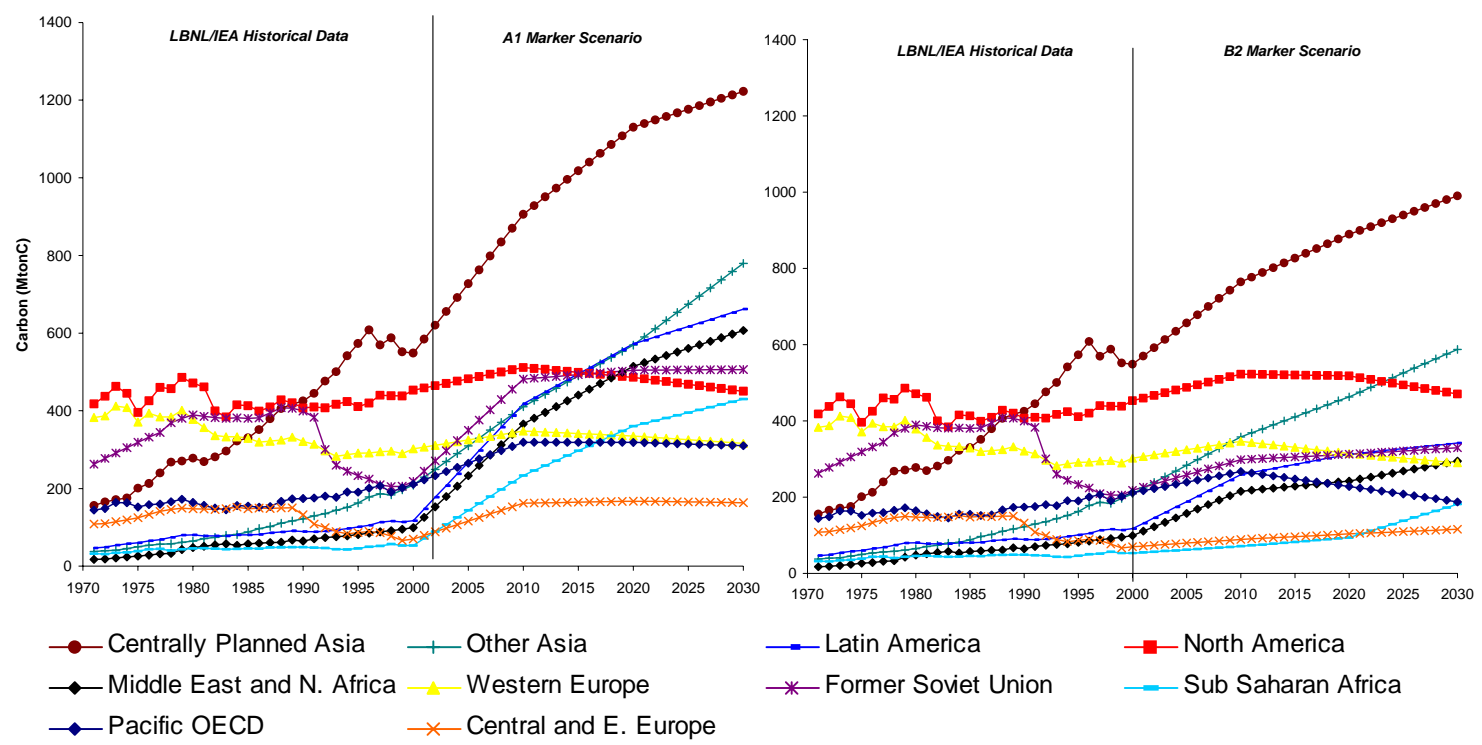




\subsection{Buildings Sector}

As shown in Table 7 and Figure 15, the A1 scenario forecasts $\mathrm{CO}_{2}$ emissions from the buildings sector to decline in the North America and Western Europe regions, while emissions in Pacific OECD region are forecast to grow at average rate of $0.5 \%$. The B2 scenario projects $\mathrm{CO}_{2}$ emissions from industrialized countries to level off around 2020 for the North America and Pacific OECD regions. The projection for transition economies varies between scenarios and reflects the differences of energy consumption during the period that followed the collapse of the Soviet Union. In absolute terms, the A1 scenario projects that the two Asian regions will have exceed the amount of $\mathrm{CO}_{2}$ emitted in the North America region by 2030, currently the highest emitting region. The B2 scenario envisions that most of the developing countries still remain at a lower level of emissions than industrialized countries in terms of level of absolute emissions in 2030.

Table 7. Historical and Projected Buildings Sector $\mathrm{CO}_{2}$ Emissions, 1971-2030 (MtC)

\begin{tabular}{|c|c|c|c|c|c|c|c|c|c|c|c|}
\hline & \multicolumn{2}{|c|}{ Historical } & \multicolumn{3}{|c|}{ A1 } & \multicolumn{3}{|c|}{ B2 } & \multicolumn{3}{|c|}{$\begin{array}{c}\text { Average Annual } \\
\text { Growth Rate }\end{array}$} \\
\hline & 1971 & 2000 & 2010 & 2020 & 2030 & 2010 & 2020 & 2030 & $\begin{array}{l}1971- \\
2000\end{array}$ & $\begin{array}{c}\text { A1 } \\
2000- \\
2030\end{array}$ & $\begin{array}{c}\text { B2 } \\
2000 \\
2030\end{array}$ \\
\hline Pacific OECD & 57 & 176 & 202 & 212 & 220 & 175 & 183 & 182 & $4.0 \%$ & $0.7 \%$ & $0.1 \%$ \\
\hline North America & 457 & 633 & 585 & 545 & 495 & 818 & 969 & 963 & $1.1 \%$ & $-0.8 \%$ & $1.4 \%$ \\
\hline Western Europe & 313 & 329 & 393 & 397 & 383 & 352 & 380 & 415 & $0.2 \%$ & $0.5 \%$ & $0.8 \%$ \\
\hline Central/E. Europe & 66 & 77 & 47 & 52 & 55 & 72 & 74 & 93 & $0.5 \%$ & $-1.1 \%$ & $0.6 \%$ \\
\hline Former Soviet Union & 213 & 241 & 99 & 119 & 140 & 234 & 280 & 301 & $0.4 \%$ & $-1.8 \%$ & $0.7 \%$ \\
\hline Centrally Planned Asia & 59 & 225 & 517 & 779 & 1,020 & 306 & 428 & 609 & $4.7 \%$ & $5.2 \%$ & $3.4 \%$ \\
\hline Other Asia & 20 & 143 & 307 & 502 & 693 & 125 & 183 & 260 & $7.0 \%$ & $5.4 \%$ & $2.0 \%$ \\
\hline Latin America & 22 & 66 & 201 & 303 & 379 & 64 & 80 & 108 & $3.8 \%$ & $6.0 \%$ & $1.7 \%$ \\
\hline Sub Saharan Africa & 14 & 28 & 127 & 224 & 415 & 19 & 30 & 54 & $2.5 \%$ & $9.4 \%$ & $2.2 \%$ \\
\hline Middle East/N. Africa & 12 & 141 & 241 & 349 & 461 & 95 & 112 & 128 & $8.8 \%$ & $4.0 \%$ & $-0.3 \%$ \\
\hline World & 1,233 & 2,060 & 2,719 & 3,482 & 4,261 & 2,260 & 2,719 & 3,114 & $1.8 \%$ & $2.5 \%$ & $1.4 \%$ \\
\hline
\end{tabular}

Figure 15. Historical and Projected Buildings Sector $\mathrm{CO}_{2}$ Emissions, 1971-2030 (MtC)

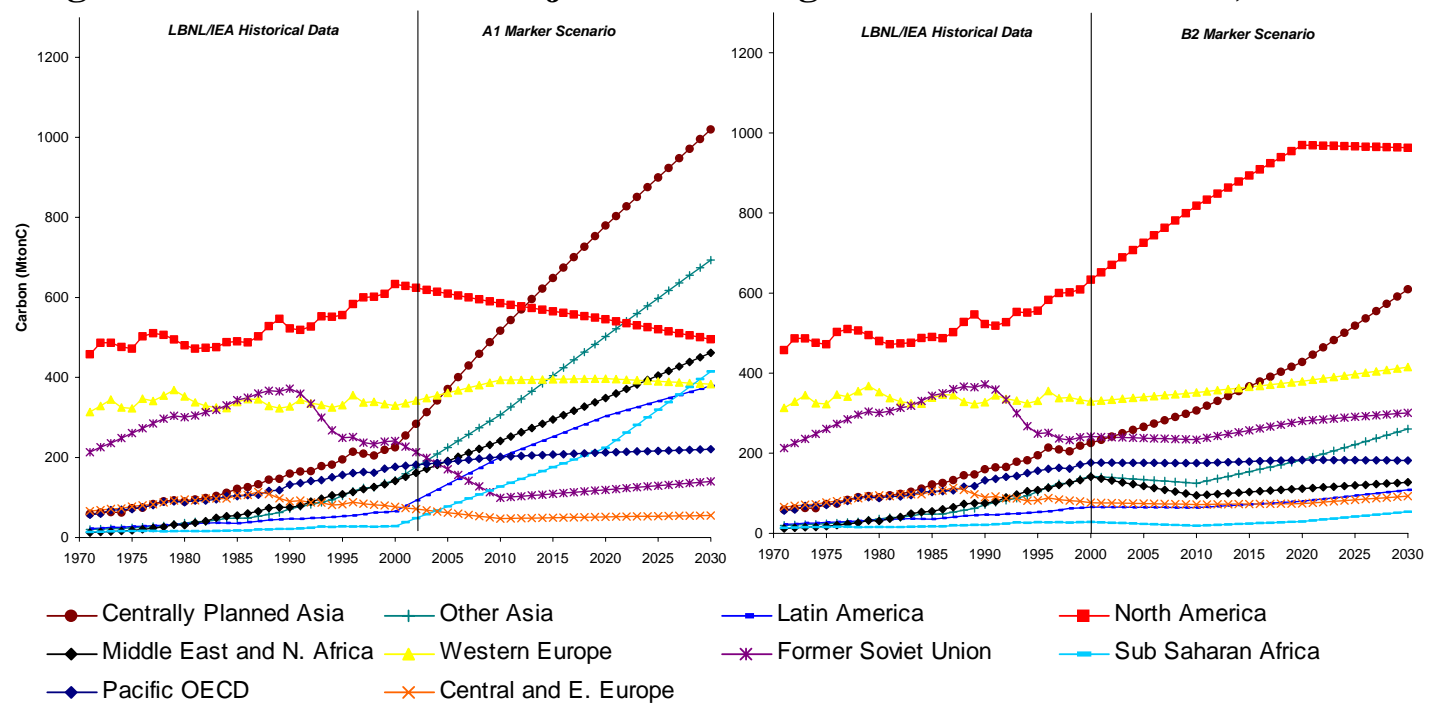




\subsection{Transport Sector}

Transportation is the fastest-growing source of $\mathrm{CO}_{2}$ emissions globally. $\mathrm{CO}_{2}$ emissions from industrialized countries have grown at an average annual rate of $2.5 \%$ over the last 30 years. Both scenarios forecast emissions from industrialized countries to continue to grow at a slower pace over time (see Table 8 and Figure 12). Conversely, developing countries in both scenarios are expected to grow rapidly, albeit much more rapidly in the A1 scenario. In absolute terms, the additional $\mathrm{CO}_{2}$ emissions per year in 2030 versus 2000 are higher in developing countries. However their contribution is lower in the B2 scenario, where the growth in emissions from developing countries only represents $60 \%$, compared to $80 \%$ in the A 1 scenario.

Table 1. Historical and Projected Transport Sector $\mathrm{CO}_{2}$ Emissions, 1971-2030 (MtC)

\begin{tabular}{|c|c|c|c|c|c|c|c|c|c|c|c|}
\hline & \multicolumn{2}{|c|}{ Historical } & \multicolumn{3}{|c|}{ A1 } & \multicolumn{3}{|c|}{ B2 } & \multicolumn{3}{|c|}{$\begin{array}{c}\text { Average Annual } \\
\text { Growth Rate }\end{array}$} \\
\hline & 1971 & 2000 & 2010 & 2020 & 2030 & 2010 & 2020 & 2030 & $\begin{array}{l}1971- \\
2000\end{array}$ & $\begin{array}{c}\text { A1 } \\
2000- \\
2030\end{array}$ & $\begin{array}{c}\text { B2 } \\
2000 \\
2030\end{array}$ \\
\hline Pacific OECD & 45 & 129 & 175 & 238 & 303 & 181 & 197 & 190 & $3.7 \%$ & $2.9 \%$ & $1.3 \%$ \\
\hline North America & 378 & 589 & 540 & 622 & 662 & 717 & 764 & 838 & $1.5 \%$ & $0.4 \%$ & $1.2 \%$ \\
\hline Western Europe & 130 & 272 & 466 & 534 & 563 & 376 & 387 & 391 & $2.6 \%$ & $2.4 \%$ & $1.2 \%$ \\
\hline Central/E. Europe & 21 & 26 & 23 & 25 & 26 & 34 & 38 & 41 & $0.8 \%$ & $-0.1 \%$ & $1.5 \%$ \\
\hline Former Soviet Union & 62 & 79 & 57 & 70 & 86 & 128 & 149 & 190 & $0.8 \%$ & $0.3 \%$ & $3.0 \%$ \\
\hline Centrally Planned Asia & 15 & 98 & 179 & 326 & 469 & 171 & 232 & 314 & $6.6 \%$ & $5.4 \%$ & $4.0 \%$ \\
\hline Other Asia & 23 & 93 & 214 & 397 & 626 & 208 & 286 & 333 & $4.9 \%$ & $6.5 \%$ & $4.3 \%$ \\
\hline Latin America & 43 & 125 & 251 & 413 & 557 & 205 & 215 & 262 & $3.8 \%$ & $5.1 \%$ & $2.5 \%$ \\
\hline Sub Saharan Africa & 14 & 30 & 103 & 184 & 298 & 41 & 57 & 87 & $2.7 \%$ & $8.0 \%$ & $3.7 \%$ \\
\hline Middle East/N. Africa & 11 & 76 & 208 & 348 & 502 & 199 & 229 & 301 & $7.0 \%$ & $6.5 \%$ & $4.7 \%$ \\
\hline World & 741 & 1,517 & 2,216 & 3,157 & 4,092 & 2,260 & 2,555 & 2,947 & $2.5 \%$ & $3.4 \%$ & $2.2 \%$ \\
\hline
\end{tabular}

Figure 16. Historical and Projected Transport Sector $\mathrm{CO}_{2}$ Emissions, 1971-2030 (MtC)
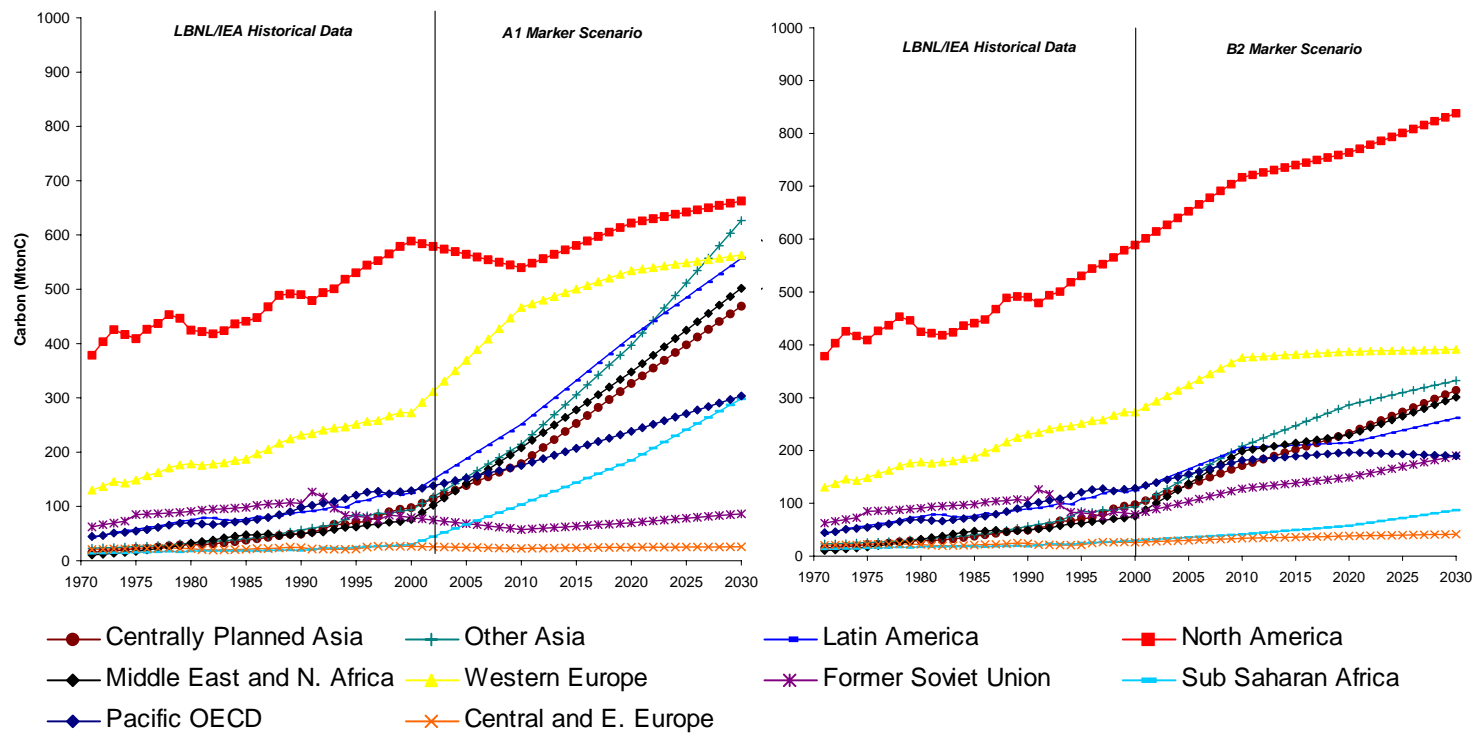


\section{Disaggregation of SRES A1 and B2 Scenarios}

\subsection{Macro Level Drivers}

At the macro level, the drivers affecting growth of $\mathrm{CO}_{2}$ emissions in an economy include the rate of population growth, the size and structure of the economy (depending on consumption patterns and stage of development), the amount of energy consumed per unit of activity, and the specific carbon emissions of the fuel mix used. Our discussion of the drivers is guided by the terms of the so-called Kaya identity (Kaya, 1989) as outlined by Equation 1.

Equation 1:

\begin{tabular}{llllllll}
$\mathrm{CO}_{2}$ & $\underline{\text { GDP }}$ & & \multicolumn{2}{c}{ Final Energy } & & \multicolumn{2}{c}{ Primary Energy } \\
$\underline{\mathrm{CO}}_{2}$ & & & & & & \\
Emissions = Population & x & Population & x & GDP & x & Final Energy & x \\
Primary E. & & & & &
\end{tabular}

Figure 17 shows that $\mathrm{CO}_{2}$ emissions have grown by approximately $70 \%$ during the last 30 years. The main macro driving forces behind this growth are composed of GDP/population, population, the ratio of primary energy to final energy, the ratio of $\mathrm{CO}_{2}$ emissions to primary energy, and the ratio of final energy to GDP.

\section{Figure 17. Historical Evolution of $\mathrm{CO}_{2}$ Emissions and Macro Drivers} (1971 =100)

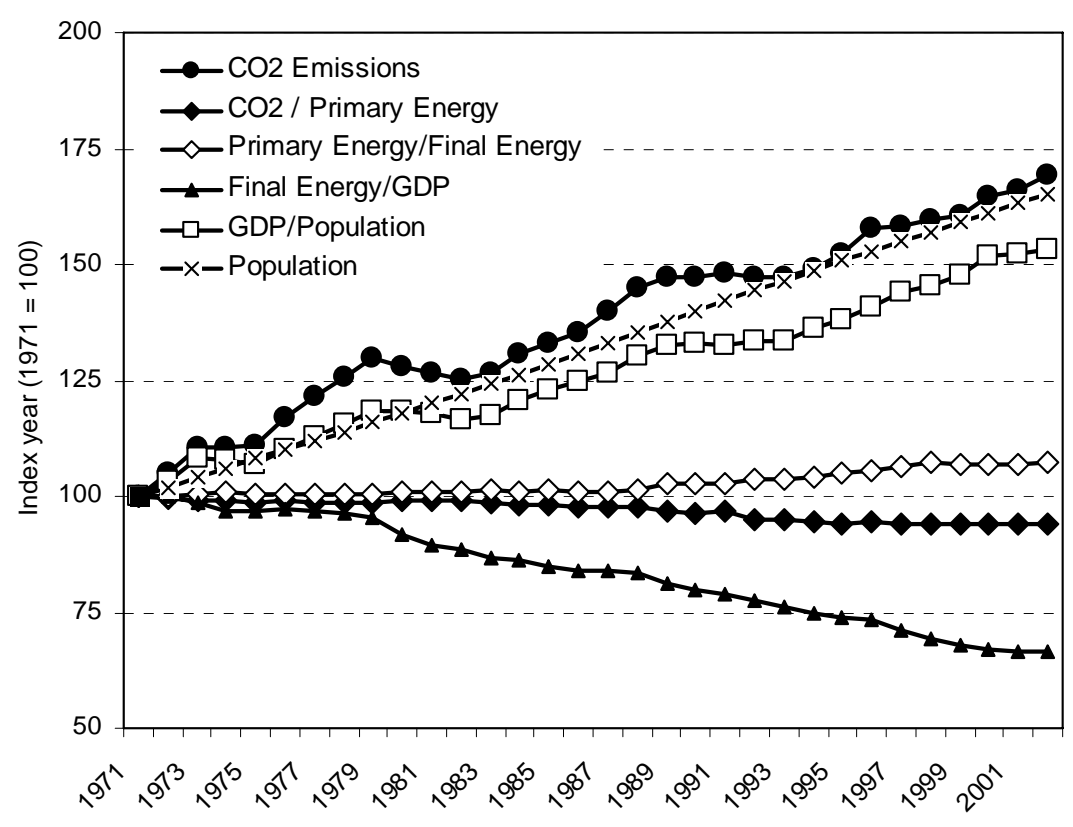

$\mathrm{CO}_{2}$ emissions per unit of primary energy represent the fuel mix in an economy. This factor has declined $6 \%$ over the last 30 years, an average annual growth rate of $-0.2 \%$, reflecting a decarbonization of energy consumption (Grübler and Nakićenović, 1996). This is explained by a switch to cleaner fuels that emit less $\mathrm{CO}_{2}$ and to the increasing 
share of nuclear energy that has no $\mathrm{CO}_{2}$ emissions associated with its use. However, since no $\mathrm{CO}_{2}$ emissions are associated with biomass consumption in the international accounting methodology, switching from biomass energy use to a more modern form of energy increases this ratio.

The ratio of primary energy per unit of final energy reflects the inverse efficiency of energy conversion occurring in the economy. Historically, this ratio has increased by $7 \%$ over the last 30 years (average annual growth rate of $0.23 \%$ ), meaning that more primary energy was required to produce the final energy that was ultimately consumed by endusers. This is explained by an increase in the demand for electricity, which requires a substantial amount of primary energy to be generated. However this growth in demand was dampened by an increasing share of nuclear and renewables energy for which the energy conversion is $100 \%$ using the direct equivalent method.

Final energy use per unit of gross domestic product (GDP) represents the final energy consumed in the economy per unit of value added produced. It is an indicator of the intensity of the energy use compared to the evolution of GDP. Historically, this indicator has significantly decreased by $34 \%$ over the past 30 years, reflecting a de-coupling of energy use and the growth of the economy.

GDP per capita tracks changes in how wealthy countries and regions are; other things being equal, growth in per capita GDP is accompanied by rising demand for energy services. Finally, population is the raison d'etre for demand for energy services.

\section{Figure 18. Evolution of $\mathrm{CO}_{2}$ Emissions Projections from the A1 and B2 Scenarios} $(1971=100)$
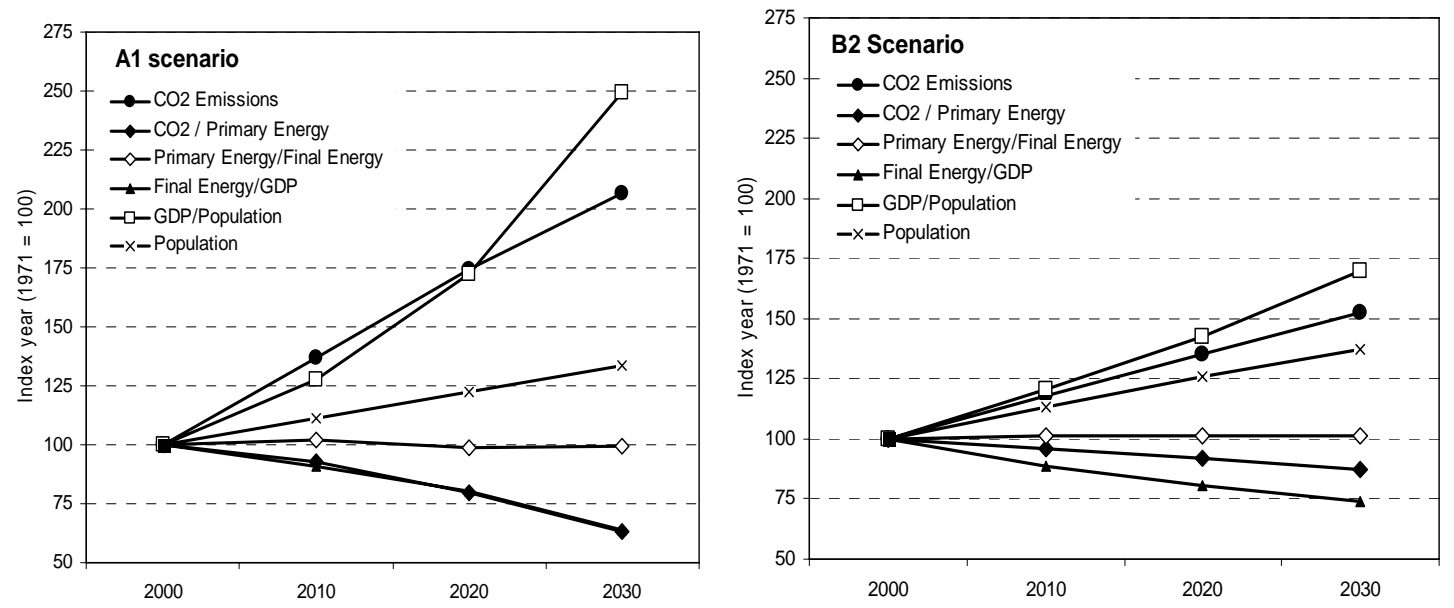

Figure 18 shows the projection of these macro indicators for the SRES A1 and B2 scenarios. The A1 scenario results in a $100 \%$ increase in total $\mathrm{CO}_{2}$ emissions between 2000 and 2030, compared to increases of approximately 70\% historically (from 1971 to 2002) and about $50 \%$ between 2000 and 2030 for the B2 scenario.

The difference in the outcomes of the scenarios stems mainly from different assumptions regarding the evolution of GDP. The A1 scenario is a scenario with high GDP growth while the B2 scenario has intermediate GDP growth. However, both scenarios refer to 
historical trends in building assumptions about increases in GDP per capita. The A1 scenario projects an increase of $150 \%$ in GDP/capita while the B2 scenario project an increase of $70 \%$ compared to historical growth which was $50 \%$ over the last 30 years. One reason is that population is projected to grow more slowly in the next 30 years, allowing a smaller distribution of the revenue.

Both scenarios have similar assumptions concerning population. Population is forecast to grow by approximately $35 \%$ over the next 30 years, lower than the $65 \%$ growth experienced during the past 30 years. As shown on the previous graph, historically, the major explanation for $\mathrm{CO}_{2}$ emissions to solely track population growth and not GDP growth was largely due to the substantial decline in final energy demand per unit of GDP. Final energy per GDP decreased considerably in industrialized countries (34\%) after the 1973 oil embargo when prices escalated. Structural changes such as the decreased share of energy-intensive industries and the increased service sector share in the value added of the GDP also explain this decrease. ${ }^{1}$ The A1 scenario forecasts GDP energy intensity to continue to decrease in a similar manner over the next 30 years $(36 \%)$ while the B2 scenario forecasts this indicator to decrease only by $26 \%$.

The high GDP growth in the A1 scenario is accompanied by a rapid decrease in the $\mathrm{CO}_{2}$ per primary energy indicator $(37 \%)$, reflecting a switch toward an increasing share of less carbon intensive fuels such as renewables and nuclear. The B2 scenario projects this indicator to decrease at a much slower rate of $12 \%$. However this still reflects a projection of relatively more intense decarbonization of the economy than has historically occurred $(6 \%)$. The primary energy per final energy consumption indicator is forecast to remain constant in both scenarios. The projected increasing share of electricity and other secondary energy produced will be accompanied by continuing improvement in technology conversion and an increasing share of nuclear and renewables that reduce primary energy demand.

\subsection{End-Use Sector Drivers}

It is important to understand the relationship of these macro level drivers to the drivers of energy use and related greenhouse gas emissions within the end-use sectors. To do this, we have redefined the Kaya identity terms to reflect our interest in understanding end-use energy demand as the fundamental driver for $\mathrm{CO}_{2}$ emissions. Overall, energy demand is driven by activity levels and the energy intensity of the specific energy-consuming activities, as shown in Equation 2:

Equation 2:

\begin{tabular}{|c|c|c|c|c|c|c|}
\hline $\begin{array}{l}\text { Energy-related } \\
\mathrm{CO}_{2} \text { emissions }\end{array}$ & function of & $\begin{array}{l}\text { Energy } \\
\text { Demand }\end{array}$ & $=$ & Activity & $\mathrm{x}$ & $\begin{array}{l}\text { Energy } \\
\text { Intensity }\end{array}$ \\
\hline
\end{tabular}

\footnotetext{
${ }^{1}$ Additional information on historical trends for OECD countries is available in IEA (2004e).
} 
The various terms are defined differently in each end-use sector. For example, while activity is generally linked to population in all sectors, it also includes commodity production levels in the industrial sector, number of persons per household in the residential sector and square meters of building space in the commercial sector. Energy intensity is related to both the characteristics of specific technologies and the economic drivers that lead to specific technologies being developed, disseminated, and adopted.

In order to further disaggregate the SRES A1 and B2 scenarios in an effort to better understand the factors affecting energy consumption, LBNL is using the Long-range Energy Alternatives Planning (LEAP) software developed by the Stockholm Environment Institute-Boston ${ }^{2}$ to decompose energy consumption at the end use level.

\subsubsection{Industrial Sector}

In the industrial sector, the main driver is the production of commodities. The disaggregation introduces physical energy intensities in terms of energy use per ton (or other unit) of industrial product produced for a portion of the industrial sector. Industrial energy consumption is divided into two sub-sectors: energy-intensive industries and light (or non-energy-intensive) industries. Physical production values for specific energyintensive industries (crude steel, aluminium, cement, pulp and paper, ethylene and ammonia) are multiplied by industry average physical intensities for a given country or region and then summed to derive energy consumption values for the energy-intensive industries sub-sector as a whole. Any other energy-intensive industrial production, along with production from light industries, is treated as a remainder (see Equation 3).

Equation 3:

\begin{tabular}{|c|c|c|}
\hline $\begin{array}{l}E_{I, i}= \\
\text { where: }\end{array}$ & & $\left.\sum_{c}^{\text {OPTION }} Q_{c, i} \times E I_{c, k, i}+L_{k, i} \times E I_{L, k, i}\right)$ \\
\hline $\mathrm{E}_{\mathrm{I}, \mathrm{i}}$ & $=$ & final energy demand in the industry sector for region $\mathrm{i}$ \\
\hline $\mathrm{k}$ & $=$ & energy type \\
\hline $\mathrm{c}$ & $=$ & commodity type \\
\hline $\mathrm{Q}_{\mathrm{c}, \mathrm{i}}$ & $=$ & quantity of energy-intensive commodity c produced in region i \\
\hline $\mathrm{EI}_{\mathrm{c}, \mathrm{k}, \mathrm{i}}$ & $=$ & $\begin{array}{l}\text { average intensity of energy type } \mathrm{k} \text { for producing energy-intensive industrial } \\
\text { commodity c in region i in } \mathrm{GJ} / \text { metric ton }\end{array}$ \\
\hline $\mathrm{L}_{\mathrm{k}, \mathrm{i}}$ & $=$ & value added of the light industries sector in region i in monetary terms \\
\hline $\mathrm{EI}_{\mathrm{L}, \mathrm{k}, \mathrm{i}}$ & $=$ & $\begin{array}{l}\text { average economic energy intensity in the light industries sector in region } \mathrm{i} \text { in } \\
\mathrm{MJ} / \text { (unit value added-year) }\end{array}$ \\
\hline
\end{tabular}

\footnotetext{
${ }^{2}$ For information on LEAP see http://forums.seib.org/leap/.
} 


\subsubsection{Residential Sector}

Energy services in the residential sector are driven by the living space, the size of households, and the number of households. For different end uses either the size of living space or the number of households will serve as a driver. The disaggregation identifies energy consumed per type of energy services (cooking, space heating, lighting and energy use per major appliances) and introduces physical energy intensities, i.e., energy use per square meter (see Equation 4). Energy use per square meter is used as a driver for space heating and lighting energy consumption. For cooking, water heating, and appliance usage, the number of households is considered as the driver. For some countries, particularly developing countries, urban and rural homes exhibit very different energy intensities that are important to consider.

Equation 4:

$\left.\left.E_{R B, i}=\sum_{k}^{\text {OPTION OPTION }} \sum_{m}^{P_{m, i}} \frac{F_{m, i}}{F_{m, i}} \times\left(S H_{m, i}+S C_{m . i}\right)\right)+\left(\sum_{j} p_{m, i, j} \times U E C_{i, j}\right)+C_{m, i}+L_{m, i}+R_{m, i}\right]$

where:

$\mathrm{E}_{\mathrm{RB}, \mathrm{i}}=$ final energy demand in the residential buildings sector in region $\mathrm{i}$

$\mathrm{k} \quad=$ energy type

$\mathrm{m} \quad=$ locale type (urban, rural)

$\mathrm{H}_{\mathrm{m}, \mathrm{i}} \quad=$ number of household in locale type $\mathrm{m}$ in region $\mathrm{i}$

$\mathrm{C}_{\mathrm{m}, \mathrm{i}}=$ average cooking and water heating energy use per household in locale type $\mathrm{m}$ in region $\mathrm{i}$ in $\mathrm{MJ} /$ household-year

$\mathrm{j}=$ type of appliance or end-use device

$\mathrm{p}_{\mathrm{i}, \mathrm{j}}=$ penetration of appliance or device $\mathrm{j}$ in region $\mathrm{i}$ in percent of households owning appliance in locale type $\mathrm{m}$ in region $\mathrm{i}$ in percentage

$\mathrm{UEC}_{\mathrm{i}, \mathrm{j}}=$ average energy intensity of appliance $\mathrm{j}$ in region $\mathrm{i}$ in $\mathrm{MJ}$ or $\mathrm{kWh} /$ year

$\mathrm{F}_{\mathrm{m}, \mathrm{i}}=$ average floor area per household in locale type $\mathrm{m}$ in region $\mathrm{i}$ in $\mathrm{m} 2$

$\mathrm{SH}_{\mathrm{m}, \mathrm{i}}=$ space heating energy intensity in residential buildings in locale type $\mathrm{m}$ in region $\mathrm{i}$ in $\mathrm{MJ} / \mathrm{m} 2$-year

$\mathrm{L}_{\mathrm{m}, \mathrm{i}}=$ average lighting energy use per household in locale type $\mathrm{m}$ in region $\mathrm{i}$ in $\mathrm{MJ}$ $/ / \mathrm{m} 2$-year

$\mathrm{R}_{\mathrm{m}, \mathrm{i}}=$ residual household energy use in locale type $\mathrm{m}$ in region $\mathrm{i}$ in $\mathrm{MJ}$ /householdyear

\subsubsection{Commercial Services Sector}

To disaggregate energy use in the commercial services sector, energy intensity can be defined as intensities in terms of energy use per unit of commercial floor space or in 
terms of energy use per employee in the sector. The first approach can be represented as show in Equation 5.

Equation 5:

$E_{C B, i}=A_{C B, i} \times \sum_{k}^{\text {OPTION }} E I_{C B, k, i}$
where:
$\begin{array}{ll}\mathrm{E}_{\mathrm{CB}, \mathrm{i}}= & \text { final energy demand in the commercial buildings sector in region } \mathrm{i} \\ \mathrm{k}= & \text { energy type } \\ \mathrm{A}_{\mathrm{CB}, \mathrm{i}}= & \text { total commercial floor area in region } \mathrm{i} \text { in } \mathrm{m} 2 \\ \mathrm{EI}_{\mathrm{CB}, \mathrm{k}, \mathrm{i}}= & \text { average floor area energy intensity of energy type } \mathrm{k} \text { in the commercial } \\ & \text { sector in region } \mathrm{i} \text { in } \mathrm{MJ} / \mathrm{m} 2 \text {-year }\end{array}$

\subsubsection{Transport}

In the transport sector, final energy is used by a large variety of modes and technologies to provide a small range of end-use services, i.e., the transport of passengers and goods, ultimately representing a single service: mobility. While for the other sectors the combination of fuel and technology is nearly always sufficient to determine the end-use service provided, this is not necessarily true for transport. Neither does the combination of the end-use and technology alone provide a level of detail adequate to accurately estimate end-use energy demand. For example trucks and locomotives used to haul freight can share the same engine technology and fuel and provide the same end-use service, but the associated energy intensity will be significantly different. It is thus necessary to introduce a breakdown by type of transport (passenger and freight) as well as by mode of transport (i.e., road, rail, air, water, and pipeline) (see Equation 6).

\section{Equation 6:}

\begin{tabular}{|c|c|}
\hline \multicolumn{2}{|c|}{$\begin{array}{l}E_{T R, i}=\sum_{k}^{\text {OPTION OPTION OPTION }} \sum_{t} \sum_{r} Q_{t, r, i} \times E I_{T R, k, t, r, i} \\
\text { where: }\end{array}$} \\
\hline $\mathrm{E}_{\mathrm{TR}, \mathrm{i}}$ & $=$ final energy demand in the transport sector in region $\mathrm{i}$ \\
\hline $\mathrm{k}$ & $=$ energy type \\
\hline $\mathrm{t}$ & $=$ transport type (passenger, freight) \\
\hline $\mathrm{r}$ & $=$ mode type (road, rail, water, air, pipeline) \\
\hline $\mathrm{Q}_{\mathrm{t}, \mathrm{r}, \mathrm{i}}$ & $\begin{array}{l}\text { quantity of transport service of type } t \text { in mode } r \text { of region } i \text { in passenger-km } \\
\text { and tonne-km }\end{array}$ \\
\hline $\mathrm{EI}_{\mathrm{TR}, \mathrm{k}, \mathrm{t}, \mathrm{r}, \mathrm{i}}$ & \\
\hline$=$ & $\begin{array}{l}\text { average energy intensity of energy type } \mathrm{k} \text { for transport service of type } \mathrm{t} \text { in } \\
\text { mode } \mathrm{r} \text { of region } \mathrm{i} \text { in } \mathrm{MJ} / \text { (passenger-km-year) and } \mathrm{MJ} / \text { (tonne-km-year) }\end{array}$ \\
\hline
\end{tabular}




\subsection{Disaggregation Example: Residential Sector in China}

Two general approaches have been used for the integrated assessment of energy demand and supply - the so-called "bottom-up" and "top-down" approaches. The bottom-up approach focuses on individual technologies for delivering energy services, such as household durable goods and industrial process technologies. For such technologies, the approach attempts to estimate the costs and benefits associated with investments in increased energy efficiency, often in the context of reductions in greenhouse gas (GHG) emissions or other environmental impacts. The top-down method assumes a general equilibrium or macroeconomic perspective, wherein costs are defined in terms of changes in economic output, income, or GDP, typically from the imposition of energy or emissions taxes. Each approach captures costs or details on technologies, consumer behavior, or impacts that the other does not. Consequently, a comprehensive assessment should combine elements of each approach to ensure that all relevant costs and impacts are accounted for and that technology trends and policy options for reducing energy consumption or mitigating climate change are adequately understood.

This section describes a nascent effort to disaggregate the A1 and B2 scenarios in detail for the residential sector in China and other countries to show the importance of bottom up analysis for interpreting macro scenario results at the end use level. China represents the bulk of the Centrally Planned Asia region, making it easier to interpret the regional macro results of the $\mathrm{A} 1$ and $\mathrm{B} 2$ scenarios. In this section, we disaggregate the scenarios based on the scenario storylines as well as on historical trends specific to the residential sector in China.

\subsubsection{Estimating China's Residential Buildings Sector Energy Consumption}

The two SRES scenarios only provide projection results on a regional basis and do not provide scenarios specifically for China. To estimate China's buildings sector final energy share of the Centrally Planned Asia region, we evaluated past time series of primary and final energy consumption for the Centrally Planned Asia region and China and determined that China's share was roughly 90\% between 1997 and 2002.

The two SRES scenarios also only provide projections for the total buildings sector; no values specifically for residential buildings are reported. To estimate the residential buildings share of total buildings, we use a regression analysis to correlate the share of commercial energy use in total buildings sector to income level for a large number of countries and years. This provides us with a statistical method for estimating the share of energy used in the commercial versus residential buildings sectors for the A1 and B2 scenarios in 2030. We find that the share of commercial energy increases with raising incomes (see Appendix 4). Similarly, we use a regression analysis to estimate the share of electricity allocated to the commercial sector versus the residential sector (see Appendix 5). The rest of the fuels are assumed to evolve similarly in both the residential and commercial sectors.

Figure 19 shows the results of our disaggregation of energy consumption in China's residential buildings sector for the A1 and B2 scenarios. The top line in Figure 15 represents primary energy consumption for the Centrally Planned Asia region for the buildings sector and the second line indicates final energy consumption for the Centrally Planned Asia buildings sector. The total shaded areas show the resulting estimate for final 
energy consumption in the residential sector in China. Fuel shares are estimated as being the same as those at the regional level for total building energy consumption in China. However, at the residential level, electricity is broken down according to the regression analysis shown in Appendix 5. The share of electricity allocated to the commercial sector versus the residential sector is higher and reaches $59 \%$ in the case of $\mathrm{A} 1$ and $56 \%$ in the case of B2. Table 9 provides information on the breakdown of projected 2030 energy consumption in China's residential sector by fuel for each scenario.

In 2000 , biomass energy represented $71 \%$ of total residential energy consumption in China (IEA, 2004a). Both scenarios estimate that biomass energy consumption will decrease considerably. The A1 scenario estimates an almost total phase out of this fuel consumption by 2030 with a share of $4 \%$ of total residential energy consumption while the B2 scenario foresees a drop to $14 \%$. This decrease is in large part compensated by increasing demand for coal. In 2030, final consumption of coal increases from $15 \%$ in 2000 to $61 \%$ in the A1 scenario and to $43 \%$ in the B2 scenario. The second largest fuel to grow after coal is gas in the A1 scenario from a share of $2 \%$ to $16 \%$ and electricity in the B2 scenario, from $6 \%$ to $20 \%$.

Table 2. Disaggregation of Final Energy Consumption by Fuel in China's Residential Buildings Sector for the A1 and B2 Scenarios (EJ)

\begin{tabular}{|l|c|c|c|c|c|c|c|c|}
\hline & \multicolumn{2}{|c|}{ Historical } & \multicolumn{3}{c|}{ A1 } & \multicolumn{3}{c|}{ B2 } \\
\hline & $\mathbf{2 0 0 0}$ & Share & $\mathbf{2 0 3 0}$ & AAGR & Share & $\mathbf{2 0 3 0}$ & AAGR & Share \\
\hline Coal & 1.80 & $15 \%$ & 14.6 & $7.2 \%$ & $61 \%$ & 9.20 & $5.6 \%$ & $43 \%$ \\
\hline Oil & 0.56 & $5 \%$ & 1.3 & $2.8 \%$ & $5 \%$ & 2.32 & $4.9 \%$ & $11 \%$ \\
\hline Natural Gas & 0.26 & $2 \%$ & 3.9 & $9.4 \%$ & $16 \%$ & 1.50 & $6.0 \%$ & $7 \%$ \\
\hline Electricity & 0.79 & $6 \%$ & 3.1 & $4.7 \%$ & $13 \%$ & 4.21 & $5.7 \%$ & $20 \%$ \\
\hline Biomass & 8.74 & $71 \%$ & 1.1 & $-6.8 \%$ & $4 \%$ & 3.07 & $-3.4 \%$ & $14 \%$ \\
\hline Other & 0.22 & $2 \%$ & - & - & - & 1.14 & $5.7 \%$ & $5 \%$ \\
\hline Total & 12.36 & $100 \%$ & 23.89 & $2.2 \%$ & $100 \%$ & 21.44 & $1.9 \%$ & $100 \%$ \\
\hline
\end{tabular}

Final energy consumption is the energy ultimately consumed by the end-user in the residential sector and does not account for the losses occurring in the transformation of electricity or of other secondary energy product. Hence results in this section are presented in terms of final energy. However, it is essential to keep in mind that electricity requires up to three times more energy for its production. The A1 and B2 scenarios project the primary electricity factor to decrease for the CPA region from 3.17 in 2000 (historical data) to 2.81 and 2.06 in 2030, respectively. Historical trends for developed countries have shown that consumers switch to cleaner fuels as economic development allows. The concept of an energy ladder has been introduced in the literature to explain the transition in fuel consumed. Solid fuels such as biomass and coal are at the lowest level of the ladder and kerosene, LPG, electricity, and natural gas are on successively higher rungs. However, this transition also depends on global and local resource endowments as well as new technology development. 
Figure 19. Disaggregation of Final Energy Consumption in the Residential Buildings Sector for the A1 and B2 Scenarios (EJ)
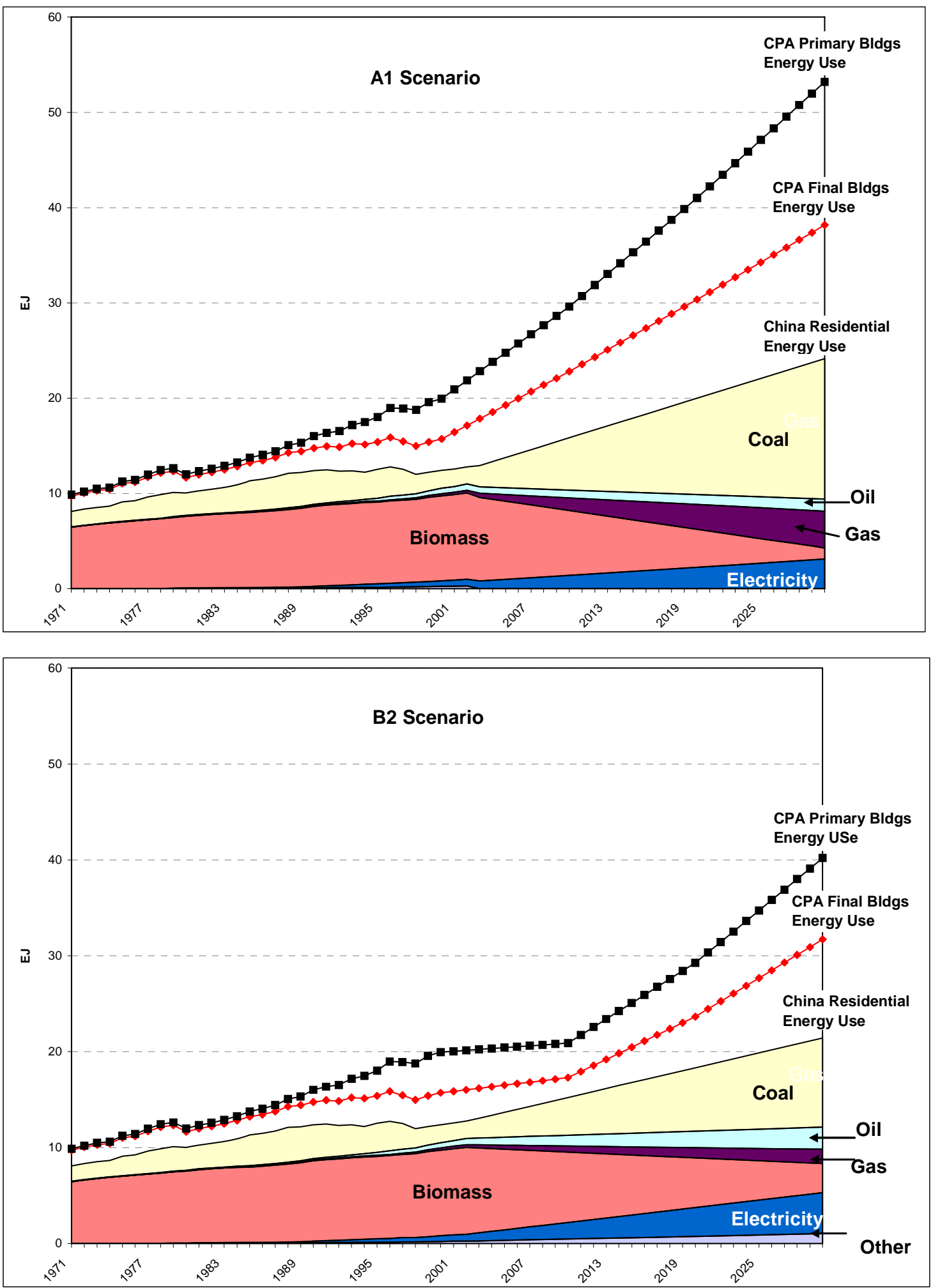

Note: The category Other includes district heat and synfuels; CPA stand for Centrally Planned Asia 


\subsubsection{Identifying Residential Buildings Sector Energy Consumption Drivers}

Equation 4 was used to disaggregate energy consumption between the growth due to activity (represented by number of households, floor area per capita and appliances ownership penetration) and energy intensity (calculated as energy per activity variable, such as energy per square footage or energy unit consumption). Table 10 outlines the main assumptions driving the China residential buildings activity variables.

Projections of population and income from both SRES scenarios were used to forecast these activity variables. The A1 and B2 scenarios project the average income in China to reach $\$ 18,335$ and $\$ 13,249$ (2000 \$US PPPs), respectively, which corresponds to an annual growth rate of $5.4 \%$ and $4.2 \%$, respectively, from 2000 .

Urbanization rate is a key driver in the model since it is assumed that urban households have higher demand for energy services than do rural households. This assumption is supported by the fact that people living in urban areas are wealthier and have a higher standard of living than the rural population. The UN projection (UN 2005) projects the most recent urban-rural growth difference observed by assuming that the proportion of urban population follows a logistic path that attains a maximum growth rate when the proportion urban reaches $50 \%$ and whose asymptotic value is $100 \%$ (UN 2003). The resulting UN urbanization rate projected for China in 2030 is 61\% (UN 2003). In order to reflect the stronger economic development in the A1 scenario, it is assumed that the urbanization rate will reach a higher level of 70\% by 2030 .

Japan is used a proxy to project the development of China. The level of energy required for urban households in China in 2030 is assumed to be similar to that consumed in urban households in Japan today. The main reasoning is that raising incomes allow Chinese households to reach upper levels of development. Demand for energy services increases as the standard of living improves. Even so, it is difficult to estimate at what intensity this increase in energy demand will occur, what kind of living standards Chinese households will achieve, and how fast energy efficiency improvements will penetrate. In order to outline answers to these questions, it is essential to observe consumption patterns at a disaggregated level.

Table 1. Main Assumptions for China Residential Buildings Activity Variables

\begin{tabular}{|l|c|c|cc|c|}
\hline & & & A1 & B2 & Japan \\
Activity Assumptions & $\mathbf{1 9 8 5}$ & $\mathbf{2 0 0 0}$ & $\mathbf{2 0 3 0}$ & $\mathbf{2 0 3 0}$ & Today \\
\hline Population (million) & 1,051 & 1,263 & 1,399 & 1,509 & 128 \\
Income (US\$ at 2000 prices and PPPs) & & 3,821 & 18,335 & 13,249 & 26,636 \\
Urbanization rate & $23 \%$ & $36 \%$ & $70 \%$ & $61 \%$ & $79 \%$ \\
Household size urban (person) & 3.89 & 3.13 & \multicolumn{2}{|c|}{2.88} & 2.88 \\
Household size rural (person) & 5.12 & 4.2 & \multicolumn{2}{|c|}{3.90} & \\
Floor space urban per capita (m $\left.{ }^{2}\right)$ & 10.0 & 20.0 & \multicolumn{2}{|c|}{30.0} & 30.0 \\
Floor space rural per capita $\left(\mathrm{m}^{2}\right)$ & 14.7 & 24.8 & \multicolumn{2}{|c|}{34.8} & \\
\hline
\end{tabular}

Source: data for 1985 and 2000 data come from the National Bureau of Statistics of China (NBS, 2005); data for Japan are based on EDMC 2002, LBNL estimates and IEA 2004e.

Using Japanese urban households as the model, it is assumed that the household size in urban areas in China in 2030 will decrease from 3.13 persons/household in 2000 to 2.88 
persons/household in 2030, the level of Japanese household size today (Table 1). It is also assumed that rural household size will be 3.9 persons/household. Floor space per capita inhabited in Chinese urban residences in 2030 is assumed to be equal to the current size in Japan households $\left(30 \mathrm{~m}^{2} /\right.$ capita) while rural residences will have $34.8 \mathrm{~m} /$ capita). Table 1 also shows the activity variable values in 1985 to provide the historical context for some of these assumptions.

The number of urban and rural households in China in 2030 is calculated by dividing urban and rural population by urban and rural household size shown in Table 1 . The resulting number of households grows at an annual average growth rate of $0.9 \%$ in the case of A1 scenario and $1.1 \%$ in B2 scenario (Table 2). The difference is due to a higher projection of the population estimate in 2030 in B2. Urban and rural households have very different projected trends. The number of urban households increases at an average annual growth of $2.9 \%$ in the $\mathrm{A} 1$ scenario and $2.7 \%$ in the B2 scenario while the number of rural households decreases at an average annual growth of $1.9 \%$ in the A1 scenario and $0.8 \%$ in the B2 scenario. Similarly, the resulting living space is projected to grow at a different pace according urban and rural areas. Total living space in urban areas increases at an average annual growth of $4 \%$ (A1) and 3.8\% (B2) while total living space in rural decreases at an average annual growth of $1.1 \%$ (A1) and increase at a slow $0.1 \%$ rate (B2). In both scenarios, the housing stock in China is projected to increase considerably. More than one-third of China's residential building stock in 2030 is expected to be constructed after the year 2000, with increased demand for heating and cooling service in the new buildings. The development of more efficient building designs suitable for Chinese conditions, and more energy-efficient windows, building materials, insulation board and ventilation options create large opportunity to save energy in the near future and over a longer term since buildings can last over 40 years.

Table 2. Households and Living Space Historical Data and Projections

\begin{tabular}{|ll|rrrr|rcc|}
\hline & \multicolumn{4}{|c|}{ Year } & \multicolumn{3}{c|}{ AAGR } \\
Activity Results & & $\mathbf{1 9 8 5}$ & $\mathbf{2 0 0 0}$ & $\mathbf{2 0 3 0}$ & $\mathbf{2 0 3 0}$ & $\mathbf{8 5 - 0 0}$ & $\mathbf{0 0 - 3 0}$ & $\mathbf{0 0 - 3 0}$ \\
& & & & $\mathbf{A 1}$ & $\mathbf{B 2}$ & & $\mathbf{A 1}$ & $\mathbf{B 2}$ \\
Total Household & million & $\mathbf{2 2 0}$ & $\mathbf{3 3 7}$ & $\mathbf{4 4 8}$ & $\mathbf{4 7 0}$ & $\mathbf{2 . 9 \%}$ & $\mathbf{0 . 9 \%}$ & $\mathbf{1 . 1 \%}$ \\
Urban Household & million & 62 & 144 & 340 & 317 & $5.8 \%$ & $2.9 \%$ & $2.7 \%$ \\
Rural Household & million & 158 & 193 & 108 & 153 & $1.3 \%$ & $-1.9 \%$ & $-0.8 \%$ \\
Total Living Space & million $\mathbf{m}^{2}$ & $\mathbf{1 4 , 3 1 4}$ & $\mathbf{2 9 , 1 7 5}$ & $\mathbf{4 3 , 9 7 4}$ & $\mathbf{4 8 , 1 0 7}$ & $\mathbf{4 . 9 \%}$ & $\mathbf{1 . 4 \%}$ & $\mathbf{1 . 7 \%}$ \\
Total Urban Living Area & million $\mathrm{m}^{2}$ & 2,417 & 9,049 & 29,377 & 27,381 & $9.2 \%$ & $4.0 \%$ & $3.8 \%$ \\
Total Rural Living Area & ${\text { million } \mathrm{m}^{2}}$ & 11,897 & 20,126 & 14,597 & 20,727 & $3.6 \%$ & $-1.1 \%$ & $0.1 \%$ \\
\hline
\end{tabular}

Following the projection of main activity variables as outlined above, we observed how the total energy consumption projected by A1 and B2 fit to more disaggregate results. We further disaggregated energy consumption by residential thermal end-uses (cooking, water heating, and space heating), and residential electric end-uses (lighting and appliances) and calculated energy intensities. 


\section{Thermal Energy End Uses: Cooking, Water Heating, and Space Heating}

Thermal energy end uses include cooking, water heating, and space heating. The assessment of cooking and water heating in China's residential sector is based on a useful energy demand analysis ${ }^{1}$ and represents the energy needed by a household to cook and boil water independently of the type of fuel used. It is then converted in final energy demand by taking into account fuel efficiency. For example, if a household has a useful energy need of $700 \mathrm{MJ}$ per year and uses only biomass to satisfy this need, the final energy consumed will be approximately nine times greater since biomass efficiency is around $11 \%$. This emphasizes the importance of fuel efficiency and fuel switching in reducing energy demand. It also allows for decomposing energy requirements and types of fuel used for improved projections.

It is assumed that the useful energy requirement of Chinese households in urban areas in 2030 will be equal to the requirement of today's Japanese household. Hence, the useful energy demand by China urban households for cooking and heating water will grow at an annual rate of $4 \%$ from 2000 to reach $2290 \mathrm{MJ} /$ household in 2030. It is assumed that rural households will have a useful energy demand for cooking that is $75 \%$ of the demand from urban households in 2030. Similarly, it is assumed that Chinese useful energy demand for water heating in urban areas will reach the level of Japanese households in 2030 of $8200 \mathrm{MJ} /$ year and rural households will reach 75\% of this amount.

Space heating is analyzed using energy intensity per heating degree day per square meter. China is divided into three regional zones (north, transition and south) in order to take into account the different climate zones in the country. Currently energy intensity per square meter for urban households is significantly higher than for rural households due to the level of poverty in the rural areas. It is assumed that space heating intensity will approximately double over the next 30 years for rural residents in north China to reach $8.4 \mathrm{~W} / \mathrm{m}^{2}$ and to increase from 0.1 to $1.9 \mathrm{~W} / \mathrm{m}^{2}$ in rural transition region (see Table 12).

Table 12. Assumptions for Thermal Useful Energy Demand

\begin{tabular}{|l|c|c|c|}
\hline Useful Energy Demand & $\begin{array}{c}\text { China } \\
\mathbf{2 0 0 0}\end{array}$ & $\begin{array}{c}\text { China } \\
\mathbf{2 0 3 0}\end{array}$ & Japan \\
\hline Cooking, MJ per household & 700 & 2,290 & 2,290 \\
\hline Urban & 700 & 1,718 & \\
\hline Rural & & 8,200 \\
\hline Water heating, MJ per household & 3,600 & 8,200 & \\
\hline Urban & 4,500 & 6,150 & 19.0 \\
\hline Rural & 22.0 & 27.0 & \\
\hline Space Heating, W/m ${ }^{2}$ - degree day & 17.5 & 18.6 & \\
\hline Urban North & 2.3 & 8.4 & \\
\hline Urban Transition & 0.1 & 1.9 & \\
\hline Rural North &
\end{tabular}

Source: China value for 2000 are based on Zhou (2003). Japan data based on EDMC (2002), LBNL estimates, and IEA (2004e).

\footnotetext{
${ }^{1}$ Useful energy is the energy available to the consumer after equipment conversion losses.
} 
Either electricity or fossil fuels can be used to meet thermal energy requirements, but such substitutability is not possible for meeting electric demand. While it is possible to heat a house or heat some water with electricity consumption, it is not possible to use fossil fuels directly for the electric energy requirement of appliances and lighting ${ }^{2}$. Interchangeability of fuel is then impossible for this particular end use. Based on our assumption that China will meet the level of actual Japanese household consumption by urban Chinese households in 2030 and in view of the low A1 and B2 scenario projection for electricity, we allocate the entire electricity consumption projection in 2030 to the electric demand only. Hence, the projection of heat energy demand is only met by fossil fuel and biomass.

The predominant energy consumption in 2000 serves the basic needs of cooking and water heating. In some low income rural areas, cooking and water heating represent up to $90 \%$ of household energy needs. Space heating is generally a superior service for which demand only increases with raising revenue.

Overall final energy demand for cooking and water heating is projected to remain relatively constant between 2000 and 2030. This is not due to a stable energy services demand but because energy will be used more efficiently through fuel switching. The substantial biomass energy consumption in today's residential sector in China is mostly used for cooking and water heating with relatively inefficient cookstoves. The switch to different fuels, in this case natural gas and coal, allows a more efficient use of energy. This switch from very inefficient biomass consumption to relatively more efficient coal consumption of $35 \%$ and natural gas of $60 \%$ offsets the increase in absolute energy consumption. The increase in efficiency compensates for the increase in useful energy consumption.

The most significant growth is the energy demand for space heating. Energy consumption for space heating in China is projected to quadruple over the next 30 years. Most of the growth comes from urban households. People moving from rural areas to cities have much higher space heating requirement levels as shown in Table 12. Moreover, floor space per capita is projected to continue to its increase, expanding the heated space. An improved standard of living in rural households also allows households to heat their housing space at a more comfortable level by 2030 .

In order to meet the energy consumption projected by the A1 scenario, fuel energy efficiency had to be maintained to the same level over time for all fuels except coal, which had to be reduced. This implies that no improvement in the use of fuel is assumed and that coal is used in a less efficient manner over the time period. In order to meet the large projected consumption of coal in the A1 scenario given the assumed activity parameters, coal stove efficiency had to be lowered from $35 \%$ to $20 \%$. Over time in developed countries the opposite trend is typically been seen, where technology improvement is introduced and diffused allowing for improvements in efficiency. One

\footnotetext{
${ }^{2}$ A small amount of kerosene is used in rural for lighting but we assumed that the projected growth will be mostly met by electric lighting.
} 
possible explanation underlying the A1 scenario coal projection is that some energy included in final energy is actually used to improve the quality of coal. For example, as explained in Section 2.3.1, some of the coal undergoes transformation before being consumed. This allows for production of relatively cleaner and higher energy value products. However, the energy required for this transformation would be accounted for in the transformation sector and reflected in the statistics given in primary energy units not in the final consumption reported here. Nevertheless, these results raise the question of how and what technology will permit such a large consumption of coal by residential households in China in 2030.

The B2 scenario assumes a world in which the emphasis is on local solutions to economic, social, and environmental sustainability, with continuously increasing population and intermediate economic development. In that context, China's natural endowment will be further exploited, explaining the large share of coal use. In order to reflect this consumption and according to the current energy consumption of China, coal consumption in the residential sector increases rapidly $(6.6 \%$ for cooking and water heating and $4.5 \%$ for space heating). In the rural sector, this will displace most of the use of biomass, allowing for slight overall energy efficiency. In order to meet the energy demand of the residential sector given by the B2 scenario, fuel energy efficiency is estimated to stay constant over the next 30 years, implying no improvement in the use of fuel.

\section{Electric Energy Requirement: Lighting and Appliances}

Energy demand for lighting and appliances used in the residential sector is typically met with electricity. Some households in rural areas use kerosene in wick or mantle lamps for lighting. However, since China is a developing country with a high electrification rate of 98.4\% (IEA, 2002), the share of household using kerosene for lighting was around $9 \%$ in 2000. Lighting and services from appliances such as TV, fans, and refrigerators constitute the fastest growing demand when income increases.

Lighting plays an important social role in domestic life and in commerce. It improves security and literacy and enables activities to be extended into nighttime. As rural incomes increase, or as people move to urban areas and gain greater access to modern fuels and electricity, lighting services and the energy used to provide them increase dramatically. By 2030, lighting in urban areas is assumed to reach the level of today's consumption of Japanese households of $675 \mathrm{kWh}$ per households, representing $5 \mathrm{~W} / \mathrm{m}^{2}$ for approximately 5 hours per day, an increase of $4 \%$ per year over current levels in China. Rural households are forecast to reach a lower level due to lower incomes. We assume that fluorescent and compact fluorescent lamps (CFLs) are four times more efficient than incandescent bulbs and the three technologies increase in efficiency by $1 \%$ per year over time. We estimate that fluorescents and CFLs will further penetrate the market in the future, growing from $20 \%$ to $40 \%$ and from 10 to $20 \%$, respectively, in urban areas. In rural areas, we estimate that fluorescent lamps will increase from $7 \%$ to 25\% and oil lamp technology will be phased out completely in 2030.

Increase in energy demand over the last 10 years has been driven by the rapid increase in number of appliances in residential households. In several countries, the largest increase in appliance ownership has been for television sets. According to Chinese statistics, color 
TV ownership grew from 5\% in 1990 to $74 \%$ in 2004 in rural areas and from $59 \%$ to $133 \%$ in urban areas (NBS, 2005). It is assumed that urban Chinese households will reach the level of appliance ownership of Japan today by 2030. Table 13 provides our assumption for each appliance.

\section{Table 13. Chinese Residential Appliance Saturation Projection based on Current Ownership Levels in Japan}

\begin{tabular}{|lccc|}
\hline & China & China & \\
& Urban & Rural & Japan \\
\hline Combination refrigerators \& freezers & $119 \%$ & $28 \%$ & $119 \%$ \\
Clothes-washers & $99 \%$ & $25 \%$ & $99 \%$ \\
Air conditioners & $142 \%$ & $7 \%$ & $142 \%$ \\
TVs & $220 \%$ & $43 \%$ & $220 \%$ \\
Clothes dryers & $21 \%$ & $3 \%$ & $21 \%$ \\
Miscellaneous* & $100 \%$ & $22 \%$ & $100 \%$ \\
\hline
\end{tabular}

Source: Chinese data from NBS (2005); Japan data based on EDMC (2002), LBNL estimates, and IEA (2004e).

* Includes set top boxes, shavers, phones, radios, hifis, video games, battery chargers, coffee makers, electric blankets, irons, toasters, hair dryers, etc.

The energy intensity for the remaining appliances in Japan is about 1,950 kWh per year per household (EDMC, 2002; LBNL estimates, IEA, 2004e). This category represents all other appliances that are not refrigerators \& freezers, clothes-washers, air conditioners, TVs, clothes dryers. It includes such appliances as set top boxes, shavers, phones, radios, hifis, battery chargers, coffee makers, electric blankets, irons, toasters, hair dryers, hot tubs, and stand by power. This category is generally the fastest growing part of energy consumption in developed countries. It is assumed that urban Chinese households in 2030 will use only $75 \%$ of the $1,950 \mathrm{kWh}$ per year that Japanese households use today, due to technology improvement and a lower standard of living.

LBNL's interpretation of the A1 scenario shows that it projects relatively low electricity consumption in China's residential sector in 2030. As discussed above, in order to be able to allocate enough electricity to meet the demand for lighting and appliances, it is assumed that no electricity is used to meet thermal demands related to cooking, water heating, and space heating. In the A1 scenario, energy demand for lighting and appliances grows an average of $3.6 \%$ and $5.5 \%$ per year, respectively. The highest growth is expected from other appliances (12.5\%), clothes dryers (9.3\%) and air conditioners (8.1\%), partly due their low current penetration levels. However, in order to reach the projected low electricity consumption levels from A1 scenario, the unit energy consumption (UEC) of all appliances must decrease by 4\% each year between 2000 and 2030. This result is very ambitious in terms of technology improvement.

In LBNL's interpretation of the B2 scenario, energy demand for lighting and appliances grows at an average annual rate of $3.8 \%$ and $5.9 \%$, respectively. The highest growth is expected from other appliances (12.4\%), clothes dryers (10.6\%), and air conditioners (9.5\%), partly due their low current level. Based on the forecast electricity levels from B2 and the previously-stated assumptions regarding appliance penetration and urbanization levels, the UECs of all appliances must decrease at an average annual rate of $2.5 \%$. This 
is a little lower than in the case of A1, but still an ambitious projection in term of technology improvement.

It is a challenging task to predict how UECs will evolve over time. While energy efficiency through technological improvement results in reduced energy consumption per appliance, higher standards of living often results in increase consumption of lighting and appliances in households.

Figure 16 shows UECs of four key appliances have evolved over the last 30 years in Japan. Further decomposition is needed to fully explained UEC evolution such as the trend in hours of usage, capacity of appliances and coefficient of performance. If urban households in China meet today's Japanese level of energy demand in 2030, UECs need to decrease $4 \%$ annually in the A1 scenario and $2.5 \%$ in the B2 scenario. According to historical trend in other countries and how fast technology improves and diffuses, this is a challenging hypothesis. Appliance standards and labeling policies have shown that such a path is possible in some cases, but implies adoption and enforcement of strong policies and standards to have such an effect on the market.

Figure 16. UEC Trends in Japan, 1971-1999

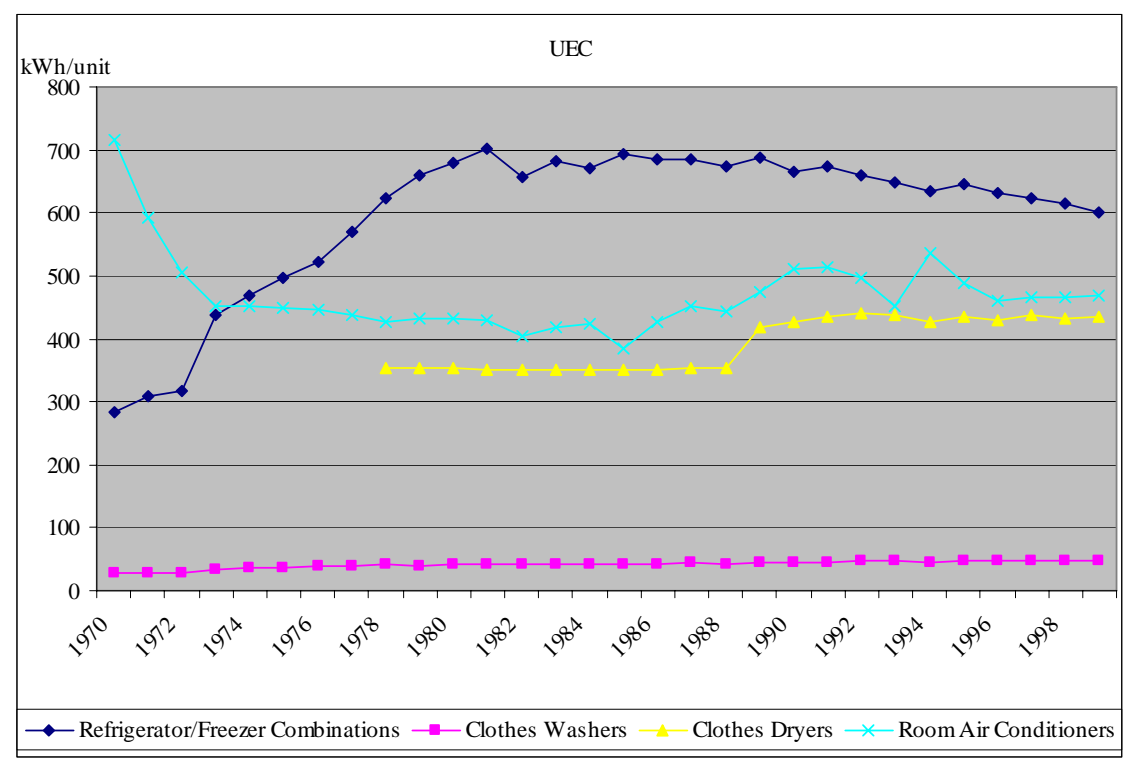

Source: based on EDMC (2002), LBNL estimates, and IEA (2004e).

\subsubsection{Findings}

Total residential electricity consumption in China is projected to grow at a moderate rate of $4.7 \%$ per year between 2000 and 2030 in the A1 scenario, while coal and natural gas consumption are projected to grow more rapidly at $7.2 \%$ and $9.4 \%$ per year. LBNL's disaggregation of the A1 scenario indicates that coal will remain the predominant fuel for cooking, water heating, and space heating and that there is a sharp increase in the consumption of coal for these end-uses between 2000 and 2030. Electricity will not meet any of the demand for water or space heating in 2030 because it will be used exclusively to meet the demand to power appliances and lighting. Electricity consumption for 
lighting is expected to grow at an annual rate of 3.6\% and electricity for appliances use at an annual rate of $5.5 \%$.

The B2 scenario projection for final use of coal is 37\% lower than in the A1 scenario, but still represents 43\% of residential energy consumption in 2030 compared to $15 \%$ in 2000. For the B2 scenario, more energy is consumed for cooking and water heating, lighting, and appliances while less energy is consumed for residential space heating than in the A1 scenario. This is due to a slower population migration to the cities in this scenario. In contrast to the A1 scenario, all fuels including electricity and syngas will be used for residential cooking and water heating in the B2 scenario. In addition, biomass will still be used to meet nearly a quarter of the energy demand for cooking and water heating in this scenario, significantly more than the $6 \%$ envisioned in the A1 scenario.

Table 14 outlines LBNL's projection of final energy consumption for residential end uses in China for the A1 and B2 scenarios by fuel type.

Table 14. Results of Projection of Final Energy Consumption for End Uses in Residential Buildings in China Based on the A1 and B2 Scenarios (PJ)

\begin{tabular}{|l|c|c|c|c|c|}
\hline & & A1 & A1 & B2 & B2 \\
AAGR
\end{tabular}


For example, the A1 and B2 scenarios appear to overestimate the level of coal consumption in China's residential sector. Fuel used for heating purposes will be used at the same efficiency level over time except for coal where a decrease of efficiency is required to align with the A1 scenario results. A decrease in efficiency is impossible unless the quality of coal declines. New technology developments exist to allow for better use of coal. The question remains regarding how much energy is needed to transform coal to a cleaner end use fuel.

The A1 and B2 scenarios also underestimate future electricity consumption in China's residential sector. Restraining electricity consumption to the levels foreseen in both scenarios while matching future end-use demand for lighting and appliances as predicted by the activity assumptions requires that efficiency for appliances has to increase dramatically in the future. Based on past experience, this will be challenging but a combination of strong standards and technological leapfrogging could lead to this result.

Finally, it is desirable to conduct this analysis in terms of primary energy in order to fully represent the energy consumption associated with end uses. Further details on secondary energy products consumption and their energy conversion requirement are required to better assess future projections of energy demand. The possibility of oil reserve depletion raises questions about the kinds of technologies that will allow substituting current oil use with other forms of energy. The potential exploitation of the large and inexpensive coal reserves remaining also raises concerns about the associated pollution. As consumers have in the past preferred switching to cleaner fuel, the perspective of increasing coal use requires consideration of the possible technologies that will allow a cleaner use of this coal. Other questions such as the energy demand for the transport of natural gas, the production of biofuels and synfuel and other energy demands also needs to be addressed to fully represent future energy demand and supply.

\section{Conclusions and Next Steps}

The disaggregation of the SRES A1 and B2 scenarios for the residential sector in China provides a demonstration of how this approach can provide insights regarding the overall feasibility of scenario projections as well as the types of technologies that they imply, including energy-intensity and saturation levels, to reach the projected energy consumption levels. Similar disaggregations can be developed for other countries or regions of the world as envisioned by the SRES or other global scenarios.

Such end-use sectoral information is valuable for policy-makers who want to understand the implications of certain projected futures as well as the types of efficiency improvements that are required to realized lower energy consumption scenarios. In applying this approach to global scenarios, a balance must be found between the level of detail needed to clearly represent major technological features, clarity of presentation to users of scenario results, and data availability across countries and regions. In principle, greater detail is desirable, but currently available statistics and survey information tends to be sketchy and intermittent for most countries, and users should not be overwhelmed with technical minutiae. 
Using this methodology, LBNL is pursuing this effort for some other major developing countries in the world. Working in collaboration with institutions around the world, LBNL is collecting data and building the LEAP model in order to provide a richer characterization of the SRES results. This methodology can be applied to any macro-level model results and, as such, is envisioned as a powerful tool for providing end-use detail associated with myriad scenario projections.

\section{Acknowledgments}

We would like to thank a number of people for their assistance in providing data, including Toshihiko Masui and Mikiko Kainuma from the National Institute for Environmental Studies (Japan) and Keywan Riahi from the International Institute for Applied Systems Analysis - IIASA (Austria) that provide us with data for the A1 and B2 scenarios, respectively. We extend our gratitude to Charlie Heaps at the Stockholm Environment Institute for providing excellent assistance on LEAP software and to Attilio Pigneri for his constructive comments on the transport sector. We would also like to especially thank Fridtjof Unander of the International Energy Agency for his helpful guidance on the modeling approach and giving us access to the IEA energy efficiency indicator database. 


\section{References}

BP, 2004. Statistical Review of World Energy. http://www.bp.com/statisticalreview2004.

EDMC 2002, "Handbook of Energy \& Economics Statistics in Japan", Energy Data Modelling Center, Institute of Energy economics. The Energy Conservation Center, Tokyo, Japan.

Grübler and Nakićenović, 1996. "Decarbonizing the Global Energy System". Technological Forecasting and Social Change 53, 97-110, 1996.

International Energy Agency (IEA), 2002. World Energy Outlook. Paris: IEA/OECD.

International Energy Agency (IEA), 2004a. Energy Balances of Non-OECD Countries, 1971-2002. Paris: IEA/OECD.

International Energy Agency (IEA), 2004b. Energy Balances of OECD Countries, 19712002. Paris: IEA/OECD.

International Energy Agency (IEA), 2004c. CO2 emissions from fuel combustion, 19712002. Paris: IEA/OECD.

International Energy Agency (IEA), 2004d. World Energy Outlook, Paris, IEA/OECD.

International Energy Agency (IEA), 2004e. Oil Crises and Climate Challenges: 30 Years of Energy Use in IEA Countries. Paris: IEA.

International Energy Agency (IEA), 2005. Electricity and Heat Annual Questionnaire 2004 and Historical Revisions, Documentation, Methodology for Apportioning Fuel Input in a CHP Plant. Paris: IEA/OECD.

http://www.iea.org/Textbase/stats/questionnaire/Eleeng.pdf

Intergovernmental Panel on Climate Change (IPCC), 2001. Climate Change 2001: Synthesis Report. Cambridge, UK and New York, NY: Cambridge University Press. Glossary: http://www.ipcc.ch/pub/syrgloss.pdf

Intergovernmental Panel on Climate Change (IPCC), 1996. Revised 1996 IPCC Guidelines for National Greenhouse Gas Inventories. Greenhouse Gas Inventory Reference Manual, Volume III. IPCC/OECD/IEA.

Kaya, Y.: 1989, Impact of Carbon Dioxide Emissions on GNP Growth: Interpretation of Proposed Scenarios, Geneva, Intergovernmental Panel on Climate Change, Response Strategies Working Group

Nakicenovic, N., Alcamo, J., Davis, G., de Vries, B., Fenhann, J., Gaffin, S., Gregory, K., Grubler, A., Jung, T.Y., Kram, T., La Rovere, E.L., Michaelis, L., Mori, S., Morita, T., Pepper, W., Pitcher, H., Price, L., Riahi, K., Roehrl, A., Rogner, H-H., Sankovski, A., 
Schlesinger, M., Shukla, P., Smith, S., Swart, R., van Rooijen, S., Victor, N., and Zhou, D., 2000. Special Report on Emissions Scenarios: Report of Working Group III of the Intergovernmental Panel on Climate Change. London: Cambridge University Press.

National Bureau of Statistics of China, 2005. China Statistical Yearbook 2005. Beijing: Info Press. http://www.stats.gov.cn/english/statisticaldata/yearlydata/

Schipper L., M. Ting, M. Khrushch and W. Golove, 1997. "The Evolution of Carbon Dioxide Emissions from Energy Use in Industrialized Countries: An End-Use Analysis," Energy Policy, Vol. 25, Nos. 7-9: 651-672..

United Nations, 2003. World Urbanization Prospects: The 2003 Revision. Department of Economic and Social Affairs. Population Division.

http://www.un.org/esa/population/publications/wup2003/WUP2003Report.pdf

United Nations, 2005. World Population Prospects: The 2005 Revision. Department of Economic and Social Affairs. Population Division.

Zhou, D., Dai, Y., Yu, C., Guo, Y. and Zhu, Y., 2003. China's Sustainable Energy Scenarios in 2020. (in Chinese), China Environmental Science Publishing Company, August,2003. 


\section{Appendices}

1. World Regions

2. Primary Energy Accounting Methodologies

3. Comparison of Disaggregated SRES Scenarios and IEA's WEO Reference Scenario

4. Regression Analyses of Commercial Sector Share and Revenue

5. Commercial Share of Electricity in Building Sector Electricity Consumption 


\section{Appendix 1. World Regions}

\begin{tabular}{|c|c|c|c|c|}
\hline & \multicolumn{2}{|c|}{ WEO 2004 Regions/Countries } & \multicolumn{2}{|c|}{ SRES (LBNL) Regions/Countries } \\
\hline Pacific OECD & OECD Pacific & Japan, Korea, Australia, New Zealand & Pacific OECD & Australia, Japan, Korea and New Zealand. \\
\hline Canada/US & US \& Canada & & North America & Canada and the United States. \\
\hline Europe & OECD Europe & $\begin{array}{l}\text { Austria, Belgium, Czech Republic, } \\
\text { Denmark, Finland, France, Germand, } \\
\text { Greece, Hungary, Iceland, Ireland, Italy, } \\
\text { Luxembourg, Netherlands, Norway, } \\
\text { Poland, Portugal, Slovak Republic, Spain, } \\
\text { Sweden, Switzerand, Turkey, UK }\end{array}$ & Western Europe & $\begin{array}{l}\text { Austria, Belgium, Cyprus, Denmark, Finland, France, } \\
\text { Germany, Gibraltar, Greece, Iceland, Ireland, Italy, } \\
\text { Luxembourg, Malta, Netherlands, Norway, Portugal, Spain, } \\
\text { Sweden, Switzerland, Turkey and United Kingdom. }\end{array}$ \\
\hline \multirow[t]{2}{*}{$\begin{array}{l}\text { Transition } \\
\text { Economies }\end{array}$} & \multirow[t]{2}{*}{ Transition Economies } & \multirow{2}{*}{$\begin{array}{l}\text { Albania, Armenia, Azerbaijan, Belarus, } \\
\text { Bosnia-Herzegovina, Bulgaria, Croatia, } \\
\text { Estonia, Federal Republic of Yugoslavia, } \\
\text { form Yugosalve Republic of Macedonia, } \\
\text { Georgia, Kazakhstan, Kyrgystan, Latvia, } \\
\text { Lithuania, Moldova, Romania, Russia, } \\
\text { Slovenia, Tajikistan, Turkmenistan, } \\
\text { Ukraine, Uzbekistan, Cyprus, Gibralta, } \\
\text { Malta }\end{array}$} & $\begin{array}{l}\text { Central and Eastern } \\
\text { Europe }\end{array}$ & $\begin{array}{l}\text { Albania, Bosnia-Herzegovina, Bulgaria, Croatia, Czech } \\
\text { Republic, Former Yugoslav Republic of Macedonia } \\
\text { (FYROM), Hungary, Poland, Romania, Serbia/Montenegro } \\
\text { Slovak Republic and Slovenia. }\end{array}$ \\
\hline & & & Former Soviet Union & 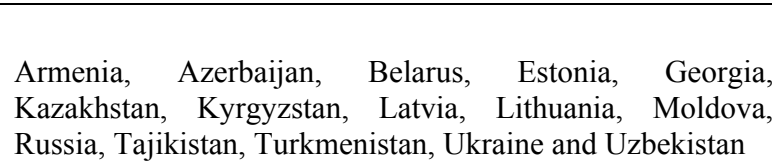 \\
\hline \multirow[t]{2}{*}{ Latin America } & Latin America & $\begin{array}{l}\text { Antigua and Barbuda, Argentina, } \\
\text { Bahamas, Barbados, Belize, Bermuda, } \\
\text { Bolivia, Brazil, Chile, Colombia, Costa } \\
\text { Rica, Cuba, Dominica, Dominican } \\
\text { Republic, Ecuador, El Salvador, French } \\
\text { Guyana, Grenanda, Guadeloupe, } \\
\text { Guatemala, Guyana, Haiti, Honduras, } \\
\text { Jamaica, Martinique, Netherlands } \\
\text { Antilles, Nicaragua, Panama, Paraguay, } \\
\text { Peru, St Kitts and Nevis, St Lucia, St } \\
\text { Vincent and Grenadine, Suriname, } \\
\text { Trinidad and Tobago, Uruguay and } \\
\text { Venezuela }\end{array}$ & \multirow[t]{2}{*}{ Latin America } & \multirow[t]{2}{*}{$\begin{array}{l}\text { Antigua and Barbuda, Argentina, Bahamas, Barbados, } \\
\text { Belize, Bermuda, Bolivia, Brazil, Chile, Colombia, Costa } \\
\text { Rica, Cuba, Dominica, Dominican Republic, Ecuador, El } \\
\text { Salvador, French Guyana, Grenanda, Guadeloupe, } \\
\text { Guatemala, Guyana, Haiti, Honduras, Jamaica, Martinique, } \\
\text { Mexico, Netherlands Antilles, Nicaragua, Panama, } \\
\text { Paraguay, Peru, St Kitts and Nevis, St Lucia, St Vincent and } \\
\text { Grenadine, Suriname, Trinidad and Tobago, Uruguay and } \\
\text { Venezuela }\end{array}$} \\
\hline & Mexico & & & \\
\hline
\end{tabular}




\begin{tabular}{|c|c|c|c|c|}
\hline \multirow[t]{2}{*}{$\begin{array}{l}\text { Africa/Middle } \\
\text { East }\end{array}$} & \multicolumn{2}{|r|}{$\begin{array}{l}\text { Bahrain, Iran, Iraq, Israel, Jordan, Kuwait, } \\
\text { Lebanon, Oman, Qatar, Saudi Arabia, } \\
\text { Syria, UAE, Yemen }\end{array}$} & $\begin{array}{l}\text { Middle East and } \\
\text { North Africa }\end{array}$ & $\begin{array}{l}\text { Algeria, Bahrain, Egypt, Islamic Republic of Iran, Iraq, } \\
\text { Israel, Jordan, Kuwait, Lebanon, Libya, Morocco, Oman, } \\
\text { Qatar, Saudi Arabia, Sudan, Syria, Tunisia, United Arab } \\
\text { Emirates and Yemen. }\end{array}$ \\
\hline & Africa & $\begin{array}{l}\text { Algeria, Angola, Benin, Botswana, } \\
\text { Burkina Faso, Burundi, Cameroon, } \\
\text { Democratic Republic of Congo, Cape } \\
\text { Verde, Central African Republic, Chad, } \\
\text { Djibouti, Egypt, Equatorial Guinea, } \\
\text { Eritrea, Ethiopia, Gabon, Gambia, Ghana, } \\
\text { Guinea, Guinea-Bissau, Ivory Coast, } \\
\text { Kenya, Lesotho, Liberia, Libya, } \\
\text { Madagascar, Malawi, Mali, Mauritania, } \\
\text { Mauritius, Morocco, Mozambique, Niger, } \\
\text { Nigeria, Rwanda, Sao Tome and Principe, } \\
\text { Senegal, Seychelles, Sierra Leone, } \\
\text { Somalia, South Africa, Sudan, Swaziland, } \\
\text { United Republic of Tanzania, Togo, } \\
\text { Tunesia, Uganda, Zambia and Zimbabwe }\end{array}$ & Sub-Saharan Africa & $\begin{array}{l}\text { Angola, Benin, Botswana, Burkina Faso, Burundi, } \\
\text { Cameroon, Congo, Cape Verde, Central African Republic, } \\
\text { Chad, Democratic Republic of Congo, Djibouti, Equatorial } \\
\text { Guinea, Eritrea, Ethiopia, Gabon, Gambia, Ghana, Guinea, } \\
\text { Guinea-Bissau, Ivory Coast, Kenya, Lesotho, Liberia, } \\
\text { Madagascar, Malawi, Mali, Mauritania, Mauritius, } \\
\text { Mozambique, Namibia, Niger, Nigeria, Rwanda, Sao Tome } \\
\text { and Principe, Senegal, Seychelles, Sierra Leone, Somalia, } \\
\text { South Africa, Swaziland, United Republic of Tanzania, } \\
\text { Togo, Uganda, Zambia and Zimbabwe }\end{array}$ \\
\hline \multirow[t]{3}{*}{ Asia } & \multicolumn{2}{|l|}{ China } & $\begin{array}{l}\text { Centrally } \quad \text { Planned } \\
\text { Asia }\end{array}$ & $\begin{array}{l}\text { China, Chinese Taipei, Hong Kong, DPR of Korea and } \\
\text { Vietnam. }\end{array}$ \\
\hline & East Asia & $\begin{array}{l}\text { Afghanistan, Bhutan, Brunei, Chinese } \\
\text { Taipei, Fiji, French Polynesia, Indonesia, } \\
\text { Kiribati, Democratic People's Republic of } \\
\text { Korea, Malaysia, Maldives, Myanmar, } \\
\text { New Caledonia, Papua New Guinea, } \\
\text { Philippines, Samoa, Singapore, Solomon } \\
\text { Islands, Thailand, Vietnam, Vanuatu }\end{array}$ & \multirow[t]{2}{*}{ Other Asia } & \multirow{2}{*}{$\begin{array}{l}\text { Afghanistan, Bangladesh, Bhutan, Brunei, Fiji, French } \\
\text { Polynesia, India, Indonesia, Kiribati, Malaysia, Maldives, } \\
\text { Myanmar, Nepal, New Caledonia, Pakistan, Papua New } \\
\text { Guinea, Philippines, Samoa, Singapore, Solomon Islands, } \\
\text { Sri Lanka, Thailand and Vanuatu. }\end{array}$} \\
\hline & South Asia & $\begin{array}{l}\text { Bangladesh, India, Nepal, Pakistan, Sri } \\
\text { Lanka }\end{array}$ & & \\
\hline
\end{tabular}




\section{Appendix 2. Primary Energy Accounting Methodologies}

Direct equivalent method (SRES method): the primary energy of the non fossil fuel energy is accounted for at the level of secondary energy, that is, the first usable energy form or "currency" available to the energy. For instance, the primary energy equivalence of electricity generated from solar photo-voltaic or nuclear power plants is set equal to their respective gross electricity output, not to the heat equivalent of radiation energy from fissile reaction, the solar radiance that falls onto a photo-voltaic panel, or neither the heat that would have been necessary by burning fossil fuels to produce the same amount of electricity as generated in a photo-voltaic cell or a nuclear reactor (as used in the socalled "substitution" accounting method) (Nakicenovic et al., 2000).

Physical energy content method (IEA method): this method uses the physical energy content of the primary energy source as its primary energy equivalent. In the case of nuclear and geothermal electricity, heat is the primary energy form considered and the conventional efficiencies are $33 \%$ and $10 \%$ respectively. In the case of other non fossil fuel energy (hydro, solar, wave/tide), the primary form of energy considered is the electricity produced and hence efficiency of $100 \%$ applies, similar to the previous method.

Substitution energy method: this method attributes 33\% efficiency for all non fossil fuel i.e. as this energy had been generated by fossil fuel power plant. 


\section{Appendix 3. Comparison of SRES and World Energy Outlook Scenarios}

This section provides a comparison of the final energy use, primary energy use, and energy-related carbon dioxide emissions for the WEO 2004 Reference Scenario and the SRES A1 and B2 Markers for the scenario base year (2000 for SRES; 2002 for WEO) to 2030. Differing from the time series presented previously in this document, 2000 data have not been adjusted to historical time series and come directly from the models time series. Hence the value differs slightly from data presented previously but only for the year 2000 .

\subsection{Comparison of Main Drivers}

Figures A3.1, A3.2, and A3.3 provide a comparison of the main driving forces behind the SRES A1 and B2 Marker scenarios and the WEO 2004 Reference scenario, respectively. The driving forces in these figures are GDP/population, population, the ratio of primary energy to final energy, the ratio of carbon dioxide emissions to primary energy, and the ratio of final energy to GDP. The ratio of primary energy per unit of final energy reflects the inverse efficiency of energy conversion occurring in the economy. Historically, this ratio has increase slightly by $7 \%$ over the last 30 years (AAGR of $0.23 \%$ ). It can also be explained by increasing share of renewables and nuclear energy which have a conversion efficiency of $100 \%$. Carbon per unit of primary energy represents the fuel mix used in an economy. This factor has been declining over the last 30 years, albeit by a small percentage of $6 \%$ over 30 years (AAGR of $0.2 \%$ ), reflecting a decarbonization of energy consumption (Grübler and Nakićenović, 1996). This is explained by a switch to cleaner fuels that emit less $\mathrm{CO}_{2}$.

\section{Figure A3.1. Main Drivers, SRES A1 Marker Scenario}

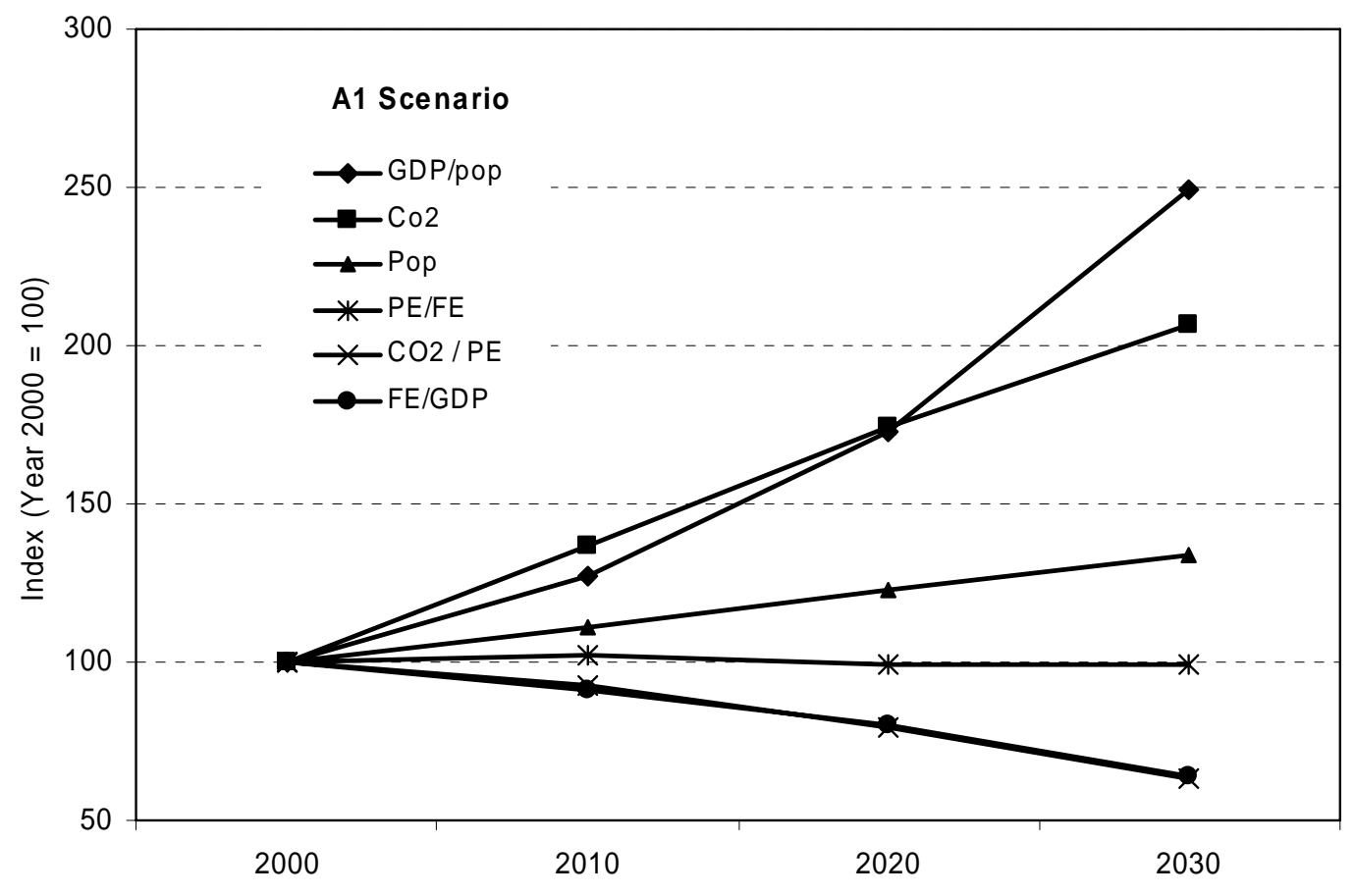


Figure A3.2. Main Drivers, SRES B2 Marker Scenario

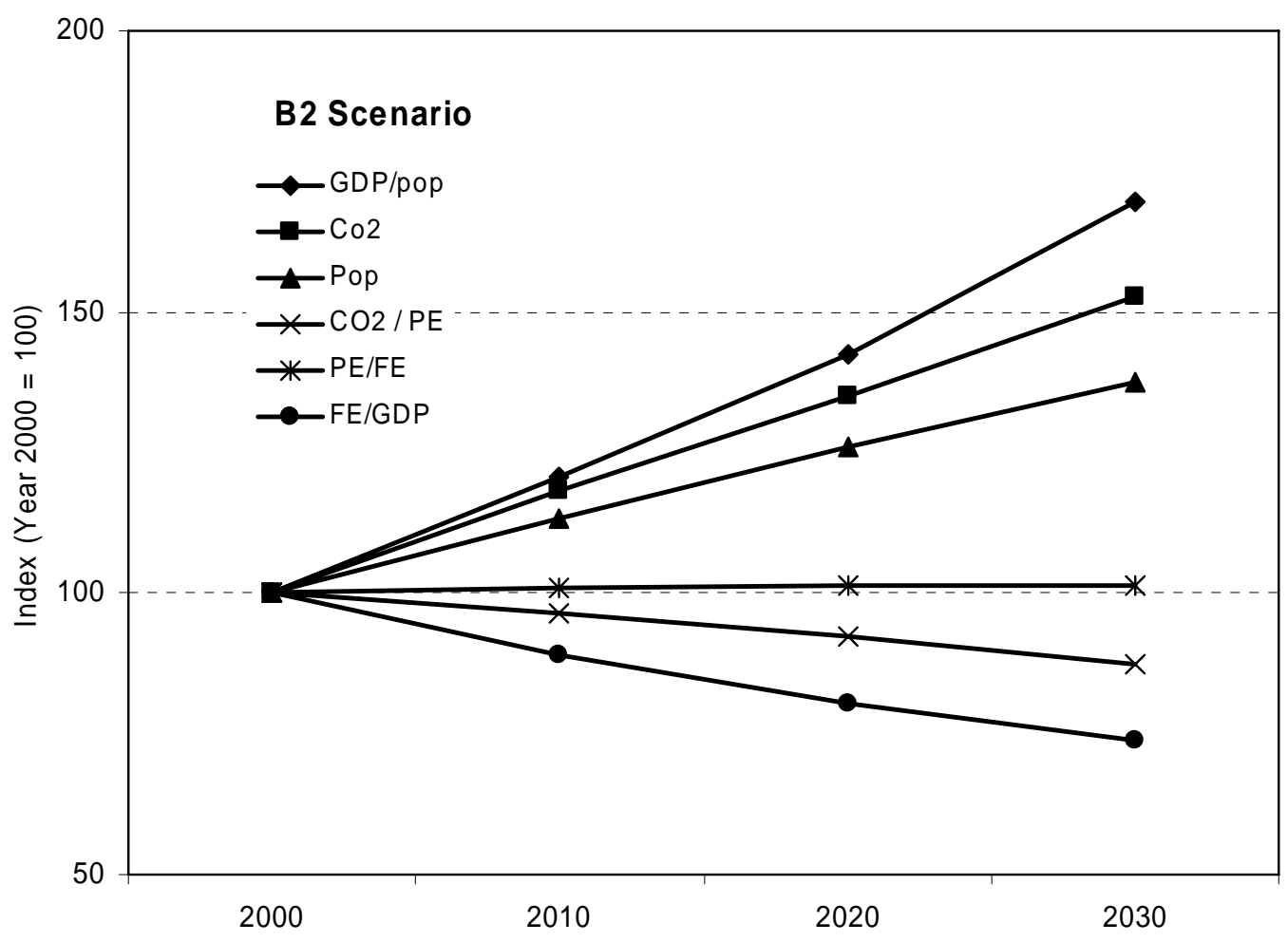

Figure A3.3. Main Drivers, WEO 2004 Reference Scenario

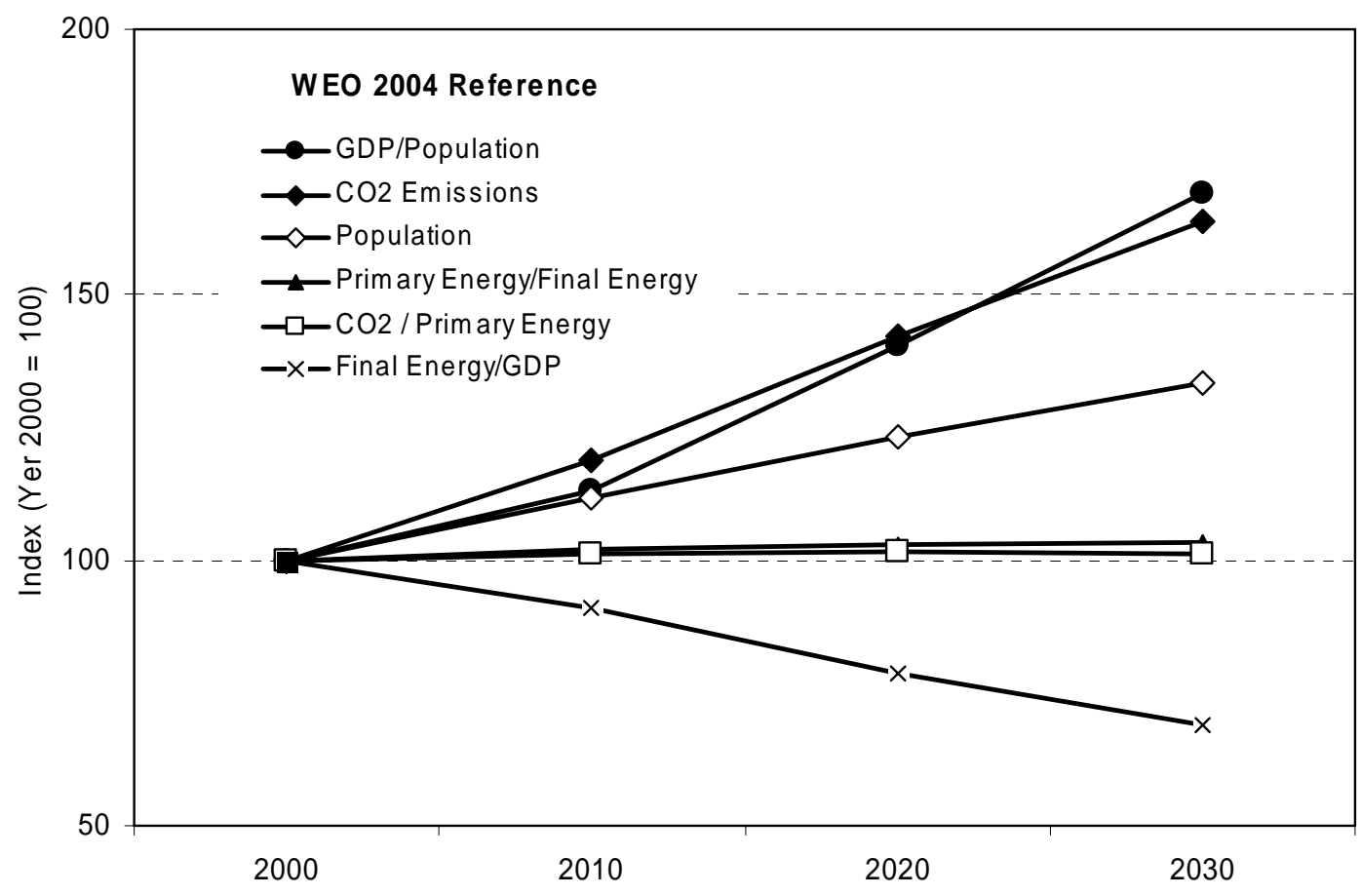


The major difference in the scenario assumption stems from the evolution of GDP. The SRES A1 Marker scenario is a scenario with high GDP growth, followed by the WEO 2004 Reference scenario with intermediate growth, and the SRES B2 Marker scenario with growth slightly lower than the WEO 2004 Reference scenario. However, all three scenarios estimate an increase of the GDP/population growth compared to historical trends. The SRES A1 Marker scenario projects a growth of 150\% while the WEO 2004 Reference scenario and the SRES B2 Marker scenario project growth of 70\%; historical growth over the last 10 yeas was $50 \%$. One reason is that population is projected to grow slower in the next 30 years allowing for a smaller distribution of the revenue. All three scenarios have relatively similar assumptions concerning population. Population is forecast to grow by approximately 35\% over the next 30 years in all three scenarios, lower than during the last 30 years $(65 \%)$.

Historically, the major reason for $\mathrm{CO}_{2}$ emissions to follow solely the growth of population and not also the growth of GDP was due largely to the substantial decline of the final energy requirement per unit of GDP. Final energy per GDP decreased considerably after the 1973 oil shock in industrialized countries, when prices escalated and some energy saving opportunities were available at negative cost, then in the 1990s it began to level off. All three scenarios forecast this indicator to not decrease as greatly in the future; one reason can be that fewer energy savings opportunity are estimated to remain. The other indicators, such as the amount of $\mathrm{CO}_{2}$ per unit of primary energy and the amount of primary energy per unit of final energy were relatively constant in the past.

The SRES B2 Marker scenario assumes that $\mathrm{CO}_{2}$ emissions will increase slightly slower than during the last 30 years. The main reasons are a steeper decrease in the $\mathrm{CO}_{2}$ per primary energy indicator (12\%), reflecting a projection of relatively more intense decarbonization of the economy. These trends are also assumed in the SRES A1 Marker scenario and at a higher intensity. $\mathrm{CO}_{2}$ emissions per primary energy are forecast to decrease significantly - by $37 \%$ over the next 30 years - explained by switch toward an increasing share of less carbon-intensive fuels, such as renewables and nuclear. In contrast, the WEO 2004 Reference Scenario assumes that CO2/primary energy remains constant during the period.

\subsection{Final energy}

Final energy consumption is the energy ultimately consumed by the consumer in industry, building and transport sectors. Historical trends for developed countries have shown that consumers switch to cleaner fuels as economic development allows it. The concept of an energy ladder has been introduced in the literature to explain the transition in fuel consumed. Solid fuels such as biomass and coal are at the lowest level and kerosene, LPG and electricity are on successively higher rungs. However, this transition also depends on resource availability and new technology development.

All three scenarios provide energy values in terms of final energy by region and by sector. Table A3.1 shows final energy consumption values for seven world regions and the world total for the WEO 2004 Reference scenario and the SRES A1 and B2 Marker scenarios. 
Table A3.1. Final Energy Consumption (EJ)

\begin{tabular}{|c|c|c|c|c|c|c|c|c|c|c|c|c|}
\hline \multicolumn{13}{|c|}{ All Sectors - Final Energy Consumption (EJ) } \\
\hline Region & \multicolumn{4}{|c|}{ WEO 2004 Reference } & \multicolumn{4}{|c|}{ SRES A1 Marker } & \multicolumn{4}{|c|}{ SRES B2 Marker } \\
\hline Pacific OECD & 24 & 27 & 29 & 31 & 21 & 25 & 30 & 37 & 23 & 26 & 30 & 32 \\
\hline Europe & 52 & 57 & 62 & 66 & 52 & 59 & 68 & 75 & 47 & 51 & 54 & 58 \\
\hline Transition Economies & 27 & 31 & 36 & 40 & 38 & 43 & 50 & 59 & 32 & 37 & 45 & 53 \\
\hline Latin America & 19 & 23 & 30 & 38 & 23 & 42 & 63 & 82 & 21 & 28 & 33 & 40 \\
\hline Asia & 67 & 83 & 105 & 128 & 72 & 101 & 144 & 195 & 69 & 93 & 122 & 158 \\
\hline World & 286 & 334 & 395 & 453 & 315 & 405 & 532 & 669 & 289 & 351 & 418 & 497 \\
\hline
\end{tabular}

The WEO 2004 Reference Scenario, which indicates total world energy growth from 286 EJ in 2002 to $453 \mathrm{EJ}$ in 2030 at an average annual growth rate of $1.7 \%$, has the lowest total final energy consumption for the world. The SRES B2 Marker scenario has slightly higher world final energy consumption values, growing at an average rate of $2.0 \%$ per year. The SRES A1 Marker scenario has the highest total energy consumption values, 35 $\%$ higher than the SRES B2 Marker scenario results and 47\% the WEO 2004 Reference scenario results, as well as the highest average annual growth rate $(2.7 \%)$.

Table A3.2. Final Energy Consumption, Average Annual Growth Rates, Base Year to 2030.

\begin{tabular}{|l|c|c|c|}
\hline Region & \multicolumn{3}{|c|}{ Average Annual Growth Rate } \\
\hline & WEO & A1 & B2 \\
\hline Pacific OECD & $1.0 \%$ & $1.9 \%$ & $1.1 \%$ \\
\hline Canada/US & $1.1 \%$ & $1.2 \%$ & $1.4 \%$ \\
\hline Europe & $0.9 \%$ & $1.3 \%$ & $0.8 \%$ \\
\hline Transition Economies & $1.5 \%$ & $1.5 \%$ & $1.8 \%$ \\
\hline Latin America & $2.5 \%$ & $4.6 \%$ & $2.3 \%$ \\
\hline Africa/Middle East & $2.3 \%$ & $4.5 \%$ & $2.6 \%$ \\
\hline Asia & $2.4 \%$ & $3.6 \%$ & $3.0 \%$ \\
\hline World & $1.7 \%$ & $2.7 \%$ & $2.0 \%$ \\
\hline
\end{tabular}

Table A3.2 shows that the scenarios are generally in agreement regarding the regional energy consumption patterns, with all three showing the largest growth in developing country regions. The growth rates of the WEO 2004 Reference scenario and the SRES B2 Marker scenario are relatively similar except the SRES B2 Marker scenario foresees higher growth in the Canada/US, Transition Economies, Africa/Middle East, and Asia regions. The SRES A1 Marker scenario projects higher growth rates than B2 for all regions except Canada/US and Transition Economies.

Table A3.3 provides final energy consumption average annual growth rates by sector. The WEO 2004 Reference scenario and the SRES A1 Marker scenario project the highest average annual growth in the transport sector, while the SRES B2 Marker scenario projects the highest growth in the industrial sector. For all three sectors, the SRES A1 Marker scenario consistently shows the highest final energy consumption. 
Table A3.3. Final Energy Consumption by Sector, Average Annual Growth Rates, Base Year to 2030.

\begin{tabular}{|c|c|c|c|c|c|c|c|c|c|}
\hline \multirow{3}{*}{ Region } & \multicolumn{3}{|c|}{ Transport } & \multicolumn{3}{|c|}{ Industry } & \multicolumn{3}{|c|}{ Buildings } \\
\hline & \multicolumn{3}{|c|}{ Average Annual Growth Rates } & \multicolumn{3}{|c|}{ Average Annual Growth Rates } & \multicolumn{3}{|c|}{ Average Annual Growth Rates } \\
\hline & WEO & A1 & B2 & WEO & A1 & B2 & WEO & A1 & B2 \\
\hline Pacific OECD & $1.1 \%$ & $3.3 \%$ & $1.1 \%$ & $0.7 \%$ & $0.6 \%$ & $0.5 \%$ & $1.1 \%$ & $2.2 \%$ & $1.9 \%$ \\
\hline Europe & $1.3 \%$ & $1.1 \%$ & $0.8 \%$ & $0.7 \%$ & $1.0 \%$ & $-0.1 \%$ & $0.8 \%$ & $1.7 \%$ & $1.3 \%$ \\
\hline Transition Economies & $2.2 \%$ & $1.6 \%$ & $2.3 \%$ & $1.3 \%$ & $1.7 \%$ & $1.8 \%$ & $1.2 \%$ & $1.1 \%$ & $1.6 \%$ \\
\hline Asia & $4.1 \%$ & $6.6 \%$ & $4.3 \%$ & $2.2 \%$ & $3.7 \%$ & $3.1 \%$ & $1.8 \%$ & $2.3 \%$ & $2.2 \%$ \\
\hline World & $2.1 \%$ & $3.3 \%$ & $2.0 \%$ & $1.5 \%$ & $2.6 \%$ & $2.1 \%$ & $1.5 \%$ & $2.4 \%$ & $1.8 \%$ \\
\hline
\end{tabular}

Table A3.4. World Final Energy Consumption by Fuel Type (EJ)

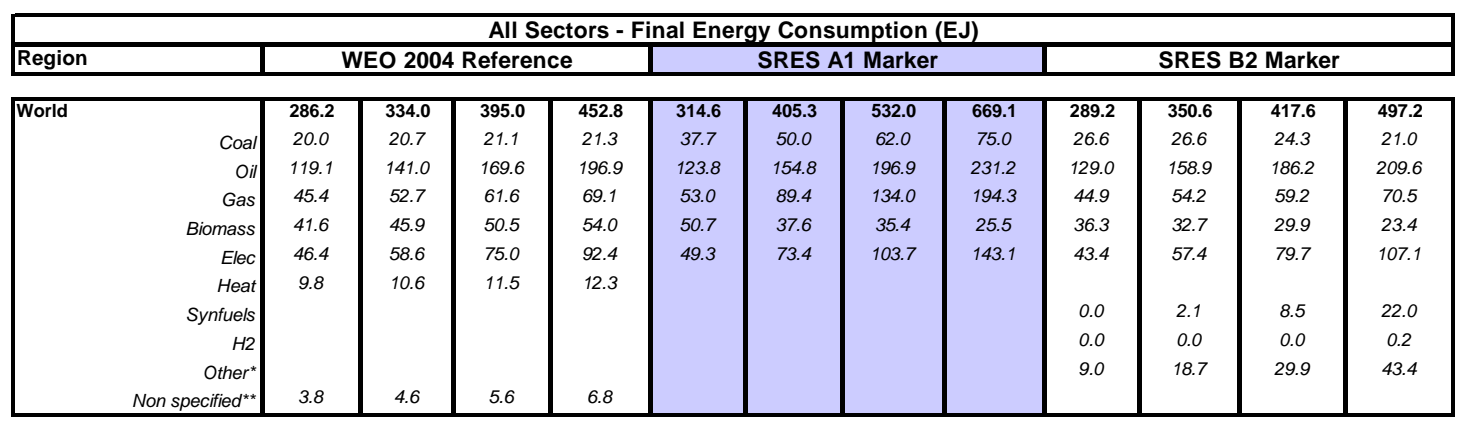

*The category other includes district heat and synfuels in B2 scenario for building and Industry sector. **includes fuel consumption in the transport sector that is not oil, concerned only WEO scenario.

Table A3.4 provides a breakdown of projected world energy consumption by fuel type. For the three scenarios, oil is the most consumed fuel, representing 43\% (WEO 2004 Reference), $42 \%$ (SRES B2) and 35\% (SRES A1) of total final energy consumption. The transport sector drives the consumption since oil represents $95 \%$ of the energy consumed in the WEO 2004 Reference scenario, 88\% in the SRES A1 Marker scenario and $81 \%$ in the SRES B2 Marker scenario in 2030. The SRES B2 Marker scenario also estimates synfuels will represent $16 \%$ of total fuel consumed in the transport sector in 2030.

The three scenarios have very similar shares of electricity consumption in 2030: the WEO 2004 Reference scenario - 20\%, SRES A1 Marker scenario - 21\%, and SRES B2 Marker scenario - 22\%. The WEO 2004 Reference scenario and the SRES B2 Marker scenario have similar projections concerning the share of the fuel consumed in 2030, the main differences are seen in biomass consumption. The WEO 2004 Reference scenario estimates biomass consumption to increase by $30 \%$ between 2002 and 2030 while the SRES B2 Marker scenario estimates that it will decrease 36\%. The SRES A1 Marker scenario estimates a similar trend but with a more marked decrease of $50 \%$.

The SRES A1 Marker scenario is the scenario that stands out the most primarily because the total amount of final demand is much higher and secondly because to meet this demand, more coal and more gas is consumed compare to the other two scenarios. Coal consumption represents $11 \%$ of total consumption in the SRES A1 Marker scenario, compared to 5\% in the WEO 2004 Reference scenario and 4\% in the SRES B2 Marker scenario. Natural gas represents $29 \%$ of total consumption in the SRES A1 Marker scenario, compared to $15 \%$ in the WEO 2004 Reference scenario and 14\% in the SRES B2 Marker scenario. 


\subsection{Primary Energy}

The three scenarios only provide primary energy supply information and do not provide data on primary energy consumption by sector. In statistics, energy loses occurring during the conversion of primary energy into secondary products are generally shown under a sector called "Transformation". For this comparison, we reallocate this energy use to the end-use sectors in proportion to their consumption of secondary products.

We converted final energy consumption into primary energy consumption by multiplying secondary products (electricity, heat and synfuels) consumed by each end-use sector by a final-to-primary conversion factor that account for conversion, transmission and distribution losses. This factor varied by year and regions group and was determined by comparing the final to primary energy values reported in the different scenarios.

For the SRES A1 Marker scenario, only electricity was available as secondary product. For the SRES B2 Marker scenario, the modelers provided data for the following secondary products: synfuels, heat and electricity. For the WEO 2004 Reference scenario, detail on the power sector allowed us to calculate a specific primary factor for electricity, the rest of transformation loses were distributed proportionally to all other fuel consumed.

Table A.3.5 provides primary energy consumption values for the seven world regions and the world total for the WEO 2004 Reference scenario and the SRES A1 and B2 Marker scenarios. The SRES B2 Marker scenario envisions the lowest total world primary energy consumption, growing from $384 \mathrm{EJ}$ in 2000 to $648 \mathrm{EJ}$ in 2030, slightly lower than the WEO 2004 Reference scenario value of 673 EJ that year. The SRES A1 Marker scenario projects significantly higher primary energy consumption in 2030 of $892 \mathrm{EJ}$.

Table A.3.5. Primary Energy Consumption (EJ)

\begin{tabular}{|c|c|c|c|c|c|c|c|c|c|c|c|c|}
\hline \multicolumn{13}{|c|}{ All Sectors - Primary Energy Consumption (EJ) } \\
\hline Region & \multicolumn{4}{|c|}{ WEO 2004 Reference } & \multicolumn{4}{|c|}{ SRES A1 Marker } & \multicolumn{4}{|c|}{ SRES B2 Marker } \\
\hline Pacific OECD & 33 & 37 & 41 & 42 & 31 & 34 & 39 & 45 & 31 & 34 & 36 & 36 \\
\hline Europe & 70 & 77 & 84 & 89 & 70 & 78 & 85 & 90 & 59 & 64 & 67 & 72 \\
\hline Transition Economies & 48 & 55 & 62 & 68 & 51 & 56 & 64 & 72 & 48 & 50 & 59 & 69 \\
\hline Latin America & 26 & 32 & 42 & 54 & 34 & 63 & 88 & 118 & 26 & 35 & 43 & 53 \\
\hline World & 415 & 490 & 585 & 673 & 423 & 557 & 709 & 892 & 384 & 457 & 546 & 648 \\
\hline
\end{tabular}

The WEO 2004 Reference scenario assumes that primary energy consumption will grow, on average, at roughly the same rate between 2002 and 2030 as final energy consumption, with a slight improvement in conversion efficiencies in the Canada/US and Transition Economies regions and a slight worsening in the Latin America, Africa/Middle East, and Asia regions. The SRES A1 Marker scenario foresees a lower growth in primary energy compared to final energy in all regions except Africa/Middle East and Asia. The SRES B2 Marker scenario projects a significantly lower average annual growth rate of primary energy compared to final energy in the Pacific OECD and Transition Economies and an increase in the Latin America and Africa/Middle East regions. 
Tables A.3.6 and A.3.7 provide primary energy consumption average annual growth rates by sector. All three scenarios project the highest growth rates of primary energy consumption in the transportation sector, followed by the buildings sector in the SRES A1 Marker Scenario and the WEO 2004 Reference scenario and the industrial sector in the SRES B2 Marker scenario.

Table A.3.6. Primary Energy Consumption, Average Annual Growth Rates, Base Year to 2030.

\begin{tabular}{|l|c|c|c|}
\hline Region & \multicolumn{3}{|c|}{ Average Annual Growth Rates } \\
\hline & WEO & A1 & B2 \\
\hline Pacific OECD & $1.0 \%$ & $1.4 \%$ & $0.6 \%$ \\
\hline Canada/US & $1.0 \%$ & $0.8 \%$ & $1.2 \%$ \\
\hline Europe & $0.9 \%$ & $0.9 \%$ & $0.7 \%$ \\
\hline Transition Economies & $1.3 \%$ & $1.2 \%$ & $1.3 \%$ \\
\hline Latin America & $2.6 \%$ & $4.5 \%$ & $2.5 \%$ \\
\hline Africa/Middle East & $2.5 \%$ & $4.9 \%$ & $2.7 \%$ \\
\hline Asia & $2.7 \%$ & $3.8 \%$ & $3.1 \%$ \\
\hline World & $1.7 \%$ & $2.7 \%$ & $1.9 \%$ \\
\hline
\end{tabular}

Table A.3.7. Primary Energy Consumption by Sector, Average Annual Growth Rates, Base Year to 2030.

\begin{tabular}{|c|c|c|c|c|c|c|c|c|c|}
\hline \multirow{3}{*}{ Region } & \multicolumn{3}{|c|}{ Transport } & \multicolumn{3}{|c|}{ Industry } & \multicolumn{3}{|c|}{ Buildings } \\
\hline & \multicolumn{3}{|c|}{ Average Annual Growth Rates } & \multicolumn{3}{|c|}{ Average Annual Growth Rates } & \multicolumn{3}{|c|}{ Average Annual Growth Rates } \\
\hline & WEO & A1 & B2 & WEO & $\overline{\mathrm{A} 1}$ & B2 & WEO & A1 & B2 \\
\hline Pacific OECD & $1.1 \%$ & $3.3 \%$ & $1.1 \%$ & $0.7 \%$ & $0.0 \%$ & $0.0 \%$ & $1.1 \%$ & $1.4 \%$ & $1.0 \%$ \\
\hline Europe & $1.2 \%$ & $1.2 \%$ & $1.1 \%$ & $0.7 \%$ & $0.3 \%$ & $-0.4 \%$ & $0.9 \%$ & $1.1 \%$ & $1.1 \%$ \\
\hline Transition Economies & $2.1 \%$ & $1.5 \%$ & $2.5 \%$ & $1.2 \%$ & $1.3 \%$ & $1.4 \%$ & $1.1 \%$ & $0.9 \%$ & $0.8 \%$ \\
\hline Asia & $4.1 \%$ & $6.7 \%$ & $4.9 \%$ & $2.3 \%$ & $3.6 \%$ & $3.1 \%$ & $2.5 \%$ & $3.0 \%$ & $2.5 \%$ \\
\hline World & $2.1 \%$ & $3.5 \%$ & $2.4 \%$ & $1.5 \%$ & $2.4 \%$ & $1.8 \%$ & $1.7 \%$ & $2.6 \%$ & $1.6 \%$ \\
\hline
\end{tabular}




\subsection{Carbon Dioxide Emissions}

Similar to the procedure described above for calculating primary energy, we have redistributed the $\mathrm{CO}_{2}$ emissions due to energy transformation to the end-use sectors. To do so, we calculated a $\mathrm{CO}_{2}$ secondary product factor reflecting the quantity of $\mathrm{CO}_{2}$ emitted during the process of energy transformation.

For the SRES A1 Marker scenario, only the $\mathrm{CO}_{2}$ emissions due to the production of electricity were available. For the SRES B2 Marker scenario, total $\mathrm{CO}_{2}$ emissions from all conversions were already reallocated to the end use sectors. For the WEO 2004 Reference scenario, $\mathrm{CO}_{2}$ emissions from electricity generation and $\mathrm{CO}_{2}$ resulting from other transformation were available. We used these data to calculate two factors, one related solely to the production of electricity and one related to the other transformation that we applied to all other fuel consumed in the final sectors.

Table A.3.8 shows that the SRES A1 Marker scenario projects significantly higher energy-related $\mathrm{CO}_{2}$ emissions than either the SRES B2 Marker or the WEO 2004 Reference scenarios, which project relatively similar world $\mathrm{CO}_{2}$ emissions. The WEO 2004 Reference and SRES B2 Marker scenarios envision these emissions to be distributed by region in a relatively similar manner, with $32 \%$ in the Asian region in 2030 , followed by $21 \%$ and $23 \%$, respectively, in the Canada/US region. In contrast, the SRES A1 Marker scenario foresees $35 \%$ of the emissions in the Asia region, followed by $20 \%$ in the Africa/Middle East region and only 11\% in the Canada/US region in 2030.

Table A.3.9 provides average annual growth rates in energy-related $\mathrm{CO}_{2}$ by region for the three scenarios. All three scenarios envision average growth rates under $1 \%$ per year for the developed regions of Pacific OECD, Canada/US, and Europe. Similar trends are seen for the Transition Economies in the SRES A1 and B2 Marker scenarios, but the WEO 2004 Reference scenarios envisions much higher average annual growth in $\mathrm{CO}_{2}$ emissions for that region. The SRES A1 Marker scenario projects significantly larger average annual growth in $\mathrm{CO}_{2}$ emissions in all developing country regions than is projected by the other two scenarios.

Table A.3.8. Carbon Dioxide Emissions (Mt CO2)

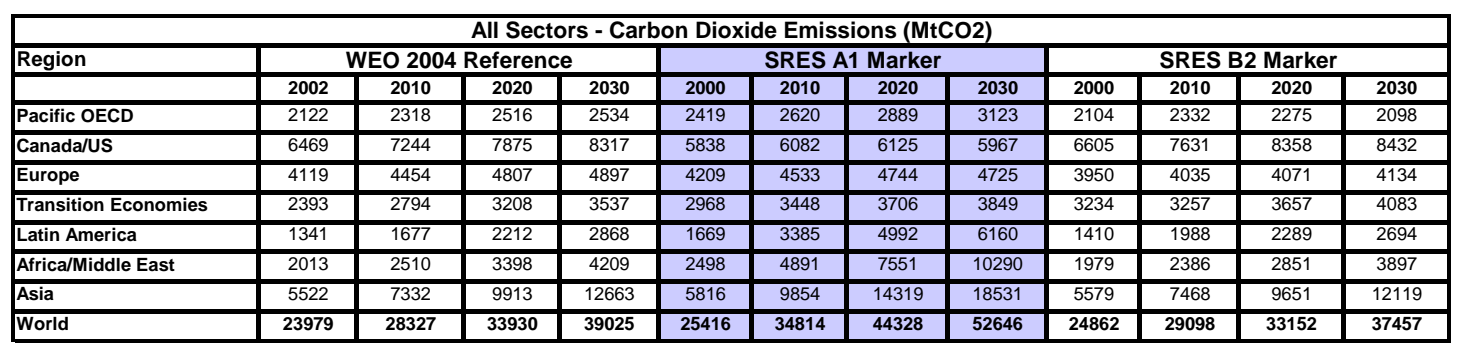


Table A.3.9. Carbon Dioxide Emissions, Average Annual Growth Rates, Base Year to 2030.

\begin{tabular}{|l|c|c|c|}
\hline Region & \multicolumn{3}{|c|}{ Average Annual Growth Rates } \\
\hline & WEO & A1 & B2 \\
\hline Pacific OECD & $0.6 \%$ & $0.9 \%$ & $0.0 \%$ \\
\hline Canada/US & $0.9 \%$ & $0.1 \%$ & $0.9 \%$ \\
\hline Europe & $0.6 \%$ & $0.4 \%$ & $0.2 \%$ \\
\hline Transition Economies & $1.4 \%$ & $0.9 \%$ & $0.8 \%$ \\
\hline Latin America & $2.8 \%$ & $4.8 \%$ & $2.3 \%$ \\
\hline Africa/Middle East & $2.7 \%$ & $5.2 \%$ & $2.4 \%$ \\
\hline Asia & $3.0 \%$ & $4.2 \%$ & $2.8 \%$ \\
\hline World & $1.8 \%$ & $2.6 \%$ & $1.5 \%$ \\
\hline
\end{tabular}

Table A.3.10 shows that the WEO 2004 Reference scenario and the SRES A1 Marker scenario project the highest average annual growth in emissions to be in the transport sector, while the SRES B2 Marker scenario shows the highest growth rate in the buildings sector. In all three sectors, this growth is largest in the developing countries; both the SRES A1 and B2 Marker scenarios project declining average growth rates in the industrial sector in the Pacific OECD, Canada/US, and European regions.

Table A.3.10. Carbon Dioxide Emissions by Sector, Average Annual Growth Rates, Base Year to 2030.

\begin{tabular}{|c|c|c|c|c|c|c|c|c|c|}
\hline \multirow{3}{*}{ Region } & \multicolumn{3}{|c|}{ Transport } & \multicolumn{3}{|c|}{ Industry } & \multicolumn{3}{|c|}{ Buildings } \\
\hline & \multicolumn{3}{|c|}{ Average Annual Growth Rates } & \multicolumn{3}{|c|}{ Average Annual Growth Rates } & \multicolumn{3}{|c|}{ Average Annual Growth Rates } \\
\hline & WEO & A1 & B2 & WEO & $\overline{A 1}$ & B2 & WEO & $\overline{A 1}$ & $\overline{B 2}$ \\
\hline Pacific OECD & $0.9 \%$ & $3.1 \%$ & $0.6 \%$ & $0.4 \%$ & $-0.2 \%$ & $-0.9 \%$ & $0.7 \%$ & $0.5 \%$ & $0.5 \%$ \\
\hline Europe & $1.1 \%$ & $1.1 \%$ & $0.5 \%$ & $0.3 \%$ & $-0.3 \%$ & $-0.9 \%$ & $0.6 \%$ & $0.2 \%$ & $0.7 \%$ \\
\hline Transition Economies & $2.3 \%$ & $1.2 \%$ & $1.6 \%$ & $1.4 \%$ & $0.7 \%$ & $0.6 \%$ & $1.1 \%$ & $1.4 \%$ & $0.8 \%$ \\
\hline Latin America & $3.0 \%$ & $5.6 \%$ & $2.1 \%$ & $2.4 \%$ & $3.9 \%$ & $2.5 \%$ & $2.9 \%$ & $5.3 \%$ & $2.5 \%$ \\
\hline Asia & $4.1 \%$ & $6.5 \%$ & $3.5 \%$ & $2.1 \%$ & $3.0 \%$ & $2.1 \%$ & $3.8 \%$ & $4.8 \%$ & $3.7 \%$ \\
\hline World & $2.1 \%$ & $3.5 \%$ & $1.5 \%$ & $1.4 \%$ & $2.0 \%$ & $1.1 \%$ & $1.9 \%$ & $2.9 \%$ & $1.9 \%$ \\
\hline
\end{tabular}




\section{Appendix 4. Regression Analyses of Commercial Sector Share and Revenue}

parameter asymptotic regression, commercial_share $=b 1 *\left(1-b 2^{\wedge}\right.$ revenue_ppp $)$

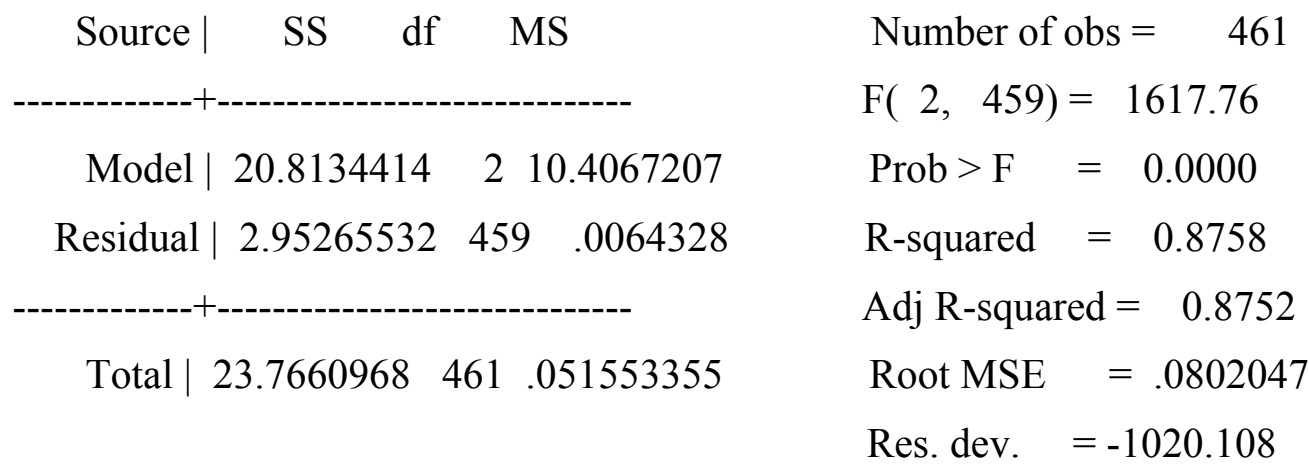

commercial e $\mid$ Coef. Std. Err. $\quad \mathrm{t} \quad \mathrm{P}>|\mathrm{t}| \quad$ [95\% Conf. Interval]

b1 | $\begin{array}{llllll}4200874 & .0237762 & 17.67 & 0.000 & .3733637 & .466811\end{array}$

\begin{tabular}{l|llllll} 
b2 & .9999351 & $6.64 \mathrm{e}-06$ & 0.000 & .9999221 & .9999482
\end{tabular}

\begin{tabular}{|l|lc|}
\hline 2030 projections & GDP/ca & Commercial Energy Share Estimates \\
\hline A1 & 18,335 & $29 \%$ \\
B2 & 13,249 & $24 \%$ \\
\hline
\end{tabular}

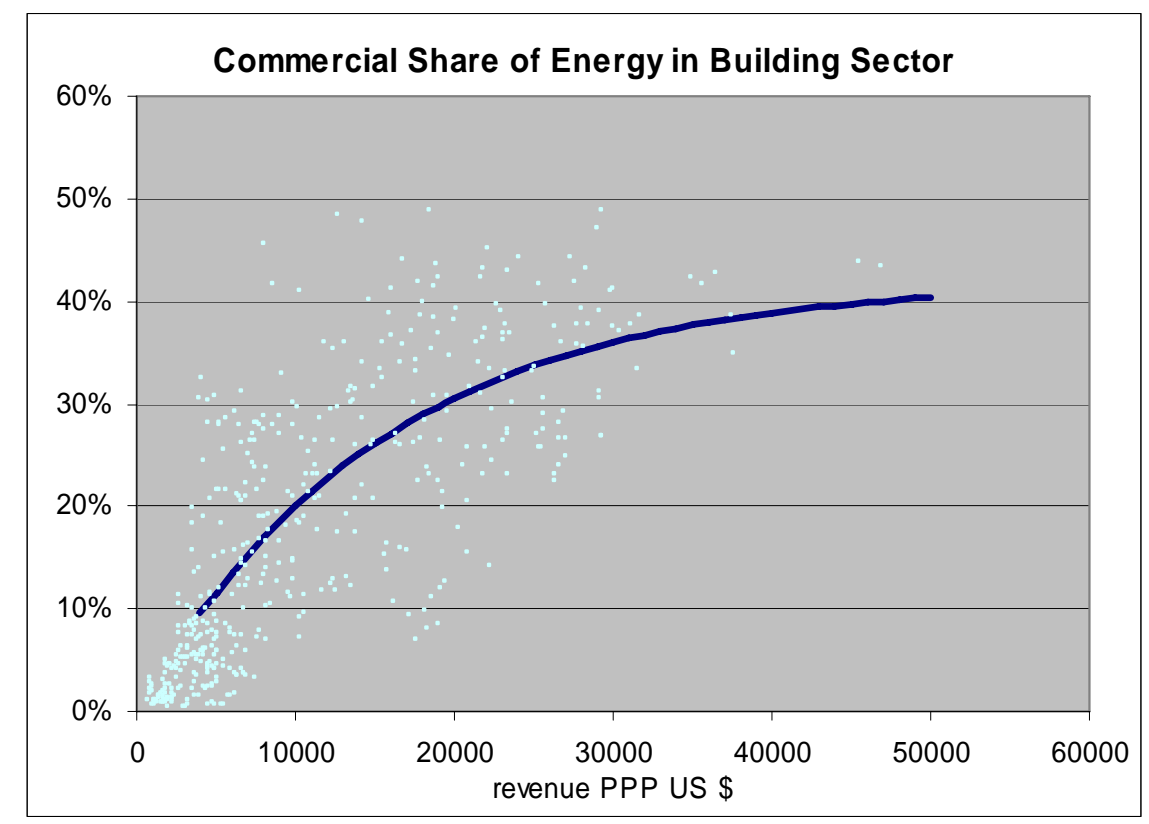




\section{Appendix 5. Commercial Share of Electricity in Building Sector Electricity Consumption}

parameter logistic function, commercial_share $=b 1 /(1+\exp (-b 2 *($ revenue_ppp - b3)) $)$

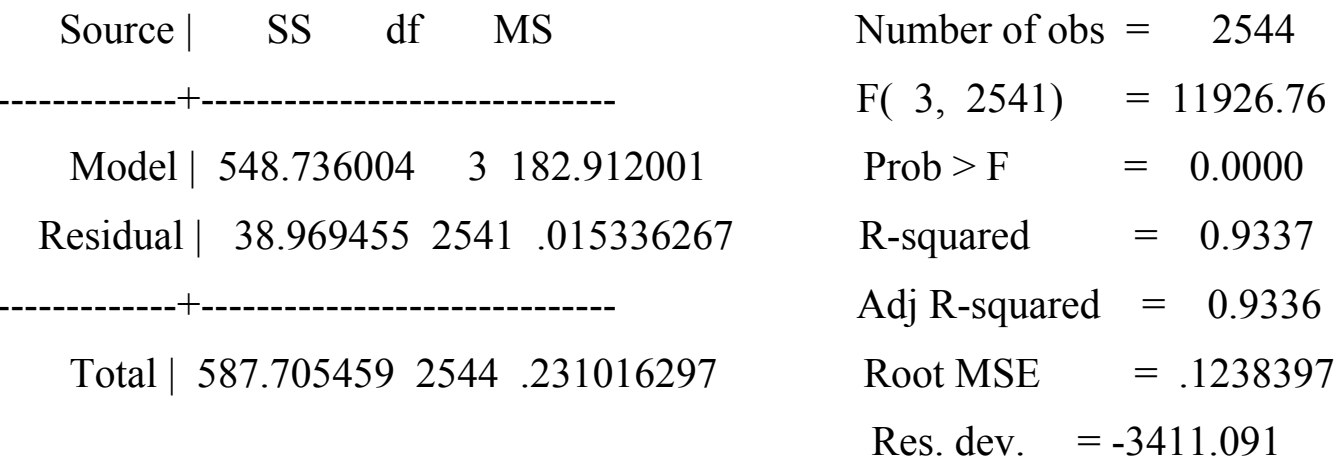

commercial e $\mid \quad$ Coef. Std. Err. $\quad \mathrm{t} \quad \mathrm{P}>|\mathrm{t}| \quad$ [95\% Conf. Interval]

\begin{tabular}{c|cccccc} 
b1 & .5984155 & .0058527 & 102.25 & 0.000 & .586939 & .6098921 \\
b2 & .000229 & .0000121 & 18.96 & 0.000 & .0002053 & .0002527 \\
b3 & 1835.333 & 141.4315 & 12.98 & 0.000 & 1558 & 2112.666
\end{tabular}

Results applied to China Projections

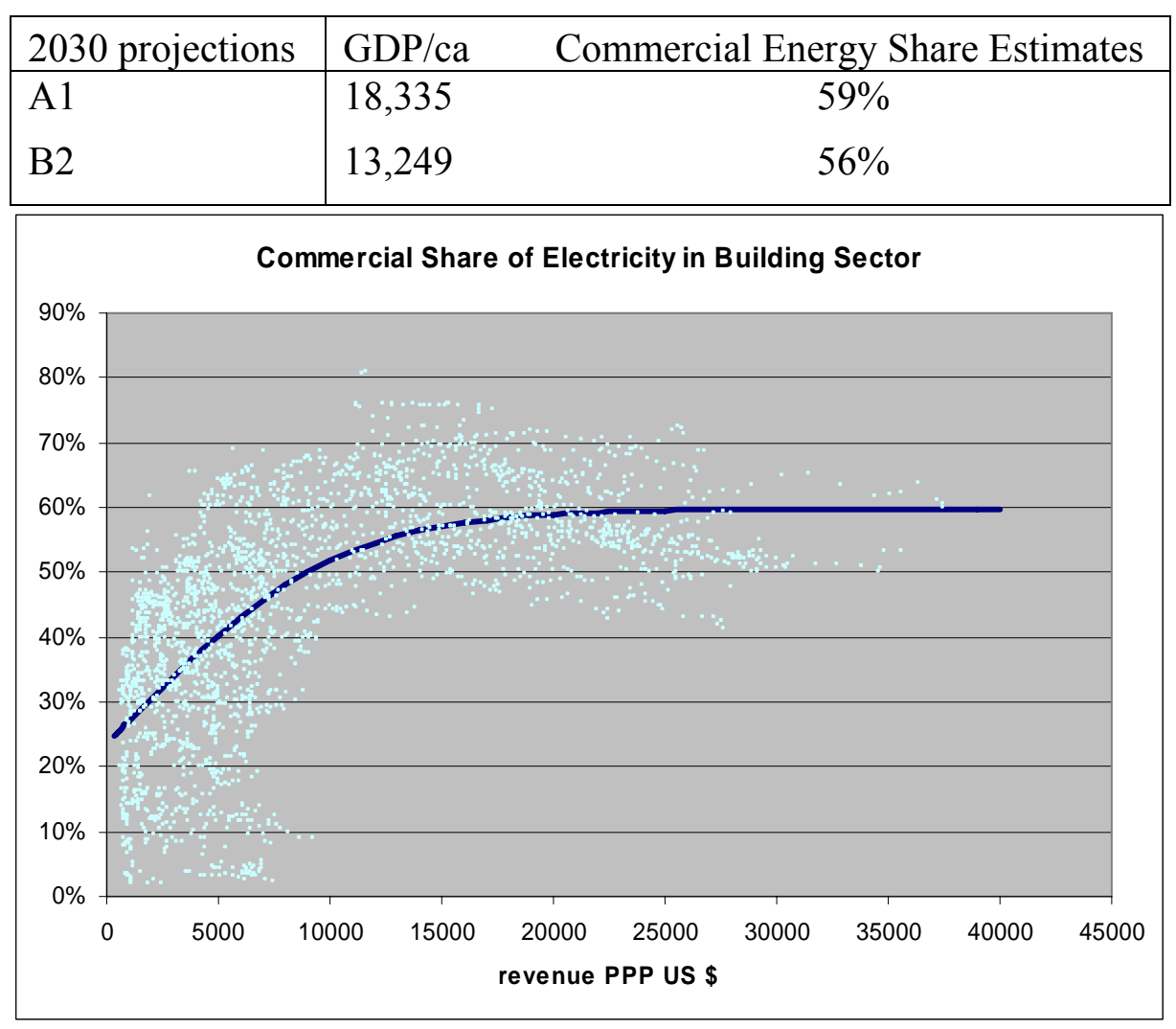

